\title{
CRIPPLING THE WILL OF A PEOPLE: MORPHOSTATIC STRUCTURES OF VIOLENCE AND THE CRAWL-SPACE OF AGENCY IN THE LIVES OF ERITREAN REFUGEES
}

[title image removed due to copyright]

JARED COMMERER

A THESIS SUBMITTED TO VICTORIA UNIVERSITY OF WELLINGTON IN FULFILMENT OF THE REQUIREMENTS FOR THE DEGREE OF MASTERS OF ARTS IN CULTURAL ANTHROPOLOGY 



\section{ABSTRACT}

In conjunction with an exposition of the larger historical and political context of the nation of Eritrea, this thesis examines the life narratives of five refugees hailing from the Horn of Africa. In doing so, certain institutional, relational, and embodied forms of violence are identified as permeating Eritrea's socio-political fabric and thus also the inter- and intra-personal lives of the participants. Where morphostatic structures are deemed as those that constrain an individual's capacity to pursue their ultimate concerns, it is maintained that violence in the form of extreme nationalism, routinised fear, and varying subjective affects partially accounts for the fact that an estimated 5,000 people are fleeing this small, modernising African nation every month. Following this, I argue that, by examining the life-narratives of Eritrean refugees, violence can be understood as transpiring at the interstices of an ongoing - albeit skewed - dialectic between, on one hand, morphostatic structures of violence appearing in institutional, relational, and embodied forms, and, on the other, a degree of mimetic agency that, when harnessed, acts as a crawl-space through which individuals - if they are to realise their ultimate concerns - must absent themselves relative to such structures of violence. 


\section{ACKNOWLEDGEMENTS}

My highest thanks and unremitting gratitude go to the participants whose stories are outlined in this thesis. On the far side of the personal gains that have come my way via undertaking such a project - and if the act of storytelling can be considered a "vital human strategy for sustaining a sense of agency in the face of disempowering circumstances" - I hope that those who took the time to share their lives with me have, in doing so, also benefitted in some small way.

Throughout the course of this thesis, my supervisors - Catherine Trundle and Jeff Sissons - have been an unshakable form of encouragement and guidance. In particular, Catherine's ongoing support - including during the period leading up to the commencement of this thesis - has been vital in my seeing the project through to completion - her consistent generosity and compassion does not go unnoticed. I hope that my persistent slew of questions and rejoinders during supervisor meetings have been interpreted as anthropological curiosity and emancipatory commitment, not parochial arrogance(!).

I would like to thank Sandra Grey and Charles Sedgwick for the many opportunities they provided me relevant to research experience and critical insight over the years preceding the outset of this thesis. Also, thanks to Diane O'Rourke for assistance during the formative stages of the project.

Outside the immediate arena of my anthropological interests, many thanks to Sanjay Dixit and John Psathas for sustained friend- and mentor-ship over the years; it was through conversations with John that I eventually turned directly toward the anthropology of war, conflict, and violence.

As always, my lucidity is maintained via copious amounts of coffee and tangential conversation with Luke and the Clapham family, Lisa Gregg, and Oksana Pudailo. Also, much love goes to Anna Lehman, Stefane Guercio Bin, and Riley Kinnunen for their own reciprocal love from afar. Thanks to Karen Pashley for assisting by way of providing the physical space that solitude necessitates.

Lastly, I would like to proffer deep bows and appreciation to Marguerite Agnès Tercier for appearing at the right time - "Society — That's true! I can't believe it..." 


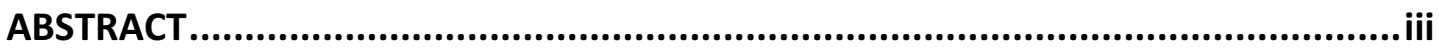

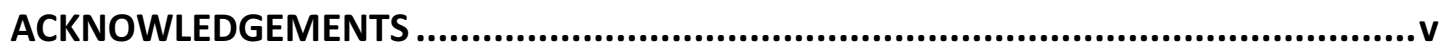

LIST OF FIGURES .................................................................................................... viii

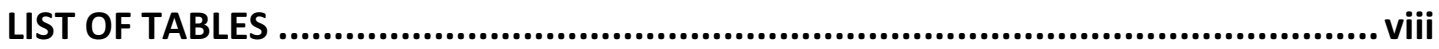

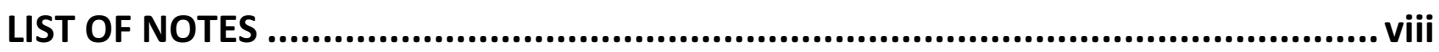

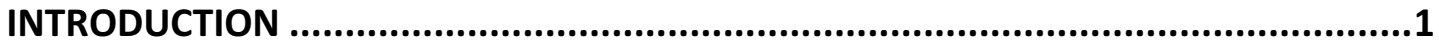

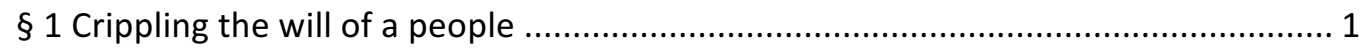

$\S 2$ Eritrea: a history of violence coalescing in crimes against humanity ...................... 3

$\S 3$ Anthropological perspectives on war, conflict, and violence ................................ 4

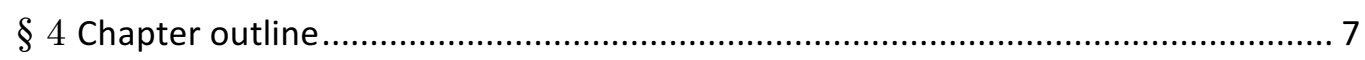

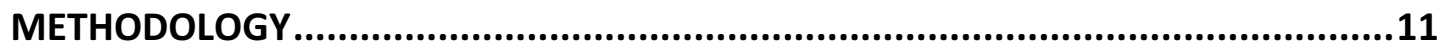

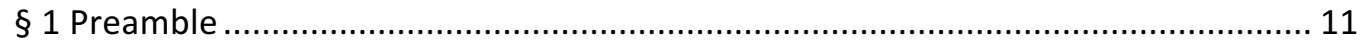

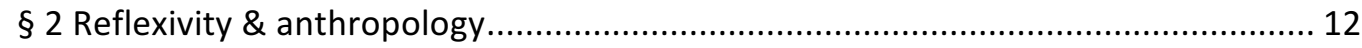

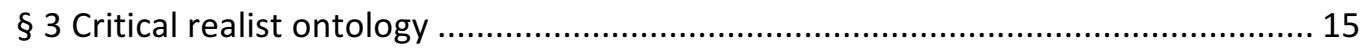

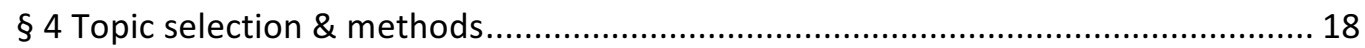

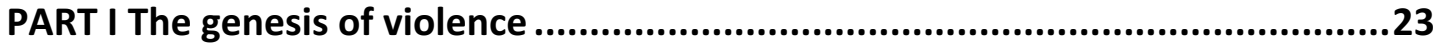

CHAPTER 1 The chronicity of Eritrea's violent past: participant introductions and pre-

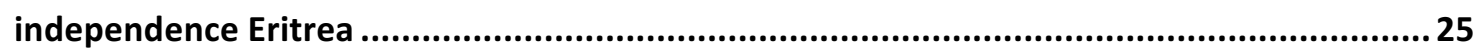

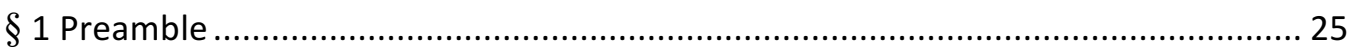

$\S 2$ Participant introductions: a narrative overview .................................................. 26

$\S 3$ Eritrea - a brief history: from antiquity to independence ..................................... 31

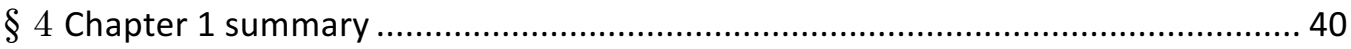

CHAPTER 2 "Take us to the front, mate; give us the gun": formative narratives and

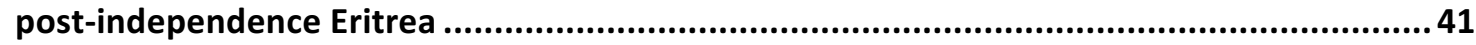

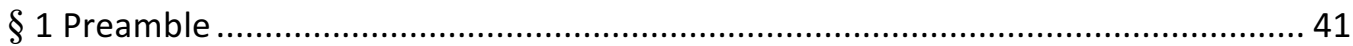

$\S 2$ The harbingers of extreme nationalism ............................................................. 41

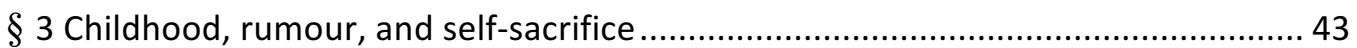

$\S 4$ Militarism, repression, and the denial of democracy .......................................... 47

$\S 5$ National service: moral obligation or fallacious coercion? ................................... 48

$\S 6$ The Ethiopia-Eritrea border war, 1998-2000 ..................................................... 49

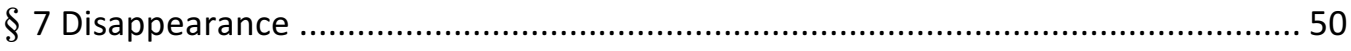

$\S 8$ Enduring suppression and 'no war, no peace' .................................................. 52

$\S 9$ A state of emergency and indefinite conscription ............................................ 54 
$\S 10$ The 'North Korea of Africa'

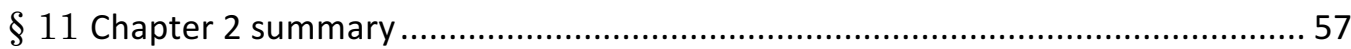

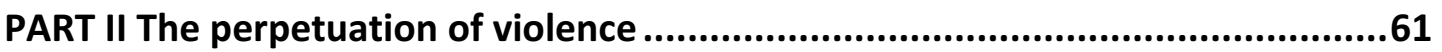

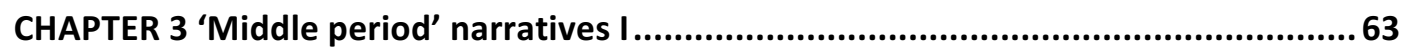

$\S 1$ National service, mimetic deception, and a universe of fantasy ............................63

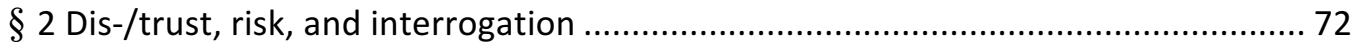

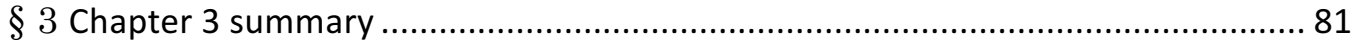

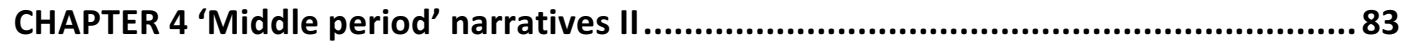

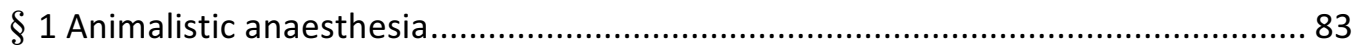

$\S 2$ "If you wanna be successful in your life, you have to be corrupt like them" ......... 86

$\S 3$ Fractured families and the "useless" by-products of war ...................................... 91

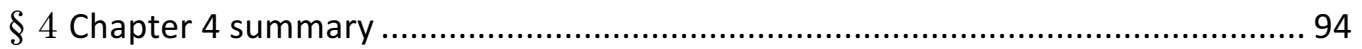

PART III The subjective reverberations of violence ...........................................99

CHAPTER 5 Violence, subjectivity, and resettlement ..................................................99

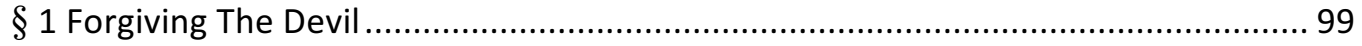

$\S 2$ Repeated ruptures and the subjective residue of imprisonment ......................... 100

$\S 3$ Reflection, bare-life, and 'the secret life of the state' ......................................... 101

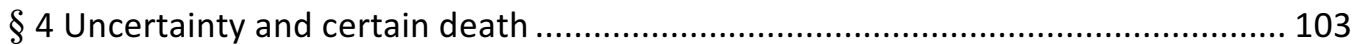

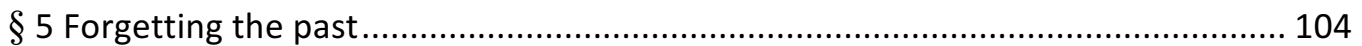

$\S 1^{\prime}$ Violence of the past reflected in new beginnings ............................................. 107

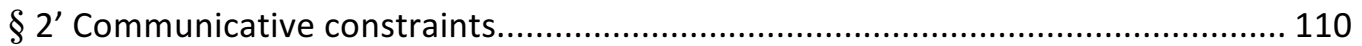

$\S 3^{\prime}$ Disruption and relative freedom ...................................................................... 111

$\S 4$ 4' Fractured families and the irony of contingent freedom .................................. 112

$\S 5^{\prime}$ Familial friction and regaining ownership of one's life ...................................... 114

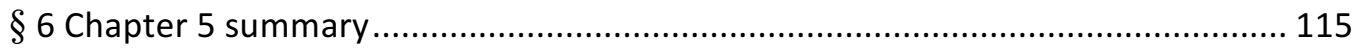

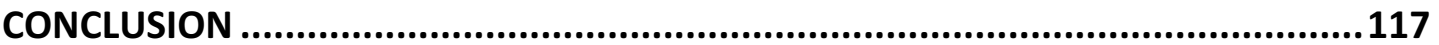

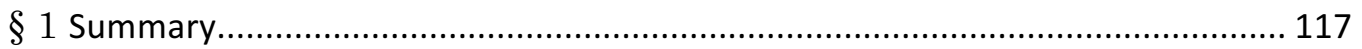

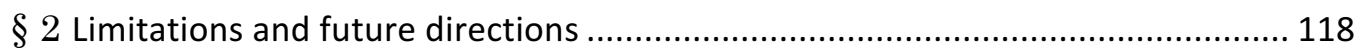

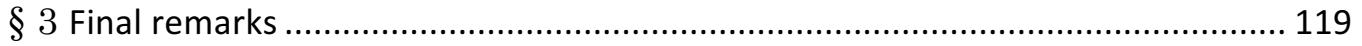

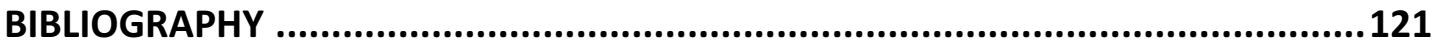




\section{LIST OF FIGURES}

Figure 1: Map of Eritrea.

\section{LIST OF TABLES}

Table 1: Overview of thesis structure

\section{LIST OF NOTES}

[example] denotes a word inserted in to a quote in the interests of clarity

\{example\} denotes an action performed by the interviewee

[...] denotes an instance where text or interview material has been omitted

[ ] denotes an inaudible fragment in the interview audio file

... denotes a pause of several seconds during the interview

$\Delta$ denotes a discontinuous quotation

EEBC Eritrea-Ethiopia Boundary Commission

ELF Eritrea Liberation Front

ELM Eritrean Liberation Movement

ELP-PLF Eritrean Liberation Forces - People's Liberation Forces

EPLF Eritrean People's Liberation Forces

EPRDF Ethiopian People's Revolutionary Democratic Front

EPRP Eritrean' People's Revolutionary Party

ERRC Eritrean Relief and Refugee Commission

ICU Islamic Courts Union

JEM Justice and Equality Movement

MRRC Mangere Refugee Resettlement Centre

NUEW National Union of Eritrean Women

OAU Organisation of African Unity

OLF Oromo Liberation Front

PFDJ People's Front for Democracy and Justice

PGE Provisional Government of Eritrea

RCHRD Regional Centre for Human Rights and Development

SDF Sudan Defense Force

TPLF Tigray People's Liberation Front

TSZ Temporary Security Zone

UNHCR United Nations High Commissioner for Refugees

UNMEE United Nations Mission in Ethiopia and Eritrea

WYDC Warsay-Yikealo Development Campaign

- Unless indicated, all emphases appear in the original quote or interview excerpt

- In the interests of consistency, American English spellings have been converted to

British English 


\section{INTRODUCTION}

\section{$\S 1$ Crippling the will of a people}

If storytelling is to be considered a "vital human strategy for sustaining a sense of agency in the face of disempowering circumstances" (Jackson 2013: 34), then to account for the degree of violence entrenched in the tales imparted to me by five refugees hailing from the Horn of Africa requires us to be indefinitely seated abreast a campfire that refuses to be doused. In discussing the raison d'état of violent conflict in Mozambique, Carolyn Nordstrom states that

war is about existing in a world suddenly divested of lights. It is about a type
of violence that spills out across the country and into the daily lives of people
to undermine the world as they know it. A violence that, in severing people
from their traditions and their futures, severs them from their lives. It hits at
the heart of perception and existence. And that is, of course, the goal of terror
warfare: to cripple political will by attempting to cripple all will, all sense (1995: 132)

This thesis also reveals a violence that is intent on crippling the will of a people those people are the citizens of Eritrea. Yet, as it stands, Eritrea itself is neither in state of civil war nor inter-state turmoil; instead, the violence being unleashed is that of the Eritrean state against its own civilian population.

The lives portrayed in this thesis contain many intricate and often harrowing details. From indoctrination and the imperiled navigation of shoot-to-kill policies, through to torture and state-sanctioned repatriation, the reader's willingness to permit themselves to believe the stories herein may even, at times - to continue with a metaphor of disablement - be paralysed. After all, as Hannah Arendt has noted, "anyone speaking or writing about concentration camps is still regarded as suspect; and if the speaker has resolutely returned to the world of the living, he himself is often assailed by doubts with regard to his own truthfulness, as though he had mistaken a nightmare for reality" (2000: 120).

By examining the life-narratives of five refugees of Eritrean heritage - in conjunction with the broader historical and political context of this modernising nation -, myriad and dichotomous forms of violence are revealed as being inherent to the prevailing socio- 
political context and, in turn, the inter- and intra-personal lives therein. More specifically, with regard to the 'where' of violence as a factor that inevitably shapes - yet does not wholly determine - everyday lives (see Archer 2000, 2003, and 2007), this thesis takes as ontological givens certain institutional, relational, and embodied discernments regarding the status of social structure (see Scott 2001). Also, in light of the specifically Eritrean context from which each narrative has emerged, these structures are adjudged as upholding a morphostatic guise.

The concept of a morphostatic structure as it is being evoked here is fairly straightforward in that it denotes a structure that tends to restrict, rather than enable, social actors. Archer notes that "socio-cultural configurations have their own emergent properties and powers, and the deterrent effects of morphostatic formations constrain the ability of [actors to flourish]"; furthermore, this quality can be seen to contrast the attributes of morphogenetic structures which, instead, "positively enable such [...] action [or human flourishing]" (2000: 11). Regarding violence, however, Das and Kleinman add that the "conundrum of how to square collective and individual responsibility for social violence is not readily resolvable in most cases and often returns us to the cul-de-sac of agency/structure debates in social theory" (2000: 16). Hence, the examination of violence in the lives of the five interlocutors herein is founded on a particular - that is, critical realist - conception of the relationship between structure and agency: in short, whereas

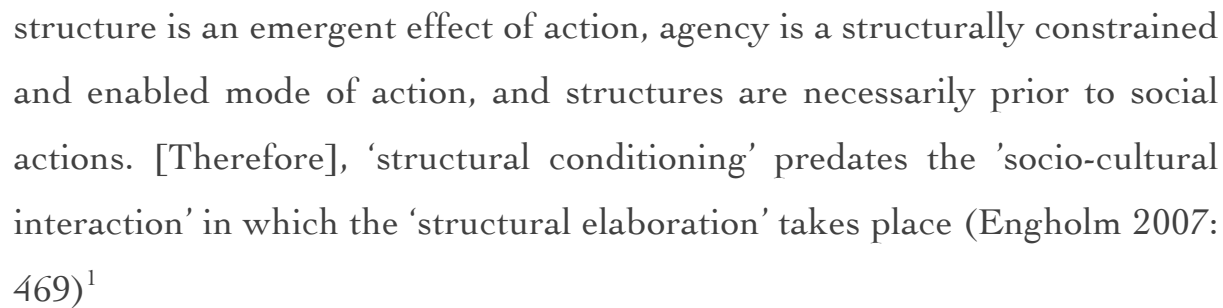

Thus, where morphostatic structures are present, agency tends to be constrained and, in turn, such structures are prone to being reproduced rather than transformed.

Lastly, the element that is seen to mediate between structure and agency is one's reflexive faculties experienced as a subjective, 'inner conversation' (Archer 2000: 1-16); an element that is also tied to the development and pursuit of one's 'ultimate concerns.'

\footnotetext{
${ }^{1}$ Otherwise known as the 'transformational model of social activity,' Engholm goes on to state that by "conceiving social structure as necessarily predating the social action in which it is either reproduced or transformed, the illicit conflations (upward, downward or central in the voluntarist, reifications and identificationary approaches) are avoided and a formal research model is supplied [...]" (2007: 469; also see Archer 2000: 1-16).
} 
Again, following Archer, ultimate concerns involve transcending instrumental rationality in order to pursue those interests "which are not a means to anything beyond them, but are commitments which are constitutive of who we are, and an expression of our identities"; furthermore, "we are who we are because of what we care about: in delineating our ultimate concerns and accommodating our subordinate ones, we also define ourselves" (2000: 4, 10).

With these preliminary tenets in mind, I argue that, by examining the life-narratives of Eritrean refugees, violence can be understood as transpiring at the interstices of an ongoing - albeit skewed - dialectic between, on one hand, morphostatic structures of violence appearing in institutional, relational, and embodied forms, and, on the other, a degree of mimetic agency that, when harnessed, acts as a crawl-space through which individuals - if they are to realise their ultimate concerns - must absent themselves relative to such structures of violence. ${ }^{2}$

As we will see - and with regard to the Eritrean situation - engaging one's crawlspace of agency implies taking the ultimate agential risk by placing one's life on the line in order to escape the confines of the nation altogether.

\section{$\S 2$ Eritrea: a history of violence coalescing in crimes against humanity}

With a trail of violent events comprising its colonial and war-stricken past, Eritrea - situated in the Horn of Africa - has come to be variously labelled - largely due to the coercive actions of its post-independence leader, President Isaias Afwerki - as an exemplar of totalitarian, authoritarian, or tyrannical rule (see Tronvoll and Mekonnen 2014). This is doubly regrettable considering the period of relative peace that transpired following the point at which independence was reached in the early 1990s; an achievement that marked the end of a thirty-year armed struggle with Ethiopia. As the turn of the millennium encroached, however, the two nations descended once more into a full-scale border conflict during 1998-2000. Since then - and for reasons that will be explained throughout the course of this thesis -, Eritrea has come to be one of the highest refugee-producing nations in the world with recent estimates claiming that up to 5,000

\footnotetext{
${ }^{2}$ It should be noted that the allusion to structures of violence does not entail the conceptual framework theorised by, among others, Philippe Bourgois (2004), Paul Farmer (2004), and Nancy Scheper-Hughes (2004) that has come to be understood as structural violence (see below).
} 
people take it upon themselves to flee the country each month (United Nations 2015: $42) .^{3}$

Relatively-speaking, anthropological research concerning Eritrea is scarce. This is likely due to the fact that the insular ethos of the Eritrean state has consistently denied journalists, NGOs, and other researchers the necessary visas and permits that would allow them to conduct 'official' research (Tronvoll and Mekonnen 2014: 42-43, 94, 122). However, the decade and a half since the end of the Ethiopia-Eritrea war has seen research undertaken in varying capacities relevant to the prevailing strife that is the outcome of a highly concentrated state power coupled with extreme forms of nationalist ideology and militaristic judicial and educational systems. ${ }^{4}$

In contrast to the scarce amount of anthropological research undertaken with regard to Eritrea, 'violence' as a focus of research has underpinned a vast swathe of anthropological and social scientific scholarship that harks back a century and a half.

\section{$\S 3$ Anthropological perspectives on war, conflict, and violence}

Writing more than four decades ago in her influential book On Violence, Hannah Arendt observed that, because violence has permeated human affairs throughout history, it had effectively become naturalised. Thus, it was not surprising that "violence [had] been singled out so seldom for special consideration" (1970: 8). While this may ring true

\footnotetext{
${ }^{3}$ This number is significant given the estimated total population is only 4.5 million (Tronvoll and Mekonnen 2014: 159).

${ }^{4}$ Hedru's documentation of the period leading from 1991 to 2003 posits the notion that the transition to dictatorship was partly due to "the fact that the [Eritrean] people willingly conferred absolute power on the leadership of a guerrilla movement that won their freedom from Ethiopian occupation" - the same leadership that went on to "deprive them of liberty" (2003: 435). Subsequently, in examining Eritrea's political culture once Afwerki's dictatorship was solidified, Reid (2009) argued that, at the time of writing, conflictual border issues with Ethiopia were yet to be resolved and, in fact, had lead to the justification for an increasingly militarised education system in Eritrea. In 2009, two books were released that respectively dealt with, firstly, the transnational nature of the Eritrean revolution by examining the convergence of U.S.-based Eritrean refugees and guerrilla fighters situated in the Horn of Africa (see Redeker Hepner 2009), and, secondly, ongoing issues pertaining to biopolitics, militarism, and development throughout contemporary Eritrea (see O'Kane and Redeker Hepner 2009). More recently, scholars have examined post-war "alternative nationalisms" throughout the region (Riggan 2011), the top-down strategies employed during state-lead nation-building (O'Kane 2012), and, indeed, the way in which Eritrea has been written about since the turn of the century (Reid 2014). Additionally, a special issue of Africa Today was published in 2013; the focus of which was Eritrea's ongoing 'state of exception' and issues pertaining to citizenship (see Woldemikael 2013). Lastly, The African Garrison State: Human Rights and Political Development in Eritrea (Tronvoll and Mekonnen 2014) was followed by a 483-page report issued by the United Nations (2015) in mid-2015; both of which detailed large-scale human rights abuses and crimes against humanity being committed at the mandate of the Afwerki administration.
} 
for fields such as political science and philosophy, the discipline of anthropology has an extensive, rich, and sometimes contentious history of examining the phenomena of war and violence. As Otterbein (1999) notes, since the mid-19th Century, four major periods of anthropological research surrounding warfare can be delineated: Foundational (c.1850-c.1920); Classical (c.1920-1960); Golden Age (c.1960-c.1980); and, Recent (c.1980-). Likewise, Accomazzo (2012) divides the history of anthropological theories and concepts of violence into three distinct eras: founding (c.1880-c.1940); modern (c.1950-c.1970); and post-modern (c.1980-present). Additionally, whereas the work of anthropologists has undeniably been shaped by major historical events such as colonial expansion, World War II, the Vietnam War, and, more recently, ethnic wars and the breakup of states, scholars have also traditionally investigated prehistoric 'war' and the conflicts of non-literate peoples (Otterbein 1999: 794). It is important to note that with regard to colonial expansion, anthropology has its own historical 'heart of darkness.' Because in many respects colonialism 'produced' the subjects of the discipline of anthropology, many scholars tended to avoid addressing indigenous forms of violence for fear of "exacerbat[ing] Western stereotypes of primitivity, savagery, and barbarism [...]" (Scheper-Hughes and Bourgois 2004: 5-6). However, this proclivity has faded in contemporary times with anthropologists investigating violence directly, subsequently theorising and delineating its many contexts, causes, forms, and consequences.

An initial, non-exhaustive survey of the literature relating to anthropological perspectives on violence reveals the notion that violence is seen as a complex phenomena often constituted by a continuum or spectrum, rather than as definable by a particular attribute or set of attributes. Contrary to conventional views, anthropologists tend to look beyond an interpretation of violence that maintains such occurrences as being solely physical in nature; Scheper-Hughes and Bourgois assert that the "social and cultural dimensions of violence are what gives violence its power and meaning" (2004: 1). Following this, violence underpins a vast amount of anthropological research and is recognised in its physical, symbolic, structural, and normalised configurations: ${ }^{5}$ whereas the physical elements of violence are usually hypervisible, symbolic violence entails "[d]omination, hierarchies, and internalised insult [...] legitimised as natural [or] deserved"; furthermore, where structural violence manifests as the "violence of poverty, hunger, social exclusion and humiliation" (Scheper-Hughes and Bourgois 2004: 1),

\footnotetext{
${ }^{5}$ See Bourgois (2009: 19) for a Table outlining 'The Pandora's Box of Invisible Violence.'
} 
normalised violence is comprised of "routinised bureaucracies that render violence invisible and produce social indifference" (Bourgois 2009: 19).

Accordingly, varying theoretical approaches to the study of violence have emerged within the discipline. Jeffrey Sluka points to E. V. Walter's Terror and Resistance (1969) as the first systematic effort to develop a general theory of state terror and violence (Sluka 2000: 14-15). However, this structural-functional theory - where the resort to violence as a matter of 'functional necessity' is seen as being due to the weakness of the modern state - is not without its limitations in contemporary times. Because Sluka views issues pertaining to social stratification as being central to problems of violence, he goes on to argue that "the most promising approach [to studying state violence] is a powerconflict theory that focuses on the operation of elites within a global system of social stratification" (2000: 30). With these varying perspectives in mind, it is possible to see that different underlying assumptions regarding violence will align more aptly with certain theories of violence; a methodological quandary that gives credence to the anthropological view that, again, violence in its various guises is always paradoxical (Žižek 2009: 1) or dichotomous (Scheper-Hughes and Bourgois 2004: 2; Schmidt and Schröder 2001: 2; Stewart and Strathern 2002: 1).

Another framework that has provided a foundation for anthropological investigations of violence is David Riches' 'triangle of violence'; a model that discerns between the performers, victims, and witnesses of violence. Although the advantages of Riches' model lie in its abstractness - an attribute that allows for cross-cultural comparability (Schmidt and Schröder 2001: 4) - anthropologists have further developed the general concept. For example, Strathern and Stewart (2006) have conducted research that highlights the role of certain factors in the context of violence, witchcraft, and sorcery in non-Western cultures. These elements include: the immediacy of the media and its propensity to magnify the public's perception of violent events; political power; rumour and gossip; legitimacy and justification; revenge, memory and identity; and, significantly, imagination.

Schmidt and Schröder also utilise Riches' model and begin to provide a more succinct definition of violence by stating that it is: [1] never completely idiosyncratic; [2] never completely sense- or meaningless to the actor; and [3] is never a totally isolated act (2001: 3). In other words, "violence is more than just instrumental behaviour. As historically situated practice, it is informed by material constraints and incentives as well as by historical structures and by the cultural representation of these two sets of 
conditions" (Schmidt and Schröder 2001: 3). In their introductory chapter, the same authors outline a more detailed approach to studying violence that discerns three major strategies: operational, cognitive, and experiential (Schmidt and Schröder 2001: 1-2). Respectively, these perspectives consider violence in relation to: human nature and social adaption to material conditions; cultural values and forms of representation; and, individual subjectivities (Schmidt and Schröder 2001: 17). Significantly, each approach contains both advantages and limitations. Thus, as stated by Schröder and Schmidt, an anthropological approach to investigating conflict, war, and violence "should adopt an analytical, comparative perspective" (2001: 18$)$ in order to contribute to the understanding and explanation of such phenomena. ${ }^{6}$

\section{§ 4 Chapter outline}

Following Scott (2001), the outset of this introductory chapter included an allusion to the notion of social structure as being discernible in its institutional, relational, and embodied forms. Indeed, in a chapter titled 'Where is Social Structure?', the same author states that "[s]ocial structure is a concept that points to three interdependent aspects of the organisation of social life: the institutional, the relational and the embodied" (2001: 84). Moreover, the interdependence of these organising factors upholds the conviction that each need to be considered in the context of social analysis. Hence, the three primary Parts that comprise the current thesis each foreground, in turn, a specific, generalised ${ }^{7}$ form of social structure: ${ }^{8}$ whereas Part I takes up institutional structure in the form of extreme nationalism, Part II focusses on the routinised fear that is seen to underpin the participants' interpersonal relations. Lastly, Part III turns to the varying ways in which violence is embodied subjectively. ${ }^{9}$ Additionally, there are two further divisional elements that cut across this tripartite scheme: firstly, each Part corresponds with a

\footnotetext{
${ }^{6}$ Added to the scholars already mentioned, anthropologists such as Errol Valentine Daniel (1996), Alan Feldman (1991, 2004), Linda Green (1995), Michael Jackson (2009, 2013), Michael Taussig (1984, 1989, 1992, 1997), Henrik Vigh (2008), and Kay Warren (2002) have developed compelling ways in which to think about and understand violence given the intricate and tangled attributes outlined above.

${ }^{7}$ See Danermark et al. on - as the title of their chapter implies - generalisation, scientific inference, and models for an explanatory social science (2002: 73-114).

${ }^{8}$ This approach is being employed simply as a heuristic relative to the structure of the thesis itself; it should be emphasised throughout that the institutional, relational, and embodied violence revealed in the participants' narratives can be seen to be continually weaved across all three structuring strands.

${ }^{9}$ Generally-speaking, this three-part scheme aligns with the operational, cognitive, and experiential approaches discerned by Schmidt and Schröder (2001: 1-2).
} 
chronological division in the narratives - i.e. the formative, 'middle,' and resettlement periods, respectively -; and, secondly, each chronological Part correlates with an emphasis on a particular stage in the trajectory of violence - i.e. the generative, perpetuating, subjective dimensions of violence (see Table 1).

Table 1: Overview of thesis structure

\begin{tabular}{|c|c|c|c|}
\hline & Part I & Part II & Part III \\
\hline $\begin{array}{l}\text { Narrative } \\
\text { chronology }\end{array}$ & formative & 'middle' & resettlement \\
\hline Structuring form & $\begin{array}{c}\text { institutional } \\
\text { (extreme } \\
\text { nationalism) }\end{array}$ & $\begin{array}{c}\text { relational } \\
\text { (routinised fear) }\end{array}$ & $\begin{array}{c}\text { embodied } \\
\text { (subjective } \\
\text { reverberations) }\end{array}$ \\
\hline $\begin{array}{l}\text { Trajectory of } \\
\text { violence }\end{array}$ & genesis & perpetuation & $\begin{array}{c}\text { internalised } \\
\text { (reproduced or } \\
\text { transformed) }\end{array}$ \\
\hline
\end{tabular}

Following this, each Part is comprised of 1-2 chapters.

Part I, Chapter 1 is predominantly contextual in that, firstly, it introduces each of the participants - Eyob, Tesfalem, Haile, Isaac, and Iaokim ${ }^{10}$ - by way of a narrative overview that specifies the major events that have constituted the overall trajectory of their lives thereby shaping the respective ultimate concerns therein and, secondly, it details the events that have conditioned Eritrea's pre-independence era in a broader historical and political sense. Subsequently, Part I, Chapter 2 proceeds to focus on Eritrea's post-independence period by interweaving the broader historical and political context of this timespan with the formative narratives of each participant. As the trajectories continue, Chapters 3 and 4 - both of which comprise Part II - detail the 'middle period' narratives of each participant. In due course, Part III, Chapter 5 narrows in on the subjective reverberations of violence as contained in a brief vignette from each participant's narrative, after which an exposition of the particulars of resettlement act as a coda to the overall life trajectories. Lastly, the Conclusion both summarises the

\footnotetext{
${ }^{10}$ Pseudonyms have been used throughout in order to establish anonymity.
} 
research findings and outlines several limiting caveats alongside suggestions for future related research. ${ }^{11}$

Thus, taken as a whole, where the reader begins at Eritrea's inception by being presented with the external factors constitutive of the nation's early history, he or she at the concluding point of the thesis - finds themselves positioned in the mind of the participant - at least as far as that is possible - in the moment at which the life-narrative interviews took place.

The next chapter discusses the methodology and methods that underpin the thesis.

\footnotetext{
${ }^{11}$ Because each Part and Chapter, as they appear throughout the thesis, contains an overview of the relative content - and in the interests of preserving space - the chapter outline presented here is purposefully brief.
} 


\section{METHODOLOGY}

\section{$\S 1$ Preamble}

The methodological framework upon which this thesis is situated primarily follows the work of anthropologist Charlotte Aull Davies. In her book Reflexive Ethnography: A Guide to Researching Selves and Others (2008), Davies draws on the traditions of critical realism and pragmatism in order to develop "epistemological and methodological foundations that encourage and incorporate genuinely reflexive ethnographic research while maintaining that such research can be based on a realist ontology, which assumes a social reality independent of our knowledge of it" (6). Significantly, adopting a realist approach to method ascribes importance to the discernment between conceptualisation and technique (Sayer 2010: viii, xv, 2-3). Hence, this chapter recognises the crossover between social theory, philosophy of social science, and method. Simply stated, the methodological framework herein can be thought of as: reflexive ethnography underlaboured by a critical realist ontology (see Davies 2008: 6).

With regard to 'ethnography,' definitions are myriad. However, where ethnography is considered as both the written product of research and the particular process that culminates in its eventual production, a loose interpretation posits ethnography as "a research process based on fieldwork using a variety of mainly (but not exclusively) qualitative research techniques [whilst] including engagement in the lives of those being studied over an extended period of time" (Davies 2008: 5). In contrast to the admittedly broad definition above, the subjective nature of reflexivity necessitates a more nuanced examination and understanding.

Reflexivity in social research requires, at the most preliminary level, a 'turning back on oneself.' Such a process of self-reference is key to realising the way in which research as an activity in and of itself shapes the very products of research. Additionally, where subjective experience - and reflection on that experience - are seen as intrinsic to social science research, the individual ethnographer's sociocultural context cannot remain unexamined; instead, it is ideally made explicit and consciously incorporated in to the process and results of the research. As Davies notes, these attributes "become a part of the research, a turning back in the form of cultural critique that has moral and political implications [...]” (2008: 4-5). Furthermore, the acknowledgement of the selfconsciousness of one's research partners also brings-to-light the particular relevance 
pertaining to reflexivity in the context of ethnographic research: questions of interpretation and meaning are seen as being intimately tied to social inquiry (Davies 2008: 3-4, 6). ${ }^{12}$ However, contra to various postmodernist and poststructuralist approaches to social science, individual and collective self-examination in research should not result in a total 'self-absorption' whereby the "boundaries between subject and object disappear, [and] the one becomes the other" (Davies 2008: 5); to do so would be to deny the possibility of social research in the first place. Moreover, the 'critical' component of anthropological research that is contained in Davies' framework would be rendered obsolete. ${ }^{13}$ The reasons and explicit assumptions that sponsor these perspectives are explored in greater detail below.

Thus, in addition to examining methodological issues of reflexivity, ethics, and politics as they relate to this thesis - as well as technical processes such as interviewing and coding - this chapter considers 'method' in a broad sense by engaging discussion surrounding the conceptualisation and possibility of research, different modes of explanation and understanding, and the nature of abstraction.

\section{$\S 2$ Reflexivity \& anthropology}

Reflexive practice in anthropological research began to take hold in the 1970s. Whereas anthropologists working from a positivist standpoint a generation earlier had sort to maintain objectivity by ostensibly removing themselves from their research, an eventual compulsion toward authenticity arose and ethnographic texts of the time often included an opening 'arrival story.' However, the superficial nature of these 'arrival stories' soon gave way to a more professed disciplinary self-critique in the late 1960s. In particular, reflexive practice in anthropology started to emerge as a response to the undesirable relationship between anthropology and colonialism. As Davies writes, this "process of self-criticism initiated by a recognition of the ways in which the discipline had been a product and beneficiary of colonial expansion [was] furthered by considerations of whether and how it may have inadvertently aided the designs of the

\footnotetext{
${ }^{12}$ Davies, following Sayer (2000: 17-18), notes that the 'double hermeneutic' which arises due to the involvement of the self-consciousness of the objects of study distinguishes the natural from the social sciences. Furthermore, social research is inevitably "answerable to both the scientific community and to those being studied" (2008: 6)

${ }^{13}$ Davies notes that "both good and bad research are possible, and the development of criteria to recognise the difference should provide the basis of anthropological authority" (2008: 6)
} 
coloniser" (2008: 11). Additionally, both the structural-functionalism of British anthropology - headed by Malinowski and Radcliffe-Brown - and Boas's approach to anthropology developed in America came to be seen as having not recognised the impacts that colonial contact had had on the lives of the people they studied, nor the fact that they themselves were a part of this colonial imperative (Davies 2008: 12). Subsequently, ethical considerations increasingly came to the fore and eventually led to not only an examination of the interrelationships between anthropologist and native, but to the study of colonial forms and colonisers themselves. In other words, classical ethnography came to be seen as a projection of the cultural assumptions held by Western practitioners; "[a]nthropologists were perceived as having themselves constructed their objects of study" (Davies 2008: 13). Interestingly, the essential gist of these critiques have broader epistemological implications relevant to postmodernist and poststructuralist approaches to social science.

One of the major distinguishing factors in the transition from modernity to postmodernity can be seen respectively in the processes of cultural differentiation and de-differentiation. Thus, on one hand, modernisation heralded a distinction and degree of autonomy between the spheres of aesthetics, ethics, and theory ${ }^{14}$ - significantly, epistemological realism was also an outcome; a position that holds that "ideas can give a true picture of reality; it depends on the differentiation of such ideas from the reality that they are held to represent, hence scientific ideas are separate from but truly represent nature" (Davies 2008: 14). On the other hand, however, the postmodern process of dedifferentiation - or the "breaking down [of] boundaries [whilst] rejecting the autonomy of different realms" (Davies 2008: 15) - can be tied to poststructuralist critiques of the structuralist epistemologies underpinning Durkheim's 'autonomy of the social,' Radcliffe-Brown's structural-functionism, Lévi-Strauss's structuralism, and classical Marxism. ${ }^{15}$ Thus, postmodern critiques posed a very real challenge to anthropology, even resulting in a so-called 'crisis of representation' during the 1980s (Davies 2008: 14$15)$.

\footnotetext{
${ }^{14}$ This distinction was put forward by Immanuel Kant (Davies 2008: 14).

${ }^{15}$ More specifically, Durkheim's position entailed an emphasis on the social, as opposed to the individual, in relation to explanations of social facts; the structural-functionalism of Radcliffe-Brown focused on the interrelations and functions of societal structures irrespective of external factors; LéviStrauss's structuralism identified universal categories such as myth and kinship; and, classical Marxism differentiated surface appearances from infrastructure (Davies 2008: 14).
} 
This 'crisis of representation' - or the idea that ethnographic research cannot legitimately represent another society and its separate reality - is emblematic of postmodernism in its most radical form. With regard to the breaking down of boundaries, this included the de-differentiation of author and ethnography. As Davies states, this has two important ramifications:

\begin{abstract}
the first, and most obvious, is the inherent individual reflexivity of the ethnographies that are produced; carried to its logical conclusion, it could be argued that they are about the ethnographer, not the people ostensibly studied. The second implication is the denial of authority, of a privileged voice, to ethnographers in their presentation of their ethnographies [...]. In this view there is no privileged explanation, no basis on which to judge one perspective more correct or truer than another; there are only perspectives
\end{abstract} (2008: 15-16)

Essentially, ethnography came to be construed as an exercise in fiction based on the creative capacity of the individual researcher (Davies 2008: 16); the "playfulness of language took precedence" (López and Potter 2001: 5). Also, the denial of authority indicates the degree of relativism that accompanied these postmodern critiques in their more radical manifestations. Responses to these critiques has resulted in two primary strategies with respect to the production of ethnographic research. Firstly, ethnographic material such as interview transcripts can be presented in a 'raw' format with limited or no explanation or analysis; the idea being to handover the presentation to the participant(s). Secondly, rather than attempt to remove the researcher, as per the positivist tradition of times gone by, postmodern ethnographers can render the researcher more visible - often even central - to the production of ethnography. The tactic here is to "undermine [the researchers] own authority so that their interpretations become simply one perspective with no superior claim to validity" (Davies 2008: 16).

Turning, for a moment, toward ethnographic approaches to the study of violence, it is possible to see that - even in light of postmodernism's decline in the later years of the twentieth century (López and Potter 2001: 4) - how the postmodernist inclination to foreground the knowledge and experiences of the ethnographer whilst de-differentiating between author and ethnography still persist. In his edited volume, Violence: Ethnographic Encounters, Parvis Ghassem-Fachandi (2009) outlines a 'decidedly descriptive' approach to the ethnography of violence whereby "foregrounding the contingency of fieldwork experiences, the unexpected and unassimilable, [the essays in the volume] elucidate 
where the anthropological project of producing knowledge about other peoples and places ultimately finds its limits: in the body and mind of the ethnographer" (1, emphasis added). This approach can be seen as problematic in light of Davies' view that the general purpose of research is to "increase our understanding of social reality by developing explanations of social forms and events, as well as critically examine the conceptualisations used in these explanations" (2008: 6). In other words, a descriptive approach to violence that situates and contains the limits of knowledge in the body and mind of the ethnographer is "not really accessible to the critical evaluation of an informed collectivity, nor [is this approach] to be understood in terms of a realist ontology" (Davies 2008: 16). Subsequently, the emancipatory potential of such social science is inherently undermined.

Thus, it is possible to see how postmodernism and the process of de-differentiation has simultaneously given rise to valid critiques of social science theory and practice whilst detrimentally breaking down boundaries at several levels. Essentially, the result is, on one hand, a wholly desirable increased degree of reflexivity, and, on the other, a logic that "leads us inexorably to the forms of reflexivity that continually spiral inward, a process that is ultimately destructive of one of the two pillars of social research, a belief that we are able through these activities to learn about things outside ourselves, not knowable through introspection" (Davies 2008: 18). More broadly, postmodernism as an intellectual current problematised the foundations of philosophical knowledge, rationality, and science whilst providing an intellectual outlook that is ultimately incoherent (López and Potter 2001: 3). Aligning herself with others working from a critical realist standpoint, it is Davies' contention that the philosophy of critical realism accounts for both the valid insights and limitations of postmodernist philosophy and theory (2008: 118; also see López and Potter 2001: 3-16).

\section{$\S 3$ Critical realist ontology ${ }^{16}$}

At its most essential level, and for the purposes of this thesis, the original phase of critical realism ${ }^{17}$ can be thought of as an immanent critique and subsequent synthesis of

\footnotetext{
${ }^{16}$ Due to limitations of scope, this subsection provides only a brief outline of critical realism and its essential points as they relate to reflexive social science. For more detailed introductory material on critical realism, see Archer et al. (1998), and Collier (1994).

${ }^{17}$ The breadth of critical realism in its entirety includes three primary phases: original critical realism, dialectical critical realism, and the philosophy of metareality (see Bhaskar 2012)
} 
the positivistic and hermeneutic traditions across the natural and social sciences. With regard to ethnography, overcoming the dichotomy of positivism and hermeneutics has implications for interpretivism (Davies 2008: 118) and, generally-speaking, scholars working from a critical realist perspective "aspire to provide explanations, not simply descriptions, which have applicability beyond the confines of their specific research subjects and sites, without sacrificing the hermeneutic insights into the pre-interpreted nature of their subject matter and the reflexive implications of their research practice" (Davies 2008: 18). Additionally, López and Potter state that "[i]t is the crux of the critical realist viewpoint that a conscious understanding of the philosophical foundations of the possibility of social science will enable the practice of social science (and natural science as well) to be better and more successfully performed" (2001: 9). However, critical realism is yet to be significantly utilised within anthropology, and prominent anthropologists David Graeber (2015) and Tim Ingold (2005) have both noted the potential value in opening up dialogue at the intersection of these discourses. ${ }^{18}$

Postmodernism and critical realism both emerged as a response to the aforementioned positivist tradition that was at the forefront of the philosophy of science during the early twentieth century. Although the 'hypothetic-deductive' account of scientific explanation formulated by Karl Popper and Carl Hempel rejected notions of confirmation and verification in logical positivism by, instead, emphasising falsification and the precarious nature of prediction, their position can still, broadly-speaking, be seen to rest on positivist and empiricist foundations (López and Potter 2001: 6-7). Accordingly, where "the positivist account of science stresses the progressive nature of knowledge acquisition [and] has a tendency to present science as an ongoing cumulative process of discovery [that stresses] the disinterested objectivity of the scientific endeavour" (López and Potter 2001: 7), ${ }^{19}$ both critical realism and postmodernism oppose positivism as a valid position. However, they do so in different ways.

With its ties to hermeneutics, interpretivism, and the 'linguistic turn' in social science, postmodernism rightly rejects the positivist notion that science is an ongoing process of discovery and, instead - following the likes of Thomas Kuhn and his important work The Structure of Scientific Revolutions (2012) - considers the production of knowledge as a process of social construction (López and Potter 2001: 7-8). In its most radical form, this

\footnotetext{
${ }^{18}$ This is not to say that there is not already implicit crossover between critical realism and contemporary anthropology.

${ }^{19}$ López and Potter note the oversimplified nature of this definition (2000: 7).
} 
leads to the position "that 'knowledge' is whatever human beings come to socially certify as such" (López and Potter 2001: 7). However, again, with its roots in the 'linguistic turn,' postmodernism rightly recognises that social inquiry is inevitably tied to questions of meaning; a recognition that exemplifies a "conceptual opposition [...] between natural science which focuse[s] upon causal explanation and social science which focuse[s] upon understanding" (López and Potter 2001: 8). As such, understanding knowledge, theory, and social reality in general is seen as being akin to understanding a language, as opposed to a machine. The significance of this lies in the fact that a scientific understanding 'scientific,' that is, as far as a positivist understanding goes - of social reality is not possible. Accordingly, this has implications surrounding the issue of naturalism in social science: whereas positivist social scientists advocated for a misconceived naturalism, interpretivists wholly rejected this scheme based on a recognition of the inherent differences contained in natural and social objects of knowledge. Critical realism, on the other hand, both accepts the insights of interpretivism and advocates for a form of naturalism in the social sciences. However, as should be clear, unlike the postmodern and positivist traditions which both accept a positivist account of science, a qualified critical naturalism is based on a rigorous critique of this account (Bhaskar 1998: xiii).

The starting point for a realist critique of positivism and empiricism is ontology. Significantly, this is in contrast to the epistemological focus of traditional debates surrounding positivism, hermeneutics, and naturalism (Davies 2008: 19; López and Potter 2001: 10). From a realist perspective, epistemological questions rest upon answers pertaining to the nature of existence. In other words, any argument concerning epistemology will entail ontological presuppositions, explicit or otherwise. Thus, the first problematic issue for positivism and empiricism is that these positions answer ontological questions implicitly; the second, and more significant, is that the implicit ontology that they can be seen to hold is philosophically incoherent. In critical realist terms, this inconsistency presupposes the fallacy of actualism (López and Potter 2001: 10) ${ }^{20}$ Hence - as stated in the Introduction - the analytical framework utilised in this thesis presupposes the existence of social structures in institutional, relational, and embodied forms. In other words, social structures exist and shape the lives of one's research partners irrespective of whether they recognise it or not (see Archer 1998: 199).

\footnotetext{
${ }^{20}$ López and Potter writes: "Actualism thus is an event based on ontology of invariance. Empirically observed invariance is generalised, from the subset of events to all events, this being exhaustive of reality and thus the generalisation of invariance is the law of nature" (2001: 11).
} 


\section{$\S 4$ Topic selection \& methods}

Davies notes that, with regard to the initial selection of one's research topic, it is "nearly always a combination of personal factors, disciplinary culture, and external forces in the broader political, social and economic climate" (2008: 30). This sub-section elaborates on the influence of these factors as they relate to the current project.

Since formally studying anthropology, my primary areas of interest have included medical anthropology, science and technology studies, and, most recently, the anthropology of war, conflict, and violence. Although all of these sub-disciplines hold my attention to some degree, it is the latter that remains as my predominant area of focus. There are myriad reasons for this sustained focus, but in distilling my reasoning down in to two central points, it can be understood in the following way: firstly, given that it is hardly an obscured fact that there is no shortage of instances of warfare, conflict, and violence currently occurring around the globe, I have been unable to resist developing a strong compulsion to understand how and why such seemingly incomprehensible events come to transpire. Of course, as with much anthropological research pertaining to worldviews, beliefs, and behaviours that initially appear mystifying, it is often shown that there is indeed some type of internal rationality or logic sponsoring such human reasoning and action. Following this, the second central point that ushered in my interest in pursuing the current topic is the examination of the role - or potential role - that anthropological knowledge can play in alleviating such altogether undesirable circumstances. Thus, the initial regional focus of the empirical component of this thesis was Syria. ${ }^{21}$ However, after attempting to make contact with potential participants via various NGOs, refugee drop-in centres, and word-of-mouth, my project was failing to

\footnotetext{
${ }^{21}$ In 2001, the 'Arab Spring' ignited dramatic political changes with varying results across several Arab countries. The uprising catalysed relatively free elections in Egypt and Tunisia, while Libya and Syria spiralled in to violent conflict. In particular, the people of Syria faced - and continue to face - the violent and oppressive actions of, among other militant groups, both the Assad regime and the Islamic State. As a result, millions of Syrians have been displaced either within their country or by fleeing to neighbouring nations such as Jordan, Lebanon, and Turkey (Davison 2014). Adding to this, the Syrian refugee crisis was quickly seen to be 'outstripping' international aid efforts (Hilton 2015). At the time, the New Zealand government had recently agreed to resettle one hundred Syrian families - a significant portion of New Zealand's annual refugee quota of 750 (Davison 2014) - while other groups such as Amnesty International New Zealand and ActionStation were urging the government to accept additional numbers due to the deteriorating humanitarian situation (Radio New Zealand 2015; ActionStation 2015). Hence, my initial compulsion to focus on Syria was due to the relevance of the situation there, as well as pragmatic reasons tied to seeking out and finding suitable and willing participants.
} 
gain traction. At one point, I had also pursued the possibility of working with Afghani refugees due to a connection I made thanks to a senior academic at Victoria University of Wellington. Eventually, however, these loose leads dissolved and it wasn't until a chance meeting with an ex-student, Iaokim, whom I had tutored in early 2013, that things began to fall in to place.

As Iaokim spoke over coffee about his own experiences as a refugee from Eritrea, it became clear that this small African nation would constitute the new regional focus of my thesis. Furthermore, he was very willing to participate and knew many other Eritrean refugees living in Wellington that were also open to taking part. On one hand, this relieved the pressures of attempting to solicit the participation of suitable candidates for the project; on the other, however, Iaokim's willingness also gave rise to issues pertaining to ethics and the political nature of researching violence. With regard to the ethnographic investigation of violence and the inevitable place of seduction within such inquiry, Robben notes that ethnographic seduction can transpire in both intentional and unconscious ways with respect to the position of either the researcher or participant. This gives rise to the notion that "victims of violence might mo[u]ld what they tell us"; a methodological quandary that can lead to the researcher being "accused of contributing to [the participant's] victimisation" (Robben 1995: 83-84). Robben's personal account continues by elucidating several important points that are also essential to consider given the content of this thesis:

\footnotetext{
How can I place doubt on the horror stories I have been told and distrust their narrators? It is much easier to acknowledge manipulation by victimisers than by victims. We have more sympathy for unmasking abusers of power than doubting the words of their victims. I have the same sympathies. However, I also realise that in the end the victims may be harmed and their testimonies discredited if we report their views naively and uncritically. We need to analyse their accounts and be attentive to our own inhibitions, weaknesses, and biases, all to the benefit of a better understanding of both victim and victimiser. The ethnographic seduction by victims and perpetrators of violence will in this way become a font of instead of an obstruction to insight (1995: 84)
}

Therefore, with these provisions in mind, it is recognised that the participants involved in the thesis may have been selected - unconsciously or otherwise - on the proviso that they would be best-suited to support the explicitly anti-regime stance that 
Iaokim himself holds. Moreover, similar necessary considerations surrounding the study of violence meant that I upheld a preference for male participants. This preference was based on the recognition that inquiring into violence can potentially entail unintended consequences when the researcher/participant dynamic is constituted by both a male and female. In other words, if my position as a male researcher of violence happened to trigger a chain of traumatic events concerning a female participant's past experiences, then my position as a student would likely have rendered me ill-equipped to navigate such a situation effectively. Therefore, to risk inciting gender-related trauma for the sake of my own research experience was not deemed suitable given the scope and context of this project. $^{22}$

Regarding ethnographic method and the study of violence, there are considerable implications that descend on the researcher - trauma, risk, and, in some cases, death as soon as they engage fieldwork; a notion that is particularly true where the researcher's method is participant observation (see Nordstrom and Robben 1995, and Sluka 2000). It goes without saying that to study violence as it appears in relation to the Eritrean state via participant observation was not a realistic option given both the nature of the situation and the constraints of working within the confines of a relatively small-scale project such as master's thesis. Thus, if participant observation is often considered as a hallmark - perhaps even a rite of passage - of ethnographic research (see Davies 2008: $77)$, the current thesis primarily utilises a sub-ordinate ethnographic technique: lifenarrative interviews.

As Davies notes, “[n]arrative studies are often used to investigate collectivities who have shared an experience of some traumatic past event [...]; the main aim [being] to construct an understanding of informants' perceptions of particular life stories" (2008: 210). Therefore, subsequent to ethics approval and confirmation that the participants were willing to be involved in the project, invitations were extended to each of the five informants to partake in a life-narrative interview. The resulting audio recordings varied in length - the shortest being 45 minutes, the longest in excess of three and a half hours - and were transcribed verbatim over a period of weeks. Subsequently - and following Saldaña's 'pragmatic eclecticism' (2009: 47) - the transcribed interview data was subjected to First and Second Cycle coding rounds. These coding Cycles generated, firstly, a batch of Attribute, Structural, Holistic, Descriptive, In Vivo, and Values codes,

\footnotetext{
${ }^{22}$ See Christian Solidarity Worldwide (2008) for an account of sexual violence against female army conscripts in Eritrea.
} 
and, secondly, a variety of themes including Agency, Constraint, Interpersonal, Process, Subjectivity, and Violence. Ultimately, the thesis material herein has emerged from these themes and the way in which they appear throughout the chronological narrative trajectories of the participants.

This chapter has outlined the methodological precepts pertaining to reflexivity and critical realist ontology that underpin this thesis, as well as the methods that were utilised to obtain and interpret the primary data. The next section - Part I, Chapter 1 - turns to the contextual factors that generate violence. 


\section{The genesis of violence}

In addition to providing the historical and political context from which each of the participant's narratives have emerged, Part I takes as its focus the structuring elements therein that can be considered as institutional. For Scott, institutional structures are "seen as comprising those cultural or normative patterns that define the expectations that individuals hold about each other's behaviour and that organise their enduring relations with each other" (2001: 80). Thus, by considering the historical and political context of Eritrea in conjunction with the formative experiences of each participant, it is possible to discern nationaliom as a primary social institution through which the ultimate concerns, and, more broadly, life trajectories, of each participant have been shaped. ${ }^{23}$

As Woldemikael notes, "[n]ationalism is a double-edged sword. It can be a tool for bringing about a greater future or it can be a destructive force, one that is unable to produce new heights of human liberty and dignity" (2009: 14) $\cdot{ }^{24}$ With this in mind, the two chapters that comprise Part I demonstrate that it is indeed the 'destructive' edge of the knife-like nature of nationalism - particularly as it appears in its extreme form throughout Eritrea - that violently segmented the formative periods of each of the interlocutors. ${ }^{25}$

Following this, whereas Chapter 1 introduces the participants by way of a general overview pertaining to each of their life trajectories and briefly details the historical events leading up to Eritrean independence in the early 1990s, Chapter 2 continues to outline the broader circumstantial elements from this point forward whilst also interweaving the specificities of each participant's formative experiences in to the overall contextual narrative. More specifically, by drawing on the work of Bourgois, Strathern and Stewart, and Vigh, Chapter 1 demonstrates, firstly, the way in which violence

\footnotetext{
${ }^{23}$ For the purposes of this thesis, the 'formative' years of each participant include the period from birth through to the point at which each individual either joined the national service or decided to abscond from Eritrea; generally-speaking, this turning point occurred when the participant was either in his late teens or early twenties.

${ }^{24}$ See Anderson (2006) and Hage (2000) for comprehensive accounts of nationalism from an anthropological perspective.

${ }^{25}$ Woldemikael goes on to assert that " $[t]$ he Eritrean state and the ruling party, and many Eritreans at home and abroad, have wrapped themselves in a shawl of nationalism to such an extent that they are blind to the dire situation their country is in" (2009:14).
} 
operates on an invisible-hypervisible continuum, and, secondly, that violence becomes indistinguishable from its surrounding social context when conflictual crises endure endemically, as opposed to episodically. Additionally, following the identification of extreme nationalism as a primary institutional factor within the context of the Eritrean situation, Chapter 2 analyses this phenomenon as it has played out in the lives of each participant. By doing so, it is possible to understand the way in which "cultural or normative patterns" (Scott 2001: 8) such as rumour, self-sacrifice, heroism, and an ostensible perpetual state of emergency were often utilised as indoctrinating mechanisms through which the Eritrean state generated ideals of extreme nationalism among the participants. However, when examining extreme nationalism as an institutional structure as it is actualised in relation to the agentic capacities of each participant, the notion that such structures tend to influence - yet do not deterministically dictate - people's thoughts and actions is revealed. Thus, with respect to the relationship between structure and agency - notwithstanding the way in which this relationship is mediated by one's subjective and reflexive faculties - the above conviction aligns with Archer's assertion that, "in relation to [social] constraints and enablements, agential responses can vary greatly: from evasion, through compliance, to strategic manipulation or subversion" (2007: 15). Indeed, Chapter 2 evinces the way in which, for example, nationalist ideology compelled some participants to dedicate themselves to the nationalist cause in an altogether unfettered way, while others were prompted to evade compulsory national service by taking flight from Eritrea before conscription was enforced upon them - an important point relative to the notion of extreme Eritrean nationalism as a morphostatic structure of violence.

Essentially, the two chapters that comprise Part I demonstrate the generative aspects of violence as they have appeared historically during the period leading up to Eritrean independence, as well as the way in which violence has been institutionalised in a cultural sense thereby manifesting as extreme nationalism both in the lives of the participants and the broader historical and political context of Eritrea since the early nineties. 
CHAPTER 1

\section{The chronicity of Eritrea's violent past: participant introductions and pre-independence Eritrea}

\section{$\S 1$ Preamble}

This chapter outlines the historical and political context of the current Eritrean situation. As far as the extended period leading up to independence in 1991 goes - a period that runs from antiquity and the rise of the Aksumite Empire through to Italian colonisation, British occupation, and three decades of war following a failed federation with Ethiopia during the twentieth century -, the historical account presented here draws largely on the information provided in the recent report produced by the United Nations (2015). ${ }^{26}$ For this reason, it is necessary to acknowledge the contrast between internalist and externalist perspectives pertaining to histories of violence. Stewart and Strathern write:

In asking what kinds of history they should write, some anthropologists have
argued that we need to represent the histories that the peoples we study make
for themselves. History thus becomes the ethnography of indigenous
histories. This we may call an internalist perspective. Externalist
perspectives, by contrast, bring to the topic the standpoints and particularly
the explanatory theories of the outside observer (2002: 15)

The authors continue by emphasising the importance of historical contexts in the study of violence - as it is "only on the basis of a detailed understanding of such contexts that we can arrive at broader propositions" (2002: 2) - and ultimately advocate for an approach that combines both internalist and externalist perspectives (2002: 16-17). For the purposes of this thesis, however, it is not until we reach Eritrea's post-independence era that an internalist perspective - taking its cue from meaning (Stewart and Strathern

\footnotetext{
${ }^{26}$ It is recognised that relying on the historical account provided by the United Nations presents its own set of political issues. However, because re-writing a definitive history of Eritrea was never the intention of this thesis, utilising the work of the United Nations is perhaps justified, particularly given how recent the publication is. For a list of bibliographic sources contained in the United Nations report, see United Nations (2015: 478-483).
} 
2002: 15) - begins to seep in to the narrative put forward here. ${ }^{27}$ Additionally, in order to better understand the specificities outlined in each narrative, it is worth gaining an initial acquaintance with the participants by way of a more general introduction to the overall trajectories of their lives.

\section{$\S 2$ Participant introductions: a narrative overview}

Contained within the lives of the five interlocutors is a diverse range of backgrounds, affiliations, commitments, and ambitions. Whereas the majority were born in to, and are therefore of, Eritrean heritage, the exception is Eyob who was born in Ethiopia to an Ethiopian mother and Eritrean father; in Eyob's words, he is "half-half." The ages represented across the board - when wound back to their birthdates - span a particularly crucial period of time in Eritrean history: the transition from pre- to post-independence.

Now in his forties, and a self-confessed "family man," Tesfalem is the eldest of the group. With a thick accent he proceeded to tell a tale that encompassed his Christian Orthodox upbringing within a Tigrinya family of three sisters, through to his ambitions to be a teacher, and on to more harrowing experiences of forced conscription and the fleeing from Eritrea via Sudan and the Sahara Desert to Libya. However, in spite of these efforts, Tesfalem was to find himself in the surreal position - two years after absconding - of being handcuffed and on a 4-hour flight back to Eritrea subsequent to being held in Malta due to his attempt to cross the Mediterranean Sea en route to Italy - alongside 270 other asylum seekers - being thwarted by a severe storm. Now considered a national traitor in the eyes of the Eritrean state, his arrival at the airport in Asmara $^{28}$ saw immediate incarceration followed by weeks of ongoing interrogation and years of unrelenting forced labour. Eventually, his only option was to embrace various tactics of deception and make another escape attempt. This time the risk enmeshed in the decision to make the six-day trek on foot across the border to Kassala, Sudan paidoff. Understandably, such experiences were enough to secure refugee status, and, following three weeks in a refugee camp, Tesfalem found himself grappling with the idea of being resettled in New Zealand - a place "at the bottom of the world" constituted by “an impressive bird,” earthquakes, and a female Prime Minister. Since his 2008 arrival

\footnotetext{
${ }^{27}$ See Chapter 2.

${ }^{28}$ Asmara is the capital city of Eritrea.
} 
in New Zealand, Tesfalem has endeavoured to fulfil his ultimate (educational) concern by pursuing development studies as a stepping stone to realising his benevolent aims of working for an NGO geared toward addressing the seemingly endless problems faced by the people of Africa. All this whilst living up to his 'family man' status as the father of two children, aged 1 and 2.

The most recent arrival to New Zealand, and the youngest of the participants, is Isaac. Reaching New Zealand in February 2014, and 21 years of age at the time of his interview, Isaac's upbringing and teenage years alongside two brothers and two sisters unfolded in conjunction with Eritrea's transition from new-found independence to fullscale war with Ethiopia during 1998-2000; a conflict that was very much in contrast to the "respectful" relationships he experienced growing up as a Muslim among Christian friends. As we will see, the years following the war entailed ongoing political crackdown by the Eritrean government on its own people. Essentially, it was this inexorable oppression that lead to Isaac leaving school and taking-up employment aboard his uncle's fishing boat. However, this apparently simple decision to leave school early was carried out in the face of the risk of compulsory military service. As events continued to transpire, Isaac's covert existence remained unsatisfactory. Whereas the Red Sea once provided a source of income, it now formed a means of escape. Before dawn, on 21 August 2011, Isaac and a group of friends harnessed the vigour of a 40-horsepower engine tacked to a small, borrowed boat and embarked on the 4-5 hour journey to Yemen. The trip was accompanied by a dichotomy of emotions: the sadness tied to the leaving behind of one's family was countered by the potential freedoms awaiting on the shores of the Arabian Peninsula. However, any preconceived notions about life beyond the borders of Eritrea were quickly shattered. Upon arrival, the group were hastily assigned residence in a compound within which any measures to discern between 'asylum seeker' and 'convicted criminal' were phantasmic; in labelling the compound, 'refugee camp' and 'prison' could have served interchangeably. In light of this oversight, the refugee status bestowed upon Isaac and his comrades by the Office of the United Nations High Commissioner for Refugees (UNHCR) appeared as a mere formality. At times somewhat indecisive and frequently correcting himself during the interview - attributes that were perhaps a result of both the traumatic nature of what was being recounted and the necessary use of his non-native language - Isaac went on to describe experiences of directly encountering and witnessing violence in the forms of fighting, rape, stabbings, and the executions of other prisoners. This went on for more than two 
years; the all-consuming nature and close proximity of the violence even, as Isaac noted, infiltrating his dreams. ${ }^{29}$ Draped in an NBA-style jacket and basketball boots, the vibrancy of Isaac's attire failed to soften the delivery of his portrayal as he spoke with me across a modest coffee table in the anthropology library at Victoria University of Wellington. After forty-five minutes, we parted ways and Isaac re-engaged his Saturday morning in Wellington where "life has been alright" in spite of family contact being restricted by Eritrea's arcane laws pertaining to communication and the internet. For now, life in New Zealand has allowed Isaac to realise his ultimate concern of avoiding the same indefinite military-life bestowed upon his older brother. However, this also means that any physical return to Eritrea on Isaac's part is implausible due to reasons that will be alluded to as the thesis proceeds.

I met Haile in-between his shifts working as self-employed taxi driver. After insisting on paying for his own parking outside my apartment, Haile spent the next two and a half hours depicting a chain of events that has seen his family fractured and dispersed around the globe. With one sister in New Zealand, another in the USA, and a brother in Italy, Haile's upbringing foretold the militaristic and nationalistic constraints - via the experiences of his older siblings - that he would later endure. However, the second largest city in Eritrea, Keren, provided an initially "normal childhood”; a normality that only gave way in retrospect once Haile came to recognise the ignorance that he embodied through the moulding of a state regime that sermonised extreme patriotism. In Haile's words, he was of a "brainwashed mentality." The willingness to fight for his country was partially realised in 1998 when the war between Ethiopia and Eritrea ignited. At just 8 years of age, Haile's schooling was on hiatus and, instead, he was preparing bandages for wounded soldiers. By the time Haile had completed his High School education, his nationalist ambitions were closer to being fulfilled: following government policy, Haile entered the national service. However, his early inclinations of being in the "right place" based on the preconceived idea that national service fostered "the greatest nationalist people" were soon superseded by torture, punishment, and an ongoing "psychological war against [him]self." As Haile's frustrations grew, he made the decision to escape the camp, and Eritrea. With shoot-to-kill policies in place at the borders of his country of

\footnotetext{
${ }^{29}$ Indicative of things to come as this thesis unfolds, Linda Green writes: "While it is true that with repetitiveness and familiarity people learn to accommodate themselves to terror and fear, low-intensity panic remains in the shadow of waking consciousness. One cannot live in a constant state of alertness, and so the chaos one feels becomes infused throughout the body. It surfaces frequently in dreams and chronic illness" (1995: 109).
} 
origin, Haile hired a trafficker and embarked on "the most intense eight hours of [his] life." The trafficker was later shot and killed. Once in Sudan, Haile - a man of Christian faith - was holed-up by a Muslim family before making his way to a refugee camp in Khartoum. ${ }^{30}$ After being processed, he later went on to work as a cashier in a restaurant on the streets of this "unpredictable" capital city. It was only at this point that Haile was given the space to reflect; ultimately, his strategy, at the time, involved "completely erasing everything about Eritrea." Since arriving in New Zealand in 2008, Haile has pursued his ultimate concern via study and work, and considers himself as "a Kiwi." However, he also admits that his Eritrean heritage and experiences are still part of who he is; therefore, the total erasure of his past can be seen as a temporary coping mechanism.

Eyob's story differs somewhat from the other four participants. At the age of 23, his lifespan mirrors the period that Eritrea has existed as an independent state. However, growing up in Ethiopia, he has never set foot within the borders of the country that captured his father one night as the Ethiopia-Eritrea war quickly escalated. His father remains in Eritrea. Although he has spoken with his father in recent years, he has not seen him since that fateful night. As a farming family, the daily struggle became unbearable and, at 7 years of age, Eyob withdrew from school in order to help provide for his family. However, his efforts remained in vein and the family were eventually forced to leave their dying cattle and seek refuge in the city of Shire where Eyob took to plying a trade selling cigarettes on the streets at night. As the youngest in a Christian family of eight, Eyob's story was further complicated by events that lead to two of his brothers serving opposing armies at the same time; one in Ethiopia, the other in Eritrea. Sadly, this irony was only resolved following the death of his brother during combat in Eritrea. No information surrounding the death was ever provided to the family. An additional factor that is unique to Eyob in relation to the other participants is that he was exempt from mandatory national service. However, Eyob's story is of import in that it demonstrates the way in which the policies and violent actions of President Afwerki and the Eritrean government ${ }^{31}$ extend far beyond its confines: a significant degree of Eyob's life has revolved around trying to piece his family back together - indeed, this

\footnotetext{
${ }^{30}$ Khartoum is the capital city of Sudan.

${ }^{31}$ It is worth noting that each of the participants frequently referred to Afwerki and the Eritrean government simply as 'him' and 'them' respectively, with the assumption that I would know who was being alluded to.
} 
endeavour can be seen to constitute Eyob's ultimate concern. In his mind, when facing the monolithic nature of an oppressive and corrupt government, co-opting deceitful tactics such as bribery are the only plausible means to "bring [his family] outside of the bell." Since arriving in New Zealand in 2010 with refugee background status, Eyob has continued to pursue study and work. However, in many ways the struggle has continued; low wages and constraints surrounding language have not permitted him to study law - he now endeavours to study biology - or acquire the funds necessary to liberate family members. However, he is free to return to Ethiopia, where his mother still resides.

Lastly, hailing from the Hidarb tribe, Iaokim was raised in a conservative Muslim family of five brothers - one younger, three older - and a younger sister. In his late 20s at the time of his interview, Iaokim explained his lifelong passion for education and politics; predilections that were abruptly impeded when the Ethiopia-Eritrea war came to transpire in 1998. In Middle School at the time, it wasn't long before he was able to contribute to the nationalist cause by being conscripted to perform national service duties. The fact that he was much younger than 18 - the official age at which one must carry out their national duty under Eritrean policy - was no obstacle. Transported to an isolated location in the eastern region of Eritrea, Iaokim and many others began their training in a military-style camp; the barren environment providing no reprieve from the searing heat. These conditions, combined with a gruelling regiment and merciless trainers that were prone to rule by fear by punishing an entire unit of trainees for the misdeeds of an individual, catalysed a turning point; Iaokim had seen "behind the scenes," and quickly reassessed his nationalistic tendencies. However, the next six months saw sustained conformity in the face of 'professional punishers.' Subsequent events transpired including further military training, an encounter with The Devil, and his eventual escape to Sudan. Once processed in a refugee camp, Iaokim managed to secure work based on his competency in multiple languages; he transitioned from being processed to being a processor. Yet, in spite of this, his UNHCR staff member status raised suspicion among Sudanese authorities which lead to his arrest on suspicion of acting as a spy. Incarcerated alongside, among others, a member of Al Qaeda, Iaokim now found himself in a position where "anything could happen" due to the fact that not one of his co-workers knew of his whereabouts. However, after six weeks of ongoing interrogation, he was released. In due course, Iaokim arrived in New Zealand in 2008. Although he has since been exposed to gang violence and robbery, Iaokim's ultimate concern surrounding the steadfast pursuit of his education whilst harnessing his capacity 
as an "instrument of change" have resulted in his story being given airtime on national television, as well as being voiced during various campaigns surrounding social justice and equality.

When taken together, the unique elements of each of the above narratives reveal common underlying themes. Whereas Chapter 2 identifies these tropes in relation to the formative years of the participants' lives, the following sub-section provides a brief account of the historical and political milieu that preceded Eritrean independence; a period from which the early years of each interlocutor's story emerged.

\section{$\S 3$ Eritrea - a brief history: from antiquity to independence}

Eritrea is situated in the Horn of Africa. A coastal nation, the Red Sea separates Eritrea from Yemen to the east, and its neighbouring nations include Ethiopia, Sudan, and Djibouti (see Figure 1). In terms of human history, archaeologists have discovered evidence of human remains dating from one and a half million years ago in this region, thereby placing ancient Eritrea 'near the dawn of human kind.' Further evidence demonstrates that the breeding of livestock and various agricultural activities took place circa 5000 B.C. Historians have also made connections between the region that Eritrea now occupies with that of Punt, as visited and recorded by Ancient Egyptian traders during the period 2500-2000 B.C. Excavations in and around Asmara - the present-day capital of Eritrea - have uncovered evidence that the period extending from two millennia B.C. through to the first centuries A.D. included the construction of temples, weaponry, tools, and irrigation systems thought to be the products of the Gash Group and, more recently, the Kingdom of D'mt. From the second to the tenth century A.D., the Aksumite Empire (also known as the Kingdom of Aksum) arose as a hub for trade across parts of the present-day regions of Ethiopia, Yemen, Saudi Arabia, and Sudan. However, the dominance of the Aksumite Empire - once considered as having power equal to that of Persia, Rome, and China - began to wane during the seventh century A.D. due to the swift expansion of Islam. Subsequent to the economic isolation catalysed by the rise of the Islamic Caliphate, the Aksumite Empire gave way to the rule of the Medri Bahri kingdom in the tenth century A.D. The following several hundred years saw fighting throughout the region between Medri Bahri, the Abyssinians, and other neighbouring Muslim states. Eventually, toward the beginning of the seventeenth 
century, Medri Bahri was overrun by the Ottomans, and the territory came to be part of the province of Habesh Eyalet. However, it wasn't until Egyptian forces seized control of Habesh Eyalet in 1846 that the province was expanded to include significant portions of the region that is today considered as Eritrea. Egyptian rule was relatively short-lived as the 1888 Mahdist uprising in Sudan founded the conditions for European colonisation starting in the late nineteenth century (United Nations 2015: 20-21; also see Tronvoll and Mekonnen 2014: 3-4).

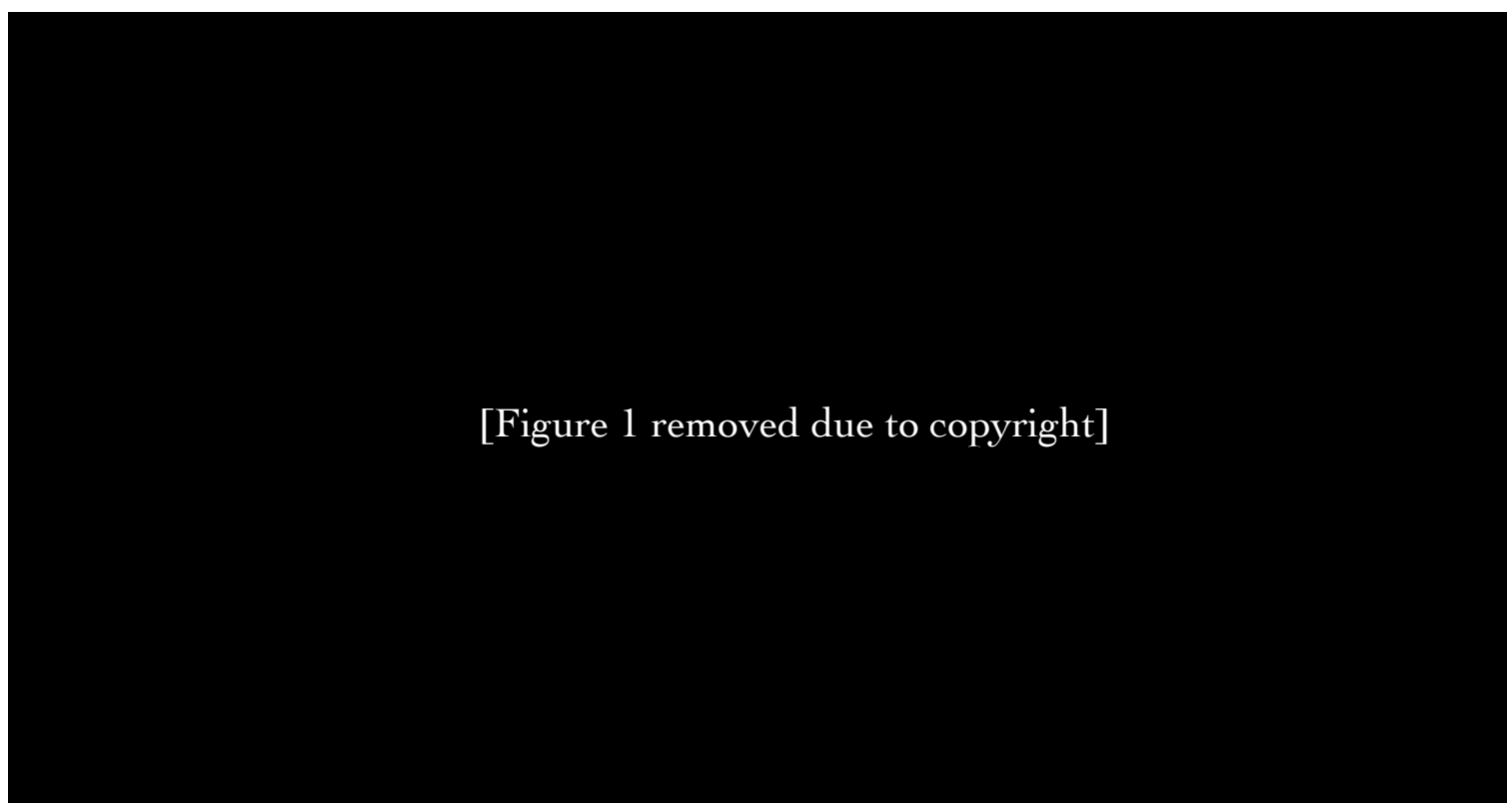

Figure 1: Map of Eritrea

Italian settlement along the coast of Eritrea had begun in 1870. By the mid-1880s Egypt had retreated from the area, and the United Kingdom withdrew its support of Egypt, instead fortifying Italy's colonial efforts in an attempt to counter French expansion in the region. In 1890, the Italian king declared the formation of the colony of Eritrea; the name of which was derived from the Greek name for the Red Sea, Erythreus. The inceptive capital city was Massawa, after which Asmara came to replace it in 1897. This period also saw development projects instilled by the Italian administration begin to materialise: among other things, railways, ports, roads, factories, and administrative centres such as police stations appeared. However, the Italian co-opting of vast areas of agricultural fields in highland areas that crossed Eritrea and Ethiopia ushered in anti- 
colonial revolt. This, in turn, evoked a forceful response from the Italians, who were defeated by Ethiopian troops in the battle of Adwa in 1896. Subsequently, Ethiopia became recognised as an independent state. Significantly, these two elements - the visibility of Italian-sponsored infrastructure and ongoing conflict with Ethiopia - are what many historians consider to be the genesis of a national consciousness in Eritrea. However, the conscription of Eritreans in to the Italian colonial army occurred alongside the development of policies that greatly limited Eritrean access to education, jobs, and social services. Indeed, by 1935 the impacts of Italy's fascist leader Benito Mussolini were visible across the Horn of Africa; at the industrial centre of this empire was Eritrea (United Nations 2015: 21-22; also see Tronvoll and Mekonnen 2014: 4-5, and Redeker Hepner and O'Kane 2009: xviii).

Already it is possible to intuit the complexity tied to Eritrea's history of violence and the role of colonial strategy therein. For Strathern and Stewart, there is a firm relationship between overt, physical violence and more subtle - or, following Bourdieu, ${ }^{32}$ symbolic - forms of violence such as seduction and coercion (2002: 52). Accordingly, "while the colonial power tends to see itself as possessing in advance a mandate to use physical force in pursuit of imperial aims, in practice a whole range of negotiations may be set in hand in order to establish a colonial presence" (Strathern and Stewart 2002: 52). Thus, with regard to the rationale of colonising powers dealing with peoples "outside their immediate territorial control but within their sphere of influence" (Strathern and Stewart 2002: 52), seductive and coercive means may prove to be more effective from a strategic vantage point. Hence, Italy's colonial presence in Eritrea included instances of violent force, as well as Eritrean conscription in the Italian colonial army coinciding with policies that lessened the entitlements afforded to Eritreans in their own country. However, Italy's colonial reign ceased in the early 1940s.

The 1941 battle of Keren saw the Italian regular army and colonial troops triumphed over by British-led forces. Subsequently, Eritrea entered a period of British military administration. As war compensation, the British took measures to disassemble Italianinstilled industries whilst fostering trade unions and political parties and publications, thereby setting the foundations for Eritrean political engagement. The same year, the Mabber Feqri Hager (the Patriotic Society) was formed by a group of Eritreans whose aim it was to overcome Italian rule in Eritrea. However, by 1946, following the victory of

\footnotetext{
${ }^{32}$ See Bourdieu (1977: 191) and Bourdieu and Wacquant (2004: 272-274) for more on symbolic violence.
} 
British forces, the Mabber Feqri Hager had split in to three predominant political parties: the Muslim League, which advocated for Eritrean independence or a UN trusteeship; the Unionist party, led by Tigrinya intellectual, Mr. Tedla Bairu, who called for a union with Ethiopia; and, the pro-independence party known as Eritreans for Eritreans. As these events coincided with the end of World War II, international interests converged on Eritrea, each bidding for different forms of control in moving forward. Whereas the aforementioned political parties attempted to lobby the British - an attempt that the British refused -, the Ethiopian Emperor lobbied the United States in an endeavour to instigate the handover of most of Eritrea to Ethiopia. Additionally, the Soviet Union supported the return of Eritrea to Italian trusteeship, while an independent state was sought by Arab states whose interests revolved around protecting the Muslim population of Eritrea. The inherent complexity of interests finally gave way in 1948 and the issue was turned over to the United Nations. However, even in light of the possible solution to partition Eritrea along religious lines, the United Nations also failed to provide an immediate resolution. Finally, on 2 December 1950, the United Nations General Assembly put forward a resolution that involved an Ethiopian-Eritrean Federation. Under this arrangement, Eritrea would be formally controlled by the Emperor of Ethiopia, Haile Selassie, whilst maintaining its own flag, official languages (Tigrinya and Arabic), judicial structures, and control over domestic affairs. The British were to exit Eritrea by late 1952, and legislative elections formed a National Assembly that accepted the new constitution put forward by the United Nations and ratified by Emperor Haile Selassie (United Nations 2015: 22-23; also see Tronvoll and Mekonnen 2014: 5-6, and Redeker Hepner and O'Kane 2009: xviii-xix).

However, from the outset of the Federation, Emperor Haile Selassie persisted in subverting the self-determination of Eritrea: the Eritrean flag was replaced with the Ethiopia flag; public services and schools were forced to use Amharic language; and Eritrean political movements and newspapers were suppressed. This threat to the autonomy of Eritreans lead to mass demonstrations by students and organised trade unions throughout 1957 and 1958. However, the ineffective impact of these peaceful protests - Ethiopian troops opened fire on, and killed, many protesters - lead to the formation of the Eritrean Liberation Movement (ELM) by Eritreans exiled in Sudan. Nevertheless, the ELM was forced to compete with the Eritrean Liberation Front (ELF) - an organisation formed in 1960 in Cairo - for members. Eventually, in 1962, the covert 
activities of the ELM were discovered by authorities and subsequently shut down (United Nations 2015: 23-24; also see Tronvoll and Mekonnen 2014: 6).

The way in which Italian colonialism and subsequent Western interventionism coalesced to create the space for ongoing inter-ethnic violence between Eritrea and Ethiopia illustrates, firstly, the unpredictable nature of violence, and, secondly, the notion that violence operates on a continuum (see Bourgois 2015: 318, 305). Bourgois writes that "[s]ymbolic violence is rarely omnipotent. It often bifurcates into a political violence of resistance, or, at least, a mimetic outpouring of nationalist or culturalnationalist oppositional mobilisation" (2015: 318). This precept directly links to the trajectory of violence that started with the aforementioned invisible - or symbolic - forms of violence enacted by Emperor Haile Selassie which, in turn, sparked the political resistance mobilised by Eritreans that inevitably lead to the bypervisible physical violence projected by Ethiopian troops in retort to the Eritrean protestors. Thus, the colonial and interventionist elements of Eritrea's history of violence can be seen to have generated the substratum for further violence. Significantly, as Bourgois states, it is the "potential for violence to destroy and brutalise as well as to expose inequalities or contradictorily to obscure true vectors of power [that] can unpredictably change - for better or usually for worse - the courses of local and even global histories" (2015: 318). Indeed, the events that transpired in Eritrea at this point bore the catalyst of three decades of war:

[The] ELM and ELF competed for supporters but none of them managed to recruit Hamid Idris Awate, a former soldier in the Italian colonial army who turned into a guerrilla and community leader. In August 1961, he was forced to find refuge on Mount Abal, between Agordat and Tessenei, to escape imminent arrest by Ethiopian police forces. That is where, on 1 September 1961, he and his companions fired the first shots of what would become the 30-year armed struggle for independence. One year later, on 14 November 1962, Ethiopian troops forced the Eritrean Parliament to dissolve. On that day, Eritrea was officially annexed as Ethiopia's fourteenth province (United Nations 2015: 24)

By 1963, the ELF had sublated members from Hamid Idris Awate's group and other Eritreans that had defected from the Sudan Defence Force (SDF). Hence, the ELF came to be the primary group fighting the struggle for independence. At this point, the ELF was comprised of around 250 fighters and included women. As the ELF started receiving arms and supplies from surrounding nations, the women involved proved to 
be of great strategic importance as they were able to carry out covert tasks and not garner attention from Ethiopian forces. Over the course of the following two years, the ELF grew to a membership of 2,000 combatants, many of whom took part in training overseas. As the organisational foundations of the ELF strengthened and the war spread, Christians from the highlands were recruited, adding to the initial intake of lowland Muslims. With support from the United States and Israel, Ethiopia responded by launching a counter-insurgency offensive that aimed to segregate Muslim and Christian ELF comrades. ${ }^{33}$ This strategy led to events - namely a defected Christian leadership within the ELF, as well as the massacre of both Muslim fighters and Christian farmers - that drove ELF members of both religions to challenge the Front's leadership by forming the Tripartite Unity Forces in September 1968. The actions of the Ethiopian army between 1967 and 1970 compelled many Eritreans to join the ELF. Although there was an initial reluctance surrounding female recruitment, it was at this point that women, students, workers, and peasants came to be seen as integral to the struggle. However, in spite of this revitalised vigour, further internal conflicts eventually lead to the formation of yet another dissident group. This development is of particular import as it signifies the first appearance of Mr. Isaias Afwerki - Eritrea's current president - in a commanding role. By 1971, the perceived lacklustre leadership of the ELF had pushed another dissident group to join forces with the ELF; together they formed the Eritrean Liberation Forces-People's Liberation Forces (ELP-PLF). Yet, in February 1972 further internal conflict transpired and the new leadership of the ELF waged war on the ELP-PLF (United Nations 2015: 24-25; also see Redeker Hepner 2009: 26-43, and Redeker Hepner and O'Kane 2009: xix). By 1973 the ELP-PLF was remodelled in to the Eritrean People's Liberation Forces (EPLF); again - alongside Mr. Romedan Mohamed as secretary - Mr. Isaias Afwerki maintained the role of military commander:

$$
\begin{aligned}
& \text { Both had studied Maoist guerrilla strategy in China in the 1960s. No sooner } \\
& \text { had it been created than the EPLF faced internal dissensions challenging the } \\
& \text { newly elected leadership. Critics were violently suppressed. To avoid a } \\
& \text { possible resurgence, the EPLF set up a new internal security apparatus } \\
& \text { known as Halewa Sewra (lit. the "Shield of the Revolution" in Tigrinya) as } \\
& \text { well as a Central Committee secretly controlled by the Eritrean People's } \\
& \text { Revolutionary Party (EPRP), a clandestine communist movement formed in }
\end{aligned}
$$

\footnotetext{
${ }^{33}$ For discussion surrounding the United States' tendency to create proxy-warrior roles for its allies in order to achieve imperialistic endeavours, see Bourgois (2015).
} 
1971 by ELF-PLF leaders, including Mr. Nur and Mr. Afwerki (United

Nations 2015: 25)

In 1974 the Ethiopian Emperor Haile Selassie was ousted by a military faction, and in spite of ongoing hostilities in northwestern Eritrea a ceasefire was reached between the EPLF and ELF in October of that year (United Nations 2015: 25-26).

Early 1975 saw both the ELF and EPLF initiate attacks on Asmara; an offensive that lead to the liberation of close to 95 per cent of Eritrea. However, ongoing friction between the two Fronts persisted and by 1977 the EPLF had triumphed in its expansionist endeavours and the ELF were subsequently left controlling smaller portions of territory in the highlands and western regions of Eritrea. Throughout this period, recruiting numbers increased and new policies were adopted by the EPLF which meant that males and females in their teens were co-opted and provided with military training. In particular, female recruits proved successful in the ongoing enlisting and organisation of female sympathisers. Significantly, the EPLF underwent further transformations at this time - including the substituting of 'Forces' for 'Front' in the name - and its first congress developed a programme geared toward realising an independent, secular, and egalitarian state that recognised gender equality and implemented land reforms; for the first time in history women were granted land ownership rights. Additionally, polygamy was abolished and student and labour organisations - including the National Union of Eritrean Women (NUEW) - were encouraged to join the struggle. However, in spite of rising membership and support, the EPLF were defeated in December 1977 by Ethiopia's new regime. Following this, the EPLF and ELF reached a unity agreement in 1978, and in a joint attempt to capture the town of Barentu in west Eritrea were again, however, overpowered by the Sovietbacked communist regime of Ethiopia (United Nations 2015: 26; also see Redeker Hepner 2009: 43-58).

As the 1980s encroached, unremitting conflict escalated in a triangular antagonism between Ethiopia, the EPLF, and the ELF - between 30,000 Eritreans and 50,000 Ethiopians are estimated to have perished between 1978 and 1983. Whereas Arab countries supported the ELF, and the EPLF engaged Mao-inspired guerrilla tactics such as 'strategic withdrawal,' both Fronts remained overpowered by the Russian-backed Ethiopian apparatus. This lead to further blame and accusations of conspiracy being levelled between the EPLF and ELF, and another round of clashes erupted between the 
two Forces in August 1980. However, by 1981 the EPLF had managed to stabilise whilst the ELF were ousted to Sudan and subsequently disarmed. Accordingly, and in light of international isolation due to the reluctance of Western allies to support a Mao-inspired liberation movement, the EPLF remained as the sole force fighting on Eritrean territory (United Nations 2015: 27; also see Redeker Hepner 2009: 58-62).

At this stage in Eritrea's history of violence, it is the unremitting or continuous nature of the conflict that can be seen to align with Vigh's (2008) notion of the chronicity of crises. In other words, by the turn of the decade leading in to the 1980s, war had become endemic as opposed to episodic. Recognising this is of significance as it allows us to consider the ways in which conflict and violence can become normalised, and, ultimately, indiscernible from the surrounding social fabric. Thus, from an anthropological perspective, violent crises are seen in the conditions that underpin decisive moments of change, rather than in explosive situations themselves (Vigh 2008: 8-9). ${ }^{34}$ Indeed, the unrelenting violence that had come to constitute Eritrea's social tapestry during the 1970s continued throughout the 1980s and, as we will see, on in to the twenty-first century.

In 1982, violence intensified and 100,000 Ethiopian troops were mobilised in what was dubbed the Red Star Campaign. However, in spite of the Ethiopian offensive involving toxic gas and air power, 33,000 Ethiopian deaths occurred; an intolerably high number when compared to the 2,000 Eritrean casualties that resulted from the Campaign. These events resulted in, on one hand, demoralisation amid the Ethiopian ranks and, on the other, a revitalised confidence within the EPLF. Again, the EPLF defence was successful even in light of the assistance provided to Ethiopia by the Soviet Union. However, by the mid-1980s, food aid from international NGOs and the Eritrean diaspora was not enough to deflect the impacts of famine within the EPLF, and territory was lost. As a period of military stalemate ensued, the EPLF endeavoured to garner more support by loosening its 1977 Marxist programme and moving toward more explicitly democratic aims. This resulted in the induction of former ELF members in to the EPLF (United Nations 2015: 29).

The stalemate was ended in 1988 when the EPLF were victorious in annexing the city of Afabet from Ethiopian control. Although Ethiopian troops engaged a significant

\footnotetext{
${ }^{34}$ Vigh goes on to state that "it should be emphasised that wars do not start with the first shot or end with the last. They may break out and cease at definable points in time, but the underlying factors leading to fighting and warfare are not singular" (2008: 9).
} 
counter-offensive, the outcome was inconclusive and the EPLF continued to gain territory across the majority of the northern and western regions of the country. This trend gained momentum in the final years of the 1980s, and by 1991 the Front had tripled in size. As a result, international interests came to the fore and talks between the EPLF and the US coincided with the Soviet Union withdrawing its military support from Ethiopia. In a strategic move that proved successful, the EPLF continued to weaken the Ethiopian regime by fortifying the efforts of Ethiopian rebel groups such as the Tigray People's Liberation Front (TPLF) and the Oromo Liberation Front (OLF). Further judicious manoeuvres executed by the EPLF saw Ethiopian access to the sea impeded and in mid-1991

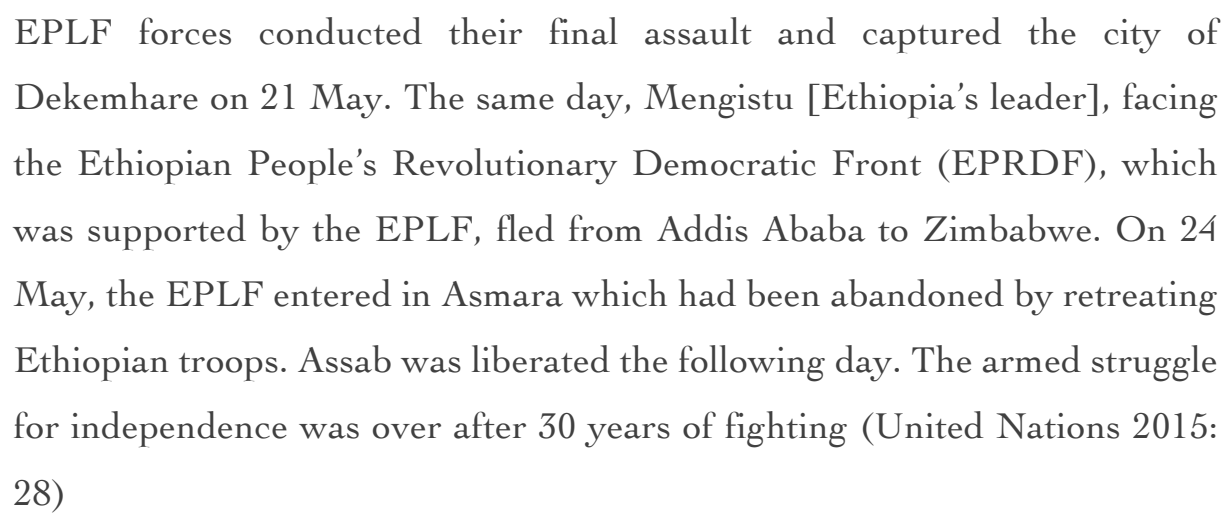

An interval of $\partial e$ facto independence supervened and Isaias Afwerki announced the formation of the Provisional Government of Eritrea (PGE) in June 1991. Following the acceptance by the new TPLF-led Ethiopian government and the United States, the PGE was configured to oversee Eritrean concerns until a self-determination referendum was arranged. Despite prior commitments to gender equality, an all-male Advisory Council constituted by 28 members representing the heads of the EPLF and military was assembled. A number of events transpired between July 1991 and April 1992 - including the Ethiopian government's support for Eritrea's self-determination - that resulted in the creation of a Referendum Commission. One year later, in April 1993, a United Nations-monitored referendum took place that saw 99.8 per cent of 1,102,410 voters advocate for Eritrean independence. Finally, on 24 May 1993, Eritrea realised sovereignty in its new-found status as an independent state (United Nations 2015: 2829; also see Tronvoll and Mekonnen 2014: 6-7, and Redeker Hepner and O'Kane 2009: xix-xxi). 


\section{$\S 4$ Chapter 1 summary}

This chapter has provided, firstly, a contextual overview of each of the participant's narratives, including what can be considered their respective ultimate concerns, and, secondly, an outline of Eritrea's pre-independence political and historical context. The factors that constitute Eritrea's violent history include colonialism, interventionism, and an ongoing chronic state of war. Furthermore, by drawing on the work of Bourgois, Strathern and Stewart, and Vigh, it is has been established that: [1] violence operates on a continuum with invisible, symbolic violence at one end, and hypervisible, physical violence at the other; and [2] where conflictual crises come to be endemic rather than episodic, the violence therein invariably becomes indistinguishable from its surrounding socio-political context. Together, these factors demonstrate the genesis of morphostatic structures of violence in Eritrea.

Chapter 2 continues this contextual trajectory by interweaving the political and historical elements of Eritrea's post-independence period with the formative narratives of each participant. 


\section{CHAPTER 2}

\section{“Take us to the front, mate; give us the gun": formative narratives and post-independence Eritrea}

\section{$\S 1$ Preamble}

This chapter follows on from Chapter 1 in that it proceeds to outline the historical and political context of Eritrea's post-independence period (1993-2015). At the time of independence, this significant juncture in the history of Eritrea stimulated a revitalised sense of optimism and hope among Eritreans. However, within a decade, conflict with Ethiopia had reignited, political crackdown had ensued, and Eritrea had come to be known as a "rogue state ruled by a rigid dictatorship" (Hedru 2003: 435); a conviction that can only be seen to have since spiralled downward, with the leaders of Eritrea more recently being accused of marring "the country's reputation inasmuch as Eritrea today is perceived as a political pariah, a regional spoiler, and an unreliable and irresponsible regime" (Tronvoll and Mekonnen 2014: 8). This chapter also includes an internalist perspective pertaining to this period as the voices of the participants are introduced and the themes across their formative narratives are elaborated on in relation to the various attributes contained within the extreme form of nationalism that prevailed at the time.

\section{$\S 2$ The harbingers of extreme nationalism}

As 24 May approached, the PGE implemented plans to form a government that would assist in the transition to constitutional rule, and, three days before independence, Isaias Afwerki was confirmed as the president of Eritrea by the National Assembly. However, on 20 May, in an effort to rebuild the country's flailing infrastructure, Afwerki issued a statement that revealed plans to keep veterans mobilised for an additional four years. This announcement sparked protests from former EPLF fighters who infiltrated the Asmara airport, thereby hindering independence celebrations. As a gesture of compromise, Afwerki met with protesters at the Asmara Stadium where the dissidents 
curbed their efforts after being promised demobilisation benefits. However, over the course of the next several days, hundreds of protesters were apprehended and incarcerated for a number of years. In retrospect, these actions - in conjunction with discontinuing Eritrea's first $\mathrm{NGO}^{35}$ - constitute the mere beginning of sustained endeavours to oppress the Eritrean people under the guise of extreme patriotism (United Nations 2015: 29).

In the initial stages of building the new state, February 1994 saw the EPLF restructured as a political party and renamed the People's Front for Democracy and Justice (PFDJ). In his inaugural speech to the Organisation of African Unity (OAU) and the United Nations, Afwerki accented elements of the thirty-year armed struggle such as self-reliance which "aimed at guiding the PFDJ and the Government; [...] principles [also] included national unity, participation, self-sacrifice, social justice and [a] strong relationship between the people and the leadership" (United Nations 2015: 30). At this point, where the national consensus developed during the struggle favoured building a state discrete from certain social and cultural affiliations, the possibility of a multi-party system was dismissed by congress on the basis that it would aid the formation of sectarian organisations. In 1994, a commission was established in order to draft a national constitution. Over the course of the next two years, an inclusive consultative process took place where commissioners met with local Eritrean communities and the diaspora to confer over the principles of the planned constitution. Foreign representatives were invited to exchange views on the proposed constitution in January 1995; a conference that, again, excluded exiled Eritrean political organisations. However, nine months prior, in March 1994, registration for the national service had commenced following the PGE's sanctioning of a Proclamation in November 1991:

\footnotetext{
The Proclamation required all Eritrean citizens aged between 18 and 40 years to undertake [an] 18-month national service, comprising six months of military training and 12 months of duties in the army or the military reserves. The official goals of the national service were to constitute a reserve force able to defend the country, forge a sense of national unity and rebuild the country. It also intended to put men and women in a position of equality for 18 months, just as they were during the liberation struggle. At first the
}

\footnotetext{
${ }^{35}$ The Regional Centre for Human Rights and Development (RCHRD) had been formed in 1992 and was, among other things, instrumental in monitoring the April 1993 referendum (United Nations 2015: 29)
} 
Proclamation was met with some resistance but, by August 1994 the registration process, promoted by a media campaign highlighting the values of sacrifice, led to the enrolment of 200,000 recruits (United Nations 2015: 30, emphasis added)

The initial group - comprised of 10,000 people - were sent to a camp in Sawa to receive military training (United Nations 2015: 30, also see Hedru 2003: 435-439).

\section{$\S 3$ Childhood, rumour, and self-sacrifice}

By the mid-1990s, each of the participants had been born and, with the exception of Eyob who was situated in Ethiopia, were growing up in Eritrea. In spite of the often subtle actions of the Afwerki administration that, in retrospect, lead to more blatant forms of political crackdown and militarisation, Haile recalled an altogether "normal" and optimistic childhood:

[...] I grew up in Eritrea, um, near the capital is called Keren which is probably the second largest city. Ah, yeah, I spent my... whole childhood over there... and... it seems a normal childhood probably; not a lot of opportunities and adventurous lifestyle, but... we seemed to... have enjoyed pretty much everything that we had $[\ldots]$ and we always try to make the most of it, um \{lightly claps hands\}, when you don't have everything [...]. So, whenever you get the opportunity, you just- you live [...] and make the most of it. And, yeah, a normal, ordinary childhood been, yeah, been living there $[\ldots]$

As Iaokim explained, the seven years of independence that preceded the EthiopiaEritrea war was a time where "people enjoyed peace" and a socially diverse environment:

$[\ldots]$ yeah... so the way I- I- I brought up or... that- that- in my area there were like Christians, Muslims... there is such a- that diversity and... from, uh, different religions, different tribes. In one, like, street - in one block - you find, like, maybe people from eight, nine tribes and also from different religions

Similarly, when asked about the place of religion in his life, Isaac reflected parallel sentiments during childhood: 
In Eritrea is- religion is Muslim, is and, ah, Christian is the same... religionthey no have religion... ah \{questioningly\} fighting over [...]. They are peaceful with each other. Yeah, because I am Muslim- part of Muslim, yeah. Everyone respect each other, we- we been friends- Christian friends, ah, a lot of Christian friends

However, as the interlocutor's stories unfolded, certain elements began to appear that tie in to the larger political context of the time concerning nationalism, ignorance, and indoctrination. In terms of the educational system, Haile noted that it was "very bard to... kind of say whether it was good or bad." He elaborated by outlining an example from the curriculum on 'Eritrean History': in retrospect, what became clear is that the 'history' being projected over Junior School students at the time was a very partial version of Eritrea's struggles that sought to instil the PFDJ's aforementioned values of national unity, self-sacrifice, and participation. Because of the struggle and sordid history with Ethiopia, rumours that evoked stereotypes pertaining to the motivations and nature of the Ethiopian people prevailed among the informants, their friends, and, ultimately, throughout wider society. After explaining that the educational system worked to include people from "extremely rural areas" who had never encountered systematic education before - and could therefore be considered as tabula rasa -, Haile expanded on the way in which negative rumours concerning the Ethiopian people provoked an unflinching willingness to engage in violence and killing in the name of Eritrean nationalism:

JC $[\ldots]$ So $[\ldots]$, at that point you were ready $[\ldots]$ to fight for your country? HAILE Yeah, 'cos wha- what else are you gonna do when somebody tells you "Oh, [Ethiopians] are coming to invade you?" [...] Ah, for me, it's the same, like, oh they are coming to... take my sisters, to kill my brothers, and torture my parents... 'cos that's the only thing you would- you would think of $[\ldots]$. And they never picture the Ethiopians as... as a good neighbours. Since the independence - or even way before that $-[\ldots]$ they are extremely hard to... to see them as a good neighbours [...]; all you- you hear- you read about them is, yeah, the negative thoughts, so- [...]. Yeah, it's- just, like, once you knew them and you don't need to hear anything about them anymore $[\ldots]$

JC And so $[\ldots]$ was that sense of wanting to fight for your country shared by your friends and siblings at the time? 
HAILE Yeab [...]. It's ah- it was a very... hot topic [...]. It's not even about joining and defending the country; it was about going and killing Ethiopians who are trying to invade the country

Haile's words begin to reveal the way in which rumour, gossip, and imagination can amalgamate as a social force, and it is worth noting how these elements are often appropriated in the political sphere. As Strathern and Stewart assert, because rumour and gossip are essentially "acts of the interpretive imagination" (2006: 4) any 'factual' basis upon which these interpretations are founded can be taken as contestable. Thus, rumour and gossip become "prime political instruments and can be used either to support or to oppose authority in the context of discussions about violence and terror" (2006: 45). In Haile's case, rumours set-out by the PFDJ pertaining to the ostensibly depraved nature of the Ethiopian people resulted in a degree of support verging on martyrdom for Eritrean governmental authority. By envisaging acts of murder and torture against his own family, as perpetrated by the Ethiopian 'Other,' Haile's own willingness to enact violent retaliation was both catalysed and legitimised. ${ }^{36}$

Along similar lines, Iaokim spoke of the way in which notions of heroism, ancestry, and nationalism were portrayed throughout the media, schooling, and, essentially, every aspect of life, resulting in an unquestioned enthusiasm for participating in national service duties:

IAOKIM $[\ldots]$ at the beginning we all accepted the national service as- as everyone want to do it; everyone want to contribute, because you hear in the media $[\sim]$, this heroism during the guerrilla war against the enemy to celebrate our- they always talk about the- the history of our ancestors and about what those people who are fighting [...], and you just want to $\partial o$ something for your country [...]. All they talk about is nationalism 24-7 [...]. So they don't talk about... like, education, they don't talk about... good stuff. All the nationalism $[\ldots]$, they just fill you up with that. So...

\footnotetext{
${ }^{36}$ There are many comparisons to be made here, but the extent to which rumour manages to trump 'facts' when political purchase is at stake is perhaps best illustrated by the 'weapons of mass destruction' case that unfolded in 2003. Whereas both the British and US governments accused Saddam Hussein of harbouring weapons capable of 'mass destruction,' nothing of the sort was ever uncovered. Yet, when combined with unverified media reporting and the emotive nature of potential violence, the case for massive military action was mobilised (Strathern and Stewart 2006: 14-15). In both the Eritrean and 'weapons of mass destruction' cases it is possible to see how "imagination transcends reality and its rational articulation; but in doing so it can bring further realities into being" (Strathern and Stewart 2006: 15).
} 
JC $[\ldots]$ Was nationalism $[\ldots]$ instilled on you through schooling as well, or just media?

IAOKIM Um... oh yeah, schooling, everything. There was ah- we had this subject called 'Civic Education' [...]; so they just teach you, like, “The country is this, the country is that, the country, we have... you have to do this for your country, you have to do this for your government" [...] - that's all they teach you about. And the- the- the young, you know, like, you get filled with that and uh... and so... everyone was influenced by this and we all want to do the... the national service. And, ah, you just couldn't wait [...]. I can tell you, like, when the war broke out I remember the High School students were demonstrating "Who wants to go?!"; like, "Take us to the front, mate; give us the gun"

Significantly, the central current that prompts the move from being imbibed with tales of valour and ancestral prestige to an eagerness to serve ones country via militaristic means is the idea of self-sacrifice; a concept that was identified earlier as an explicit tenet of the PFDJ's leadership principles. When examining the phenomenon of self-sacrifice in the context of war and terrorism, scholars have revealed the way in which "a national imaginary founded on the notion of an 'intrepid warrior' who is thought not to be afraid of death" (Strathern and Stewart 2006: 25) tends to underpin other historically- and culturally- specific factors such as benefits surrounding familial status, the honour of martyrdom, and assurances of rewards in the afterlife (Strathern and Stewart 2006: 25; also see Taussig 1992: 53-54). Furthermore, by uncovering the essence of self-sacrifice in this context, it is possible to draw comparisons relative to the way in which nationalistic and cosmological convictions - both considered as cultural imaginaries are vulnerable to being sequestered by state authority in a bid to produce fear and trepidation among their enemies. Thus, with regard to Iaokim's early experiences, it is possible to see the way in which the Eritrean authorities were "deeply involved in both creating and feeding off such an imaginary" (Strathern and Stewart 2006: 24). ${ }^{37}$

\footnotetext{
${ }^{37}$ More specifically, further insight is provided when pinpointing the sacrificial parallels between suicide bombers and those who are compelled to defend their country against its rivals, even if it is at the risk of one's own life; both can be considered as agents of the production of fear, and both embody a degree of self-sacrifice and destructiveness toward others. However, whereas the suicide bomber comes to personify the body-as-weapon in an all-consuming way, a division remains between the symbolic and embodied elements that unify a fighter with his or her weapon. Hence, a soldier is generally trained to sacrifice oneself on the premise that it is done so in the interests of the 'greater good,' as opposed to, for example, rewards in the afterlife (Strathern and Stewart 2006: 25).
} 
These proselytising tactics continued to be fortified by the Eritrean state in the years leading up to the millennium.

\section{$\S 4$ Militarism, repression, and the denial of democracy}

Later in 1994, opposing voices were further subdued at the hands of the Eritrean government: the arrest and revocation of citizenship of Jehovah Witnesses took place due to their refusal to perform military service and vote in the 1993 referendum, and disabled veterans of the armed struggle were imprisoned or killed following a public demonstration in Asmara that sought to highlight their undesirable living conditions. July 1994 - the time of the veterans protest - marked the last instance of public dissent until the early years of the twenty-first century. By late 1995, policy surrounding national service requirements had been amended: citizens between 40 and 50 years of age were now obliged to perform national service, and those endeavouring to leave the country without completing national service could only do so subsequent to posting a bond. Furthermore, national service became a requirement for those in the diaspora seeking passport renewals. Additional restrictions befell local religious institutions in that they were excluded from politics and denied the freedom to advocate on social justice issues and provide social services. The government also ceased the assets of various NGOs, and, subsequent to a ruling by the Chair of the Eritrean Relief and Refugee Commission (ERRC), many left the country due to constraints placed on their possible activities. Eritrea's judicial system also became a mechanism for exercising social control when a Special Court - comprised of senior military officers designated by Afwerki - was formed in 1996. However, "[l]acking independence from the Executive, trained personnel and guarantees of fair trial, [the Special Court] quickly became a means for the suppression of dissent and critics" (United Nations 2015: 31). The final draft of the aforementioned constitution was submitted in July 1996. The new constitution outlined the foundations for the creation of a secular state underpinned by ideals of social justice, democracy, equality between genders as well as religious and ethnic groups, and human rights. However, Afwerki refused to implement the constitution until national elections had taken place. As history demonstrates, the scheduled national elections are yet to materialise; instead, in 1998, a further two years 
of war was ignited due to border disputes between Eritrea and Ethiopia (United Nations 2015: 31-32; also see Hedru 2003: 436-437, and Redeker Hepner 2009: 123-124).

\section{$\S 5$ National service: moral obligation or fallacious coercion?}

Since an early age, Tesfalem "dreamed of becoming not a soldier [but, instead,] just to be $[\ldots]$ a teacher." However, in light of the nationalistic milieu within which his early life unfolded, he accepted the fact that national service was part of his duty as an Eritrean citizen:

[...] I felt obliged [to complete national service]- the reason because, um... as long as I'm Eritrean citizen, I have, ah, a moral and a national obligation to do that $[\ldots]$. I was happy at that time [to complete national service] [...], because it's a very strong nationalism $[\ldots]$; we had a lot of emphasis [from the government] to serve [the] country

However, as Tesfalem continued, it became clear that the way in which national service was portrayed by the Eritrean state to its people, indeed, at best, lacked clarity; and it was this thread of deception that gave rise to a willingness among Eritrean citizens to engage in their national duty: "[...] everyone was happy to go to the national service, [but] I can't say at that time I knew and I had knowledge [...] what was national service." Tesfalem elaborated on the disconnect between what he had anticipated in relation to completing his moral duty and what, in reality, national service entailed:

[National service], really it was very tough $[\ldots]$ because, ah [...], I didn't expect, you know $[\ldots]$ - my expectation was to go and $[\ldots]-$ not to train military - but to $[\ldots]$ help $[\ldots]$ people $[\ldots]$; that was my expectation. But, what I found there is really- it is very tough military training

Following this, it is possible to see how the coercive powers (see Warren 2002: 383) of the Eritrean state were evident in Tesfalem's formative experiences: Tesfalem's willingness to fulfil his moral obligation was shown to be premised on a false expectation surrounding what such a duty would actually entail. In other words, there was a disjunct between what he perceived to be true and the reality of what national service necessitated at the point that it became his lived actuality. Furthermore, this disjunct can be seen to have been actively cultivated by the state via mechanisms that feed off of the 
benevolent attributes of those citizens not unlike Tesfalem. Additionally, underlying this deceptive ethos is an active upholding of the 'epistemic fallacy.' Fundamentally, the 'epistemic fallacy' entails the collapse of ontology into epistemology "such that what is, becomes synonymous with knowledge claims about it" (Archer 2000: 30). However, from a sociological vantage point, Archer writes that the “'epistemic fallacy' is the substitution of how matters are taken to be for how they in fact are, even if we cannot or do not know the latter" (2007: 16n.21). ${ }^{38}$ Hence, with regard to the coercive powers of the Eritrean state in relation to Tesfalem's formative false beliefs surrounding national service as a moral obligation - as opposed to the militaristic reality therein - it can be seen that the Afwerki administration was actively instilling fallacious convictions among its citizens in order to strengthen its own nationalist and militaristic objectives. Tesfalem reiterated the degree of cognitive dissonance that occurred as he entered national service:

\section{[...] [National service was] quite opposite from what I expected because my expectation was $[\ldots]$, you know, very shallow; I didn't expect it deeply [...], but [what] I found was really hard [...]. What I was expected was really different from the reality $[\ldots]$ because $[\ldots]$ I didn't have any idea about the [...] military training}

Meanwhile, various events transpired that lead to full-scale war between Eritrea and Ethiopia in 1998.

\section{$\S 6$ The Ethiopia-Eritrea border war, 1998-2000}

The war with Ethiopia followed previous border altercations with Yemen concerning fishing rights in the Red Sea, and the sovereignty of the Hanish Islands. ${ }^{39}$ The border between Eritrea and Ethiopia spans approximately 1,000 kilometres; the rule of which, since Eritrean independence, was never officially specified. Hence, occasional clashes had transpired. However, an incident at Badme - an area that had been under EPLF control since 1977 - saw Ethiopian troops shoot and kill Eritrean soldiers. This event, in turn, sparked a forceful military response from Eritrea and is often considered as the fracas which escalated in to the Ethiopia-Eritrea war of 1998-2000. Fuelled by deep-

\footnotetext{
${ }^{38}$ For more on the 'epistemic fallacy' see Collier (1994: 76-85).

${ }^{39}$ Also situated in the Red Sea, the Hanish Islands are equidistant between coasts of the two countries (United Nations 2015: 32).
} 
rooted political differences and competition tied to economic markets and influence in the district, the war unfolded in three phases. Initially, Eritrean soldiers managed to cease control of the majority of the territory that was under disputation. In spite of efforts by Rwandan and American mediators to implement a proposal that would have seen Eritrean forces retract - a proposal that Eritrea rejected -, the second phase saw Eritrea secure Badme and other disputed territories by the end of February 1999. Eritrea's advantageous position prompted the acceptance of an OAU Peace Framework motion; the same scheme was, however, refused by Ethiopia. By May 2000, the third phase of the war saw ongoing Ethiopian attacks on three fronts; one of which resulted in territory close to Assab being annexed from Eritrean control (United Nations 2015: 32-33, also see Redeker Hepner 2009: 187-191). Eventually, after two years of fighting, a peace agreement was reached in December 2000, in Algiers:

The Algiers Peace Agreement established a 25-kilometre-wide Temporary Security Zone (TSZ) on the Eritrean side of the disputed border, to be monitored by the United Nations Mission in Ethiopia and Eritrea (UNMEE), which was created by the United Nations Security Council in July 2000. The Algiers Agreement provided for the creation of a joint EritreaEthiopia Boundary Commission (EEBC) under the auspices of the Permanent Court of Arbitration, with a view to issuing a definitive ruling on the demarcation of the border between the two countries (United Nations 2015: 33)

However, the Algiers Peace Agreement came too late as far as Eyob's experiences disclose.

\section{$\S 7$ Disappearance}

Born in Ethiopia, it became clear that the outset of the Ethiopian-Eritrean war aligned with Eyob's first memories. Perhaps due to his age at the time, little was said about the period leading up to the incidents that would undeniably shape the course of his ongoing struggles and ambitions:

EYOB [...] I born in Ethiopia and I grow up in Ethiopia... yeah, and, I never been to Eritrea but I am half-half; my dad is from Eritrea and my mum is from Ethiopia [...]. Because my dad had been in Ethiopia maybe, like, almost 
the rest of his life but he got his citizen because his dad and his mum was from Eritrea $[\ldots]$. He have background so... when they start the conflict or the war - I can't exactly remember, I was sort of bit young that time $[\ldots]$ - they send my dad from Ethiopia to Eritrea [...]. It was people like sending- if you are Eritrean, they will tell you off to your country [...]. So they separate us from family [...]. At that time it was very hard for us to survive because we were depending on our dad; he was a farmer [...], he got like ani- I mean animals here $[\ldots .$.$] . I can't remember when they took him. But, they came at$ night-time; they say - mum told me - and they tell them "Can we speak to you?" and then \{clicks fingers\} just night-time [...]. We don't know where he goes [...]. After a while we knew, like, they send him to Eritrea 'cos he was Eritrean [...]. But he had been working for Ethiopia government for... 'bout 40 years or 50 years his life [...] and then they didn't appreciate this JC [...] when you say 'they' came and got him at night, who is 'they'?

EYOB Ah, the Ethiopian government [...]. So many people have been separated- so- which means I haven't seen my dad... since that time

As Eyob went on to proclaim, with the forced repatriation of his father came unconscionable struggles in daily life including the interim discontinuation of his education:

JC So you did your schooling in Ethiopia?

EYOB Yes, I did [years] 1 to 10 because- which is almost High School- [...] JC $[\ldots]$ what was that like?

EYOB Like I say, since my dad left, life changed, everything became so hard. We used to live in a small city based on farm land [...]. The Ethiopian- sincewhen they send my dad, they took my brother to the army as well, which is very complicated- which is heartless government. They send my dad Eritrea- be's supposed to be look after us; me, my mum, and my sister - three of us left in the house [...]. Because no one look after the animals, and the farmers we so \{clicks fingers\}- we lost everything; we became like- life became so hard. We moved to big city $[\ldots]$; we call it Shire $[\ldots]$. Yeah, it's quite far from the capital, but still we couldn't manage the farmers because needed someone - maybe a man - especially African farm is physical job, so- the animals, like, start dying 'cos no one look after [...]. I couldn't manage it so, we became so, so poor; life became so hard. So, I stopped one year of school [...] ' $\cos I$ have to do something like at least to feed either myself- 
JC How old were you?

EYOB Um, maybe about 7 [...]. Yeah, not younger than that. But I couldn't

do much- but we got, like, cigarettes to sell on the street

Already it is possible to see how the border conflict produced severe impacts for this farming family; themes such as disappearance, separation, uncertainty and not-knowing, and political and military force are revealed in the formative years of Eyob's life - tropes that illustrate the way in which extreme nationalism can breach the physical boundaries of a nation, unleashing flow-on effects that constrain the lives of citizens at all strata of a society caught in conflict. Although the uncertainty surrounding the disappearance of Eyob's father was somewhat relieved when it was revealed that he had been exiled to Eritrea at the mandate of the Ethiopian government on the basis of his ethnic heritage, for Eyob the impacts have not wavered. Thus, disappearance can be considered as a particularly sinister form of repression (Sluka 2000: 4). The formidable nature of this draconian tactic is compounded when state accountability for such actions is rendered obsolete: disappearances are "cases where individuals are seized by military, paramilitary, or police agents of the state $[\text { or their proxies }]^{40}[\ldots]$, always without legal process, and without acknowledgement and admitted responsibility of the state" (Herman 1982, quoted in Sluka 2000: 4). ${ }^{41}$ Eyob's father remains confined within the borders of Eritrea to this day.

Furthermore, although the Algiers Peace Agreement was implemented in 2000, the two-year border conflict galvanised broader political consequences throughout Eritrea in the first decade of the new millennium.

\section{§ 8 Enduring suppression and 'no war, no peace'}

In the aftermath of between 70,000 and 100,000 deaths, criticisms were projected at both the Ethiopian and Eritrean administrations, and a fallout within the top ranks of the PFDJ prompted members to draft a letter addressed to Afwerki calling for greater transparency and freedom of expression. Initially sketched as a private correspondence with Afwerki, the document was leaked to the media and - due to the location at which

\footnotetext{
${ }^{40}$ It was unclear as to the precise 'apparatus' of the state that descended on Eyob's family and annexed his father.

${ }^{41}$ For a thorough exposition on the phenomenon of disappearance, see Sluka (2000: 4-6).
} 
it was drafted - became known as the "Berlin Manifesto." However, subsequent to Afwerki's refusal to approve draft guidelines that were formulated in the interests of political parties that were scheduled to participate during the intended December 2001 national elections, further leaks were presented to the media. Those responsible for the leaks were removed from their positions in the PFDJ. By May 2001, a group of 15 dignitaries of the PFD - known as the G-15 - published an open letter to its members arguing that Eritrea was in a state of crisis, that governmental mistakes had been disguised, and any denunciation aimed at the president had been actively suppressed. The letter went on to advocate for, among other things, the protection of human rights, democratic dialogue, and a greater degree of rule by the constitution of law on Afwerki's part. Several months later, further objections were put forward surrounding Afwerki's management of power, and a call for the dissolution of judicial practices deemed to be illegal and unconstitutional were cast. Such unconstitutional practices included the imposition of a compulsory summer work programme for which students were inadequately paid; an incident from which illegal judicial practices stemmed when protesters and university students were called to Asmara Stadium under the guise of a meeting only to be rounded up by the army and taken to military camps, intimidated over the course of several months, and, in a handful of cases, killed. Additionally, in an endeavour to scrutinise factional crimes of sub-nationalism and defeatism, Afwerki mobilised a security committee that arrested and imprisoned journalists linked to the eight privately-owned newspapers that were operating in Eritrea at the time. Further enforced disappearances took place, including the infamous ' $G-15$ ' case which saw eleven members of the G-15 detained without formal charges; their whereabouts remain unknown to this day. In many cases, any form of dissent was met with accusations of betrayal (United Nations 2015: 33-34; also see Redeker Hepner 2009: 194-198). Subsequently, the above suppressive mechanisms became legitimised in the eyes of Afwerki and his immediate circle of sympathisers:

In February 2002, during a speech to the National Assembly, President Afwerki accused the reformists of "committing treason by abandoning the very values and principles the Eritrean people fought for." The Assembly - now purged and under his control - officially approved the arrests and the closing of newspapers it accused of being "foreign-funded" and "engaged in defamation and rumour-mongering." The Assembly also adopted a law on elections, which confirmed the ban on political parties other than the PFDJ. 
At the end of February 2002, President Afwerki appointed a five-person commission to organise the long-awaited national elections - but to this day elections have not taken place (United Nations 2015: 35)

In the midst of ongoing political clampdowns, submissions made to the EritreaEthiopia Boundary Commission (EEBC) by both Ethiopia and Eritrea pertaining to the ownership of territory that had been at the centre of the border conflict of 1998-2000 were reviewed; the end result was, among other things, the awarding of Badme - the region at the hub of the conflict's inception - to Eritrea. Whereas Ethiopia rejected this decision, Eritrea accepted yet refused further negotiations. This deadlock constitutes the 'no war, no peace' status that remains between the two countries. In addition to the sustained suppression of individuals and religious groups on the basis of accusations entailing manipulation by foreign interests, the Eritrean government extended national service indefinitely, terminated demobilisation processes that were part of the Algiers Peace Agreement, and modified the duration of secondary education - the new system requiring students to complete an extra year of schooling at a Sawa military camp involving military training and a final exam (United Nations 2015: 35; also see Redeker Hepner 2009: 24).

Understandably, these factors did not bode well for Isaac and his family. Indeed, the ongoing political crackdown, militaristic school curriculum, and indefinite conscription that ensued in the aftermath of the Ethiopia-Eritrea war had a profound impact on Isaac's family life.

\section{§ 9 A state of emergency and indefinite conscription}

With her elder son consigned to the military, Isaac's mother was resolute in ensuring that Isaac was not bequeathed to suffer the same constraints protruded by the nationalistic militarism of the Eritrean state. Isaac spoke about the brotherly absence that informed his families decision to facilitate his fleeing Eritrea:

[...] My brother is... he's in military force... [...] which is- [...] I don't meet him for long time 'cos- even when I was in Eritrea he was in military force [...]. He didn't return back to us, like, 5 years [...]. Also, my mother was, you know- we think about him, and that's why I left my country because mymy mother, ah, advised me to leave because [she said] "I didn't get my first 
son; still he's- where is he? Where he...? Still I don't know" [...]. Because,

in Eritrea, that's what- this is the $[\ldots]$ basic things they do ${ }^{42}$

As the Afwerki administration prevailed in its increasingly militarised trajectory throughout the years following the Ethiopia-Eritrea war (Tronvoll and Mekonnen 2014: 165) it was not only the ruthlessness contained in the militarised practices themselves - as exhibited in the national service and, more broadly, educational reforms implemented by the state - that compelled Isaac to abscond. Indeed, the motivating factor at play was the indefinite nature of such conscription that spurred Isaac's expatriate quest. As Tronvoll and Mekonnen write, since the outset of the Ethiopia-Eritrea war in 1998, "national service recruits have been kept in the army for an indefinite period, as no demobilisation has taken place" (2014: 112). Significantly, public perception surrounding the Ethiopia-Eritrea war shifted once the conflict had officially ended, including with regard to the ongoing conscription of Eritrean youth. However, in a bid to keep large sections of Eritrean society mobilised, the government - under the guise of a post-war plan to revive the nation - implemented the Warsay-Yikealo Development Campaign (WYDC). ${ }^{43}$ Furthermore, the WYDC was put in to effect by proclamations to Eritrea's constant 'state of emergency,' thereby inciting 'moral panic' (Tronvoll and Mekonnen 2014: 180) among Eritrean citizens:

Over and above the development rhetoric apparent from the official name of the WYDC, the government frequently 'justifie[d]' the implementation of the policy $[\ldots]$ by linking it to a purported state of emergency. For example, in response to the alarming human rights crisis and obstinate refusal to conduct general elections, the Eritrean government repeatedly cite[d] the stalemate with Ethiopia as a 'legitimate' excuse to suspend the protection of fundamental rights and postpone the conduct of general elections indefinitely (Tronvoll and Mekonnen 2014: 173) ${ }^{44}$

Here it is possible to begin to understand the monolithic nature of the repressive actions of the Eritrean state. Hence, the decisions made by Isaac and his family

\footnotetext{
${ }^{42}$ See Taussig (1992: 27, 28, 48-51) for a compelling discussion of the mothers of the disappeared.

43 Tronvoll and Mekonnen write that "the WYDC was a means of extending the national service programme indefinitely. The policy was introduced by the state president and approved by his cabinet in a meeting held on 7-8 May 2002 [...]. It is important to note that the WYDC [...] was not proclaimed by law, thus bringing to light the regime's contempt for a system of governance based on a the rule of law" (2014: 173).

${ }^{44} \mathrm{It}$ is worth noting the link between reliance on the notion of a 'state of emergency' and the chronicity of crises that came to constitute Eritrea's history of violence from the 1970s onward (see Chapter 1, §2).
} 
surrounding his self-imposed exile are also understandable. Although Isaac managed to avoid the clutches of indefinite conscription, his arrival in Yemen entailed further constraints $^{45}$ and the brutality of the Eritrean state are still rampant in the present day.

\section{$\S 10$ The 'North Korea of Africa'}

Since 2002, tensions remain between Ethiopia and Eritrea. Although the two nations are not technically at war, frictions continue to arise with Eritrea allegedly supporting Somalia-based Ethiopian rebel groups and the formation of an anti-Ethiopian government in Somalia by way of supplying weaponry and military guidance to the Islamic Courts Union (ICU). In June 2006, the ICU captured the capital city of Somalia, Mogadishu; actions which provoked the deployment of Ethiopian troops into Somalia. Defeat of the ICU at the hands of Ethiopian forces saw Eritrean support for various other Islamist organisations continue. Conflict has also flared-up across the border between Eritrea and Djibouti due to the latter's support for Somali rebel groups. In June 2008, Eritrea incited international vilification after its forces crossed the border and killed nine Djiboutian soldiers in a successful bid to occupy the area of Ras Doumeira. These incidents - combined with the refusal to grant access to the United Nations in the interests of a fact-finding mission - have seen sanctions and an arms embargo placed on Eritrea. Furthermore, two reports produced in 2011 and 2012 by a United Nations Monitoring Group based in Somalia revealed that Eritrea has been consistent in its support for Ethiopian rebel groups, Islamist organisations in Somalia, as well as other armed insurgent groups such as Al-Shabaab. However, constrained by ongoing sanctions and isolation on the international scene, Eritrea withdrew troops from Djibouti and reoccupied its seat in the African Union after having initially renounced it in protest of the organisation's support for Ethiopia (United Nations 2015: 35-36; also see Tronvoll and Mekonnen 2014: 165-182). Nonetheless, antagonisms between Eritrea and Ethiopia have persisted in recent years.

As it currently stands, Eritrea is one of the largest refugee-producing nations in the world with several hundred thousand people reportedly having fled the country illegally since 2002 due to circumstances that entail indefinite conscription, a faltering economy, and a myriad of human rights abuses. Politically-speaking, Eritrea has remained

\footnotetext{
${ }^{45}$ See Chapter $4, \S 1$.
} 
essentially unchanged in the sense that the Afwerki government has endured in its position of power since independence. In addition to numerous instances of Eritrean citizens fleeing, pilots, members of the Eritrean national football team, and other national representatives have defected whilst abroad eventually seeking asylum in neighbouring countries and parts of Europe. Any opposition groups exist outside the borders of Eritrea and remain divided on issues regarding alliances with Ethiopia, as well as religious, ethnic, and other political disputes. Coupled with high levels of corruption and complicity throughout the ranks of Eritrean officials, these elements have resulted in a scenario constituted by increasing displacement, kidnapping, trafficking, torture, and death (United Nations 2015: 37-41; also see Tronvoll and Mekonnen 2014: 184-194). Estimates hold that
5,000 people leave Eritrea each month, mainly to neighbouring countries. [Additionally, the] trend has been upwards, with a marked spike during the last months of 2014. In October 2014, the registered refugee population was 109,594 in Sudan and 106,859 in Ethiopia. The total Eritrean population of concern to UNHCR in mid-2014 was 357,406 - depending on estimates of the current population, this would constitute between 6 per cent and 10 per cent of the national population (United Nations 2015: 42)

In situating Eritrea's contemporaneous standing in the global context, Tronvoll and Mekonnen have identified a slew of indexes, rankings, and surveys that demonstrate the country's unacceptable conditions: with regard to issues such as human rights and development, hunger, political freedom and civil liberties, freedom of the press and censorship, the statuses of failed states, rule by law, and corruption, Eritrea consistently finds itself at the bottom of such rankings; a pattern that has coalesced in Eritrea being labelled as the 'North Korea of Africa' (2014: 8-10).

\section{$\S 11$ Chapter 2 summary}

This chapter has interweaved externalist and internalist perspectives concerning Eritrea's post-independence era (1993-2015). By doing so, the ways in which the institutional structure of extreme nationalism has appeared historically in both the lives of the participants and, more broadly, throughout Eritrea's post-independence period have been revealed. However, in line with the notion that social structures shape - yet 
do not determine - people's lives, there was a variety of agential responses among the participants.

Firstly, it is possible to see how indoctrination and extreme nationalist ideology became solidified in the lives of Iaokim and Haile: when attributes such as fearlessness are deemed admirable and coupled with the notion of self-sacrifice for the 'greater good,' such warrior-like identities can play in to the cultural imaginary and, under a state authority that upholds enemies, result in a willingness on the part of the individuals to act as agents of the production of fear by way of potential destructiveness toward others. Accordingly, when individuals emerge as fearless in their capacity to produce fear, extreme nationalism is normalised and monolithic forms of state control ensue.

Secondly - and in contrast to the circumstances of Iaokim and Haile - such monolithic and militaristic forms of state control - often constituted by coercive state tactics involving, disappearances, the promotion of fallacious convictions among citizens, and a reliance on notions such as a 'state of emergency' in order to legitimise ongoing conscription - in fact compelled Isaac and Tesfalem to flee Eritrea altogether; albeit if it wasn't until Tesfalem's initial compliance regarding national service was revealed to be based on false expectations instigated by the state. Lastly, the disappearance of Eyob's father at the mandate of what is essentially the proxies of both the Ethiopian and Eritrean governments illustrates the way in which state terror can breach the bounds of a nation and usurp the lives of citizens situated at all strata of society.

Again, due to the fact that, as well will see, each participant found themselves eventually compelled to flee Eritrea at one stage or another, the institutional structure of extreme nationalism - and its myriad violent attributes as outlined in this chapter - can be considered, in Archer's terms (2000), as morphostatic.

Significantly - and with regard to way in which violence is generated and subsequently perpetuated - Strathern and Stewart write:

When we are considering the genesis of extreme violence, it is important to
realise that much of it emerges from the militarisation or paramilitarisation of
youth groups who are specifically trained by their political superiors to kill
others, and who seek group prestige and personal advancement by doing so (2002: 29)

Thus, where Part I has examined the genesis of violence in Eritrea, Part II turns to the way in which violence can be perpetuated by foregrounding the violent structures 
that shaped the lives of the participants in a relational sense, including their interactions with other militarised youth appearing as national service trainers. 


\section{The perpetuation of violence}

Part II proceeds by foregrounding the relational - or interpersonal - factors that structured the lives of the participants as they surfaced from the formative experiences outlined in Chapter 2. Scott describes a relational social structure as fundamentally being "the sum total of all the social relationships of all individuals at a given moment in time," and continues by stating that the "structural form of a social relation lies behind the variations of particular instances.' This persists over time, and it is constantly renewed through the actions of the individual members of [a] society" (Scott 2001: 80). Thus, certain configurations of basic social relations can constitute large-scale social structures such as divisions of labour, classes, and economies. However, Scott also notes that relational structures are comprised of the "minor face-to-face interactions" (2001: 81) upon which larger-scale social structures are founded. ${ }^{46}$ Hence, by examining the 'middle period' of each participant's narrative it is discerned that the larger relational structure underpinning each of their lives at this point is one of routinised fear and terror; following this, it is the various particular interpersonal instances - or minor face-to-face interactions - of this larger-scale relational structure that are foci of Part II. ${ }^{47}$

Drawing on her fieldwork in Guatemala, Linda Green elaborates on what it means to live in a perpetual state of fear in the following way:

\begin{abstract}
Fear destabilises social relations by driving a wedge of distrust between members of families, between neighbours, among friends. Fear divides communities through suspicion and apprehension, not only of strangers, but of each other. Fear thrives on ambiguities. Rumours of death lists and denunciations, gossip, and innuendos create a climate of suspicion. No one can be sure who is who. The spectacle of torture and death, of massacres and
\end{abstract}

\footnotetext{
${ }^{46}$ Additionally, Feldman writes that "[p]olitical agency is not given but achieved on the basis of practices that alter the subject. Political agency is relational - it has no fixed ground - it is the effect of situated practices" (1991: 1).

${ }^{47}$ With regard to the chronological trajectory of the participants' lives, the two chapters that form Part II cover what can be considered the 'middle period' of each narrative; these chapters are delineated in this way simply due to the fact that the time period contained within each is book-ended by the formative years outlined in Part I and the period of resettlement that will be detailed in Part III. Additionally, whereas Chapter 3 includes the 'middle period' of Iaokim's and Tesfalem's narratives, Chapter 4 contains the 'middle period' events of the lives of Isaac, Haile, and Eyob. The space permitted to each narrative in Part II approximately reflects the degree of detail divulged during each respective interview.
} 
disappearances of the recent past [can] become deeply inscribed in individuals and in the collective imagination through a constant sense of threat. [Fear can] become a way of life (1995: 105)

Thus, taken together, Chapters 3 and 4 demonstrate the ways in which - irrespective of whether the participants were interacting with friends, family, trainers, soldiers, colleagues, or traffickers - violence and the ambiguity that it fosters underpinned the interpersonal aspects of their lives in one form or another. However, in line with the notion that contingent violent structures shape - yet do not wholly determine - lives, it is also shown that, firstly, unexpected friendships are possible and can act as spontaneous sources of knowledge, and, secondly, that the participants often had no

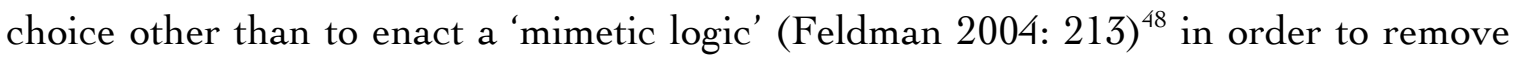
themselves from the undesirable circumstances that they constantly faced. Additionally, the notion that each participant had no choice other than to escape Eritrea if he were to pursue his respective ultimate concern supports the line of reasoning that posits the relational structure of routinised fear evident in each 'middle period' narrative as morphostatic. Inevitably, the implications of this point resulted in the participants eventually taking flight from the Horn of Africa bound for New Zealand - it is at this stage in the narratives that Part II concludes.

\footnotetext{
${ }^{48}$ For the purposes of this thesis, it should be noted that the notion of 'mimetic logic' is being evoked in a somewhat general way simply to indicate the instance where an agent mimics, mirrors, or imitates the violent actions of another individual or state agency. However, on 'mimetic logic,' Baud writes: "This imitation, as mimesis, is an attempt not only to copy the 'outside' of the 'Other,' but is also a means of usurping its power, of appropriating its meaning. [...] Sometimes great stress is laid on actual resemblance, while on other occasions this scarcely matters at all. In any case, there is no direct correlation between the accuracy of an imitation and the power ascribed to it. Rather, what matters is its effectiveness, its magic. This magic can be exploited both by those in power [...], and by those who attempt to oppose them [...]. The result is a complex interaction; imitation leads to exaggeration, repetition, misunderstanding and irony. And if the imitating Other is himself imitated, interpreting the imitation becomes an even more complex task" (1997: 104-105; also see Feldman 2004; and Taussig 1984, 1989, 1992, and 1997).
} 


\section{CHAPTER 3}

\section{'Middle period' narratives I}

\section{$\S 1$ National service, mimetic deception, and a universe of fantasy}

“[...] you hear stories [of] people being kidnapped, people extradited [...]; so, you just don't trust..."- Iaokim

During his formative years, Iaokim's fervour for fighting the nationalist cause against Ethiopia had become entrenched to the point that he held an unhindered anticipation for engaging in national service duties. The foresight provided by the experiences of his older brothers "doing the goo job" - coupled with the indoctrinating effects of the institutional structures identified in Part I - meant that any thoughts concerning the future were non-existent; instead, his ambition was contained in the present, albeit if his motivations were simultaneously underpinned by being, in his words, "part of that [Eritrean] history." However, in retrospect, Iaokim was yet to see "behind the scenes."

At age 17, Iaokim packed his bag and departed for a scheduled six-month training period. Transported to the eastern regions of Eritrea alongside other boys of a similar age - irrespective of their enthusiasm or disdain for national service ${ }^{49}$ - Iaokim's preconceptions were quickly dislodged upon arrival at the training camp: "there was nothing, it was just like a bush." Upon disembarking from the bus, the fresh conscripts were met by soldiers brandishing sticks who yelled at them to "Sit down!" After several days of logistics - the purposes of which were not made clear to the trainees -, military uniforms were distributed. Iaokim described the day-to-day regiment that swiftly disrupted what it meant to secure a place in history:

IAOKIM $[\ldots]$ you wake at 5 o'clock in the morning... and, ah, the first whistle is 5 o'clock in the morning... and then within seconds you have to dress up \{stomps feet\} fast [...]. And, the second one, you get ready in your place [...]. And in the third one, you go to the... where, like, the commander is

${ }^{49}$ Either way the training is compulsory for every citizen after they complete Grade 11 (see Chapter 2, § 8). 
waiting [...]. And then you just like "Yes, sir!" and then you stood there and then after that you go running, shouting and, ah, you get back 8 o'clock... quick breakfast $[\ldots]$. And then they give you, like, um... not proper guns, but... like, the older guns... which are disabled - don't work - for training, and, like, they teach you how to handle it, and all of this in the military training. We were being trained until, like... you start 5[a.m.] and you finish sometimes 10p.m. [...], non-stop [...]. And, after that - 10 o'clock - you go to bed and then you wake up at $5[$ a.m.] - six days; you only have Sunday off JC $[\ldots]$ that could take quite a big physical toll, I imagine?

IAOKIM \{agreeing\} Physical toll, there's no proper food, there is no... ah... it's too hot $[\ldots]$ and you don't have a shelter, it's just like a trees. But, the good thing is, when it's not too hot, then that means at night time you can sleep $[\ldots]$

JC $[\ldots]$ what did you do on the day off?

IAOKIM On the day off you just sleep... and $[\ldots] \ldots$ you also wash $[\ldots]$ your clothes. That's it, that's all you do [...] 'cos there's... there's nowhere to go; there's nothing to do. If you have a book, you read [but] you just finish the books in the $\{$ laughs $\}$ first few days $[\ldots]$ and then... you have nothing to do [...]. Your family doesn't have any access on you; no one can see you when you're in the training - no one [...]. So, there's just you and your trainers... and the trainers are obviously very cruel. You don't have mercy; that's how they've been trained, that's what they have been told: 'Be hard on [the trainees], so they can be a man!' $\Delta$

JC [...] when you went to do your training, were your parents absolutely fine with having no contact with you while you were there?

IAOKIM It's- it's not that they're fine with that, it's just they... it's just the law, it's a rule; $[\ldots]$ everyone accept it $[\ldots]$. No one can do anything about it $[\ldots]$, whether you like it or not. If you open your mouth about this, then you go to jail

The militaristic motive behind the ritualised, initiatory practices that Iaokim was required to undertake can be seen to constitute a two-stage process tied to the preparation of the body for war: control and transformation. In other words, whereas control over the body is necessary "in order to submit the recruit to the authority of the regime," transformation sees the body shaped into "an effective military machine by rendering it fit, ordered and ultimately self-regulating" (Newlands 2013: 35). 
Thus, by the third day of training, Iaokim's mind had already veered toward strategies of escape. Also by this point, Iaokim had found camaraderie in his surrounding cohort, and even with certain trainers - a factor that perhaps demonstrates the dichotomy of dis-/organisation rampant throughout the national service camp: here we have an unrelenting training regime enforced by trainers that facilitate disobedience. ${ }^{50}$ The drive to escape from the camp was compounded when Iaokim encountered a friend from Middle School who was also looking to elude the ongoing forced conformance. Even in the face of consequences that included arrest and incarceration, life as a fugitive, or living among a suspicious community if he were to return to his parent's home, a scheme was devised to evade national service by fleeing to the house of Iaokim's uncle in the port town of Massawa. ${ }^{51}$ However, this plan was foiled when fellow dissenters failed to show at the arranged time and place. Left earmarked as unworthy of parading the regalia of a 'faithful Eritrean' due to his bag being misplaced and, instead, wearing his only shirt - bright orange in colour -, Iaokim waited another three weeks for a uniform to be supplied. With fresh military attire, blending back in to the milieu of recruits required little effort because "after a month, everyone was looking sbit." The remainder of the six-month training period entailed virtually sustained compliance preceded by an initial phase that saw Iaokim and his teenage compadres occasionally stepping out of line; actions for which they were promptly disciplined:

\footnotetext{
We always end up being punished [...]. Like, $[\ldots]$ if [the trainers] wanna punish you, they call you 12 o'clock - midday - when the sun is like... when the temperature is probably $50^{\circ} \mathrm{C}[\ldots]$ and they tell you, like, to... crawl on the ground [...], like, where it's \{anguished tone\} too hot and it just burns you and... and that's our mistake because we used to do stupid things: we hide, sometimes we go for a run [...], sometimes we used- we used to break the laws $[\ldots]$. After that with the time, we just sat obeying the rules $[\ldots]$ and you don't have an option, we only gonna hurt yourself. They can punish you forever: they don't get tired, they don't get sick of that, that's what they do, they are professionals
}

\footnotetext{
${ }^{50}$ Driven by a lack of food and extreme heat - the lure and promise of cold Coca Cola notwithstanding one such excursion involved Iaokim temporarily absconding from the camp to a nearby village under the wing of a particularly "open-minded" trainer. Once there, Iaokim's indulgence got the better of him and heavy consumption of the sugary beverage on an empty stomach resulted in severe abdominal pains and diarrhoea upon his return to the camp; a condition which conjured no empathy from a medical team whose supplies were packed away in a car and ostensibly not readily accessible.

${ }^{51}$ Iaokim's estimate placed Massawa as being a 4-5 hour drive from the camp.
} 
Iaokim's transition from trainee-ship came abruptly. Six months of gruelling routine ended with sudden orders to pack his bag, not move, and await further instruction. Several hours passed before being bundled in to a truck; the fact that he did not know where he was going could not curb his feeling "very happy" upon the prospect of being anything but a national service trainee: "[...] no matter what, the worst thing is to be a trainee, [because] you have no rights." Iaokim elaborated:

[As a trainee in the national service], whatever happens to you, you're not allowed to ask, you are not allowed to say "No." But, if you are in the regular army, you have... somehow, it's better [...]. Like... it's... you're not a trainee anymore. [As a trainee in the national service], you are no one [...]. But, now you are a regular [army member], you're gonna have a gun; proper gun. And, um, somehow you... they still, like, the commanders still look at you down [...], but $[\ldots]$ you are someone

As the vehicle headed for the highlands, Iaokim's flight from the "hell place" that was the national service camp to an army base near the village of his Grandfather signified - retrospectively or otherwise - a transition from being no one to being someone. Further elation gripped the group of travellers when the driver's radio informed them that their release from conscription had roughly coincided with the ceasefire signed in Algiers in December $2000 .{ }^{52}$ Under the orders of a somewhat more relaxed battalion commander nicknamed Quattro, ${ }^{53}$ Iaokim found himself situated on the front line close to the Ethiopian border. Although restrictions on family contact remained firm, Iaokim was permitted to visit his Grandfather and collect packages sent to him by his mother. Eventually, Iaokim and several of his friends were delegated to undergo first-aid training; this was in order to replace the first-aid specialists that had been killed during the Ethiopia-Eritrea war, and the change in duties did not mean that Iaokim was relieved from being armed with a Kalashnikov. Various events transpired during Iaokim's time as a first-aid consultant, and his situation improved considerably when - after serving his time in the regular army ${ }^{54}-$ he was in a position to resume his study. However, after a year of study whilst living with his family, further debilitating circumstances ensued due to the forced labour that students were expected to complete during their summer

\footnotetext{
${ }^{52}$ See Chapter 2 , $§ 5$.

${ }^{53}$ Iaokim explained that the nickname refers to the Italian word for 'four'; he didn't elaborate on how the nickname came to be.

${ }^{54}$ The duration of which was approximately eight weeks.
} 
break. ${ }^{55}$ Following demonstrations which demanded higher pay for students who had no choice but to spend their summer engaged in back-breaking labour, the labour camps, in fact, became a blatant form of punishment:

$[\ldots]$ [the authorities] rounded everyone [up] at the uni $[\ldots]$ and, um, they also, like, they would tell you "If you don't show up, then your university dream is over" $[\ldots]$. They don't tell you it's a concentration camp $[\ldots]$; they tell you it's just, you know, it's a work, it's a part of the work that we [the nation] wanna do. And then, you don't have an option. If you don't go there- and then one day they will come and pick you up. And if you got arrested, then you are gone \{claps hands\} [...]. So you have to \{breathes in deeply\}- you have to go whether you like it or not $[\ldots]$

Often, this choicelessness was implemented under the guise of the students being betrayers of the Eritrean nation:

IAOKIM $[\ldots]$ the soldiers that were guarding us were told that "Don't show [the students] a mercy; they are traitors." So the soldiers were- they were just so hard on us

JC $[\ldots]$ what were you actually doing? Were you not doing army training, but just working?

IAOKIM No, you just work, like, they- you know, they tell you, like, to just to collect the stones in one place, and do, like... [...] all you do is just carry stones the whole day [...]. And that's just to punish you

JC $[\ldots]$ you're not actually building anything in particular?

IAOKIM No... that's to make you suffer

JC [...] so part of the punishment is for you [to realise] that you're doing something that's not really worthwhile anyway?

IAOKIM That's what makes you even more- like, tortures you $\Delta$ It is just endless misery, like, you know \{slaps knee\} [...], we left the national service and [now] this is happening

JC A step backwards?

IAOKIM [...] yeah, actually $3-4$ people had died in this camp, ${ }^{56}$ because... it was so... hard life, it was- you just... you know, you carried stones the

${ }^{55}$ See Chapter 2, $\S 7$.

${ }^{56}$ Again, refer to Chapter 2, $\$ 7$. 
whole day $[\ldots]$. It's too hot, there is no $[\ldots]$ proper food, there is no proper,

ah, health care

Aretxaga writes that the capacity of the state to enact arbitrary arrests - not to mention tortures and assassinations - can be considered as a practice of power "deployed within a universe of fantasy" (2000: 64). In other words, by pitting Iaokim and his fellow students as the traitorous 'Other,' the state legitimised its capacity to 'indulge in the excess of terrifying violence" (Aretxaga 2000: 64).

Iaokim continued by outlining how unreserved conformity and obedience was the only plausible strategy if he were to uphold any chance of re-engaging his educational ambitions at university. To dissent at this point would have likely resulted in imprisonment, disappearance, or exile; fates that those around him indeed suffered. The two-month period over summer was followed by three months of study. However, the fear generated by the prospect of being disappeared resulted in Iaokim making the decision to flee Eritrea. After a month of convincing his family that absconding from Eritrea was the only way to pursue a life unconstrained by perpetual fear, steps were put in motion to cross the border illegally to Sudan. By way of his older brother's teaching connections, a permit that allowed Iaokim to travel to the border town of Teseney - situated 25 kilometres from the Sudanese perimeter - was obtained. Obscured by the veil of a fake identification card - the details of which were thoroughly memorised Iaokim boarded a bus and commenced on the journey that would take him through a series of security checkpoints before reaching Teseney and continuing on to cross the border. Experiencing both nervousness and optimism, the primary objectives he set himself were to remain composed, imperturbable, and fearless in the face of being questioned by authorities. At one check-point, when all occupants of the bus were told to disembark, the bus assistant, in an unwritten act of solidarity - "He look at me and I gave him a sign," stated Iaokim - allowed Iaokim to remain covertly in his seat, thereby avoiding any potential interrogation surrounding his provisional status as a literacy teacher. Arriving in Teseney, Iaokim took heed of the advice conferred upon him by his family; he was to seek out a specific address whereupon his trafficker would provide further instruction:

[I] went in to town and straight away I went to the guy- to the address they gave me $[\ldots]$. I $\{$ hushed tone\} went to that guy and, ah... so, the first advice 
the man gave me was... \{suspicious tone\} "Don't trust anyone here. This town is the worst in terms of everyone is, like... work[s] for the government"

However, in spite of this, Iaokim managed to develop friendships with governmental workers that were also "sick of the life." The upshot of socialising in these circles whilst in Teseney was that it further cloaked Iaokim's expatriate motivations: "No one is going to question you when they see you with these people [...]. These people are police and security; no one is going to question you. So, that really helped me."

Eventually, as the moment of crossing the border drew near, Iaokim's identity was further shrouded as he was instructed to discard the fake identification card that had got him to Teseney. In order to cross the border he would need to adopt the demeanour of someone seen to be residing nomadically at the margin separating the two nations; deceit - that tactic so consistently employed by the Eritrean state - was now being co-opted by Iaokim himself. Covered in dust, crossing the border was somewhat seamless yet happened not before an obligatory exchange of money took place between Iaokim and his traffickers - he proffered the adage: "No money, no you." The accomplishment was crowned with a phone call home to relieve the anguish of his family. From there, Iaokim stayed one night with his smugglers in Shagarab before making his way to the office of the Sudanese National Intelligence and Security Service where he was conferred a permit that allowed him to travel to Al Qadarif. In Al Qadarif, he stayed two nights with distant family members after which he set-out to register at a UNHCR-run refugee camp. Subsequent to an interview which required him to outline his story "from A to $Z$," Iaokim was granted refugee status; a standing that would ostensibly curtail any chance of being deported back to Eritrea at the whim of either the Sudanese or Eritrean governments. However, being under the wing of the UNHCR would not be enough to avoid arrest on suspicion of being a spy.

Iaokim's advanced English language skills gained the attention of UNHCR staff. Before long, he was invited to assist in translation during interviews conducted with new entrants to the camp. The potential to earn money whilst helping fellow émigrés was enough to displace Iaokim's initial plans to meet a friend in Khartoum before pursuing his ultimate goal of education in Europe. Following this, over the course of the next two years Iaokim would move through the ranks from casual to full-time translation work, eventually filling the position of Head Interpreter - life was good, even when some days involved processing more than 200 people. It was at this point, however, that political 
tensions between Eritrea and Sudan began to flare which resulted in Iaokim and his team being treated as increasingly suspicious by Sudanese authorities.

Further political tension was transpiring between Sudan, its neighbouring nations, and the United Nations due to the conflict in Darfur which had given way to accusations of genocide on the part of the Sudanese government. ${ }^{57}$ Indeed, whereas several of Iaokim's work colleagues had been re-positioned elsewhere in order to avoid becoming embroiled in the friction, others - including Iaokim - had been arbitrarily arrested at the refugee camp only to be released after one night due to a lack of evidence pertaining to any untoward activity. Because Iaokim was not permitted the luxury of simply being repositioned in another country away from the hostilities, the only option available that resembled a reprieve from Sudanese security was a two-week break in Khartoum. However, this proved to be damning.

As he sat in a cafe in Khartoum checking his email, Iaokim was interrupted by a member of the Sudanese Intelligence who proceeded to interrogate him as to his name and other details - Iaokim was now directly caught in the indulgent, phantasmic crosshairs of the state. Realising that he was going to be arrested, Iaokim's body "electrified," and his "biggest fear" set in: "Anything could happen to me, man. No one knows where I am." Additional probing took place at one of the city's security branches; the questions revolved around other UNHCR staff members, and, in particular, a female friend of Iaokim's that had recently left for Germany - she had been assisted by the Eritrean Embassy. Later that day, Iaokim was transported to the National Centre where he was placed in a cell overnight. Unable to accept the cup of tea on offer due to his fasting for Ramadan, Iaokim was forced to contemplate the possibility that he would be deported back to Eritrea. The next day he was transferred to the "proper prison," where he was detained alongside, among others, a member of Al Qaeda - the "nicest" of the cellmates -, a former bodyguard accused of treason, and an individual who had been arrested due to criminal activity surrounding the smuggling of antiques. Iaokim's propensity to purchase and avidly read three newspapers per day whilst on the outside proved to be the sole source of news relating to current events for the unlikely roommates. After a week of further questioning and no sign of being released, Iaokim faked an illness in order to be given access to medical treatment - again, co-opting deceptive tactics was his only means for salvation. In doing so, he was able to covertly

${ }^{57}$ Armed conflict in Darfur erupted in 2003 and continues to the present day. See Human Rights Watch (2015). 
use a phone to call a colleague who, in turn, alerted the UNHCR team to the turn of events. However, the under cover call for outside intervention proved to be fruitless and Iaokim would remain imprisoned for six weeks.

Eventually, visits to the prison by various officials resulted in yet another transfer, this time to a police prison where Iaokim remained for a further ten days among other Eritreans whose plight of incarceration stretched back three and a half years. At this point, the UNHCR was doing everything it could to ensure the safety of its employees - many of whom were either European or held citizenship in non-African countries - by insisting that they leave Sudan and return home for the time-being. Of course, this was a non-applicable solution in Iaokim's case; if the UNHCR couldn't organise a suitable place of resettlement outside of Sudan, he would be forced to return to Eritrea and face the harsh penalties that come with being guilty - at least in the eyes of the state - of treason. The only status afforded to Iaokim now was persona non grata.

Efforts were made in vain to formalise a resettlement arrangement, and it would be three months before UNHCR officials returned to Sudan where Iaokim had been provided with temporary accommodation subsequent to being released from jail. In time, however, the opportunity to relocate to New Zealand was advanced by the UNHCR. Interviews and security checks ensued, and it was a further two months before his visa was processed. During the five-month period since his prison release, Iaokim experienced unreserved precariousness due to the volatile political situation. The threat of being deported or disappeared resulted in a high degree of distrust arising between himself and the people around him:

\footnotetext{
You have experience, you hear stories [of] people being kidnapped, people extradited and [...] so you just don't trust... I was- I was optimistic, um, at the one day that I would be leaving Sudan- I would be, ah, leaving this life of fear and life of always uncertainty [...]. But, and then you just don't believe it until the day comes $[\ldots]$ and until you fly
}

Indeed, following a medical check-up - a procedure that indicated Iaokim was one step closer to leaving Sudan for New Zealand - and a departure date being set for May $12{ }^{58}$ disruption in the form of escalating conflict between rebels and the Sudanese government meant that the city was on lock-down and the airport was rendered

\footnotetext{
${ }^{58} 2008$.
} 
inaccessible. ${ }^{59}$ Iaokim and the rest of the group bound for New Zealand remained suspended in a state of disappointment for several days while they awaited news informing them that it was safe to resume their scheduled flight plans; the perpetual standstill was accompanied by the sound of bomb shelling ringing out across the city. When the time came, Iaokim's first experience aboard a plane was underpinned by mixed emotions - sadness surrounding the leaving of friends, optimism about starting life anew, and apprehension tied to what this turning point in an unknown land would actually conjure:

[...] that was sad, leaving all these people behind that- knowing that I wasn't gonna to see them anytime soon. But, then, knowing that my life is [...]- the uncertainty is gonna be over $[\ldots]$ and, ah, the anxiety is gonna be over. And, ah, and then my life is gonna be- it's just a new chapter of my life was opening [...]. And, ah, yeah- even though still, like, [I asked myself] "What's gonna happen if I go and how am I gonna cope?" Ah, you know, "What kind of people are- are they- am I- am I gonna face any- any racism, for example?"

\section{$\S 2$ Dis-/trust, risk, and interrogation}

"I did- you know, because you have to lie, because it is not all lie but, you know, a mixture of lies and truth" - Tesfalem

As the eldest of the interlocutors, Tesfalem's formative period involved a six-month period of national service followed by twelve months of military training and direct involvement in the Ethiopia-Eritrea war of 1998-2000. Although he harboured a strong ambition to teach, any choice in the matter was inevitably removed by the Eritrean system and he was assigned as an elementary school instructor subsequent to his militaristic duties being completed. At this point he was in his early twenties, and, in spite of being able to live with his family whilst working as a teacher, the ongoing threat of war and political oppression resulted in Tesfalem's family deciding that the only way

\footnotetext{
${ }^{59}$ Indeed, on May 10, 2008 "the Darfur rebel group, the Justice and Equality Movement (JEM), launched an armed attack on Omdurman, one of the three towns that form greater Khartoum. This was first time that a rebel group [had] engaged government forces near the capital, marking an escalation in the Darfur conflict, which, [at the time, had] raged for more than five years" (Human Rights Watch 2008).
} 
to transcend the constraints of the Eritrean regime was to flee across the border to Sudan. ${ }^{60}$ Furthermore, he had a sister living in Germany; a factor that fuelled the impulse to set his sights on Europe. Tesfalem knew that by breaching the national divide between Eritrea and Sudan, he was quashing any possibility of return to his country of origin. However, the degree of uncertainty ahead of him would eventually reveal the reach and power of the Eritrean state. Following this, any assumption that his first escape would also be his last was ultimately shown to be unfounded.

By boarding a bus to the border town of Teseney, Tesfalem's covert pilgrimage was initiated. As the residual effects of the Ethiopia-Eritrea war endured - namely: the presence of jihadists, as well as a shoot-to-kill policy which straddled the border regions and was enforced by the Eritrean government -, Tesfalem required the services of smugglers in order to enhance the chances of his escape being successful. Two elements ensured these services were obtained: personal connections via 'The Network' ${ }^{61}$ and money:

TESFALEM $[\ldots]$ the relationship we had was money $[\ldots]$. Because, [smuggling is] a kind of business [...]; those people are experts of taking people in and out [...] from Sudan and Eritrea [...] because they have a good knowledge of that area [...]. I didn't have chance to get [...] to know him [previously] [...], but [I knew him via] someone else [...]. [The smuggler] know me, he trust me, from my $[\ldots]$ old classmate $[\ldots]$. So, [my old classmate was the person who contacted the smuggler]

JC So $[\ldots]$, you trusted [the smuggler]?

TESFALEM Yeah [...]. It is hard to put trust in someone you don't know [...], but I know [the smuggler via my old classmate] [...]; there's a Network $[\ldots]$

For Tesfalem, the violent events he was subjected to throughout national service and the Ethiopia-Eritrea war remained anywhere but in the past; indeed, the betrayal enacted by agencies of the state had understandably resulted in a loss of trust on Tesfalem's part. Hence, placing trust in those that had been commandeered to engineer

\footnotetext{
${ }^{60}$ See Chapter 5 , $§ 3$ for an elaboration on the subjective elements relative to this decision-making process.

${ }^{61}$ Although several of the participants referred explicitly to 'The Network' in relation to their soliciting of trafficker expertise, there was not enough information revealed to discern whether The Network was constituted by a formal-yet-covert system, or, instead, was simply being evoked as a term that entailed 'knowing the right people.'
} 
his escape was not easy. Yet, as Das and Kleinman note, pragmatic concerns - in this case Tesfalem's corporal survival - and "heterogenous relations endure through violence" (2001: 18). In other words, the moment Tesfalem allowed himself to trust his traffickers, was the moment his bid for freedom outstripped his cautious suspicions.

Under the wing of his smuggler, Tesfalem left Teseney - on foot - en route to Kassala, a Sudanese border town. Seven hours later, the purchased trust meant that he arrived "smoothly" at the small border town whereupon his primary objective was to call his sister in Germany. Although Tesfalem's unfamiliarity surrounding local language and cultural customs meant that contacting his sister required some persistence, he eventually spoke with her before making his way to Khartoum after staying one night in Kassala.

Tesfalem spent two years in Khartoum. Unable to work, he relied on monetary support from his family and found himself living with other Eritreans that shared his circumstances of displacement and liminality. Although he was officially granted refugee status, the arrangements specific to his case meant that any chance of pursuing asylum beyond Sudan was not realisable. In due course, the impulse to pursue education provoked plans to follow the route taken by Eritreans before him. However, by this point, Tesfalem's perception had given way to the notion that, in fact, England - as opposed to Germany or Italy - would be the place to fulfil his aspirations. He elaborated on the factors that provided a stimulus for believing that refuge in Europe was attainable:

TESFALEM [...] before us, a lot of young Eritreans, you know, cross the Sahara [...]; they went to Italy, peacefully. So, this was an inspirational experience for us and, you know- $[\ldots]$ we made similar decision to cross JC $[\ldots]$ how did you know about these other people that had already done it?

TESFALEM Well, yes, so telephone- telephone call, because [...] telephone, emails, you know, you can use email every day, and, you know, they can send email - Yahoo Messenger, for example - at that time

Once again, Tesfalem found himself playing in to the "Big Business" - or, in Warren's words, "shadow economy" 62 - that is human trafficking. The phenomena of paying smugglers to provide a means of crossing the Sahara Desert in order to reach Tripoli a port town in the north of Libya - was common enough that Tesfalem and his three

${ }^{62}$ See Conclusion. 
"best of friends" were accompanied by several dozen other optimistic sanctuary-seekers. The profit motifs tied to peddling humans - the voyage cost roughly NZD\$200 per head - meant that the group rode in, atop, and clung to the side of a single Toyota Land Cruiser. The five-day journey was permeated by risk. One on hand, the arid elements meant that any fault in the vehicles mechanics would lead to serious affliction pertaining to the body's natural ability to survive, and, on the other, the presence of Egyptian and Libyan soldiers patrolling the barren region ushered in the threat of the journey coming to an untimely and 'unnatural' cessation. In order to maintain heightened spirits, the crew joked and, from time-to-time, allowed their imaginative faculties to untether by speaking of what life was going to be like in Europe - Tesfalem: "[...] this is my, ah, destiny [...]. If I get out of Africa [...], I will be a different person for tomorrow."

The first port-of-call was Kufra, a small Libyan town. In spite of the "tight control" overlaid on the settlement by Gaddafi's security forces, early comparisons by the trafficked group pitted Libya as a step-up from life in Sudan; the high quality of bread combined with cheap restaurant prices were the deciding factors that tipped the scales in Libya's favour. From Kufra, the group transitioned to Benghazi on their way to Tripoli, the latter serving as both the capital city of Libya and the vantage point from which Tesfalem and his friends would launch their final juncture toward the shores of Europe. Tripoli remained as Tesfalem's temporary home for five months. Again, the acquisition of money was central to his transitory life, and, again, corrupt police and smugglers would be at the receiving end of many transactions - the cost of traversing the Mediterranean Sea superseded that of the Sahara Desert by about NZD\$800. Eventually, the day that Tesfalem had been anticipating arrived. Before dawn, Tesfalem boarded a modified fishing boat alongside 270 other émigrés heralding hopes of washing ashore on the coast of Italy. The favourable weather made for a calm sea, and, although conditions aboard the vessel were "compacted and overcrowded," the mood was sanguine; people even felt compelled to re-enact their favourite movie scenes:

[...] we began our journey and we travelled, you know, a day and [the weather was really] fantastic; it's sunny, you know [...]. [There were] a few people singing. I remember, you know, um, two, um, friends [...] - girlfriend and boyfriend - were together and they [...] stood, you know, [at the] front of the boat and they, like, you know, a Titanic, you know, the film. And, I remember, they were dancing in time \{laughs\} [...]. People was happy $[\ldots]$, 
you know, you see in their face, you know, because they are going [...].

Everything now we left [in] Africa; we are going to different continent

Contingency was added to the duration of the anticipated two-day journey due to the necessary avoidance of naval squadrons patrolling the Maltese coast - Malta proving to be an obstacle in the beeline to Italian shores. However, after a day at sea, the even greater degree of unpredictability latent in the environs meant that the Maltese Navy would quickly be transfigured in the eyes of the smuggled from an inconvenience to a sole means of salvation. As a storm encroached on the path of the watercraft, a sense of worry descended on the passengers. By the time the swell of the sea had risen and whitewash had begun to breach the inner sanctum of the boat, people were incessantly crying "We are going to die!" Tesfalem himself was convinced that he was living out his "last days in this world," and had turned to prayer. In the midst of this, the chaos was compounded by futility and contradiction: orders yelled by the traffickers instructed the trafficked to scoop water from the vessel whilst, in the very next breath, they were being told to maintain the boat's equilibrium by distributing the weight of their bodies evenly across the deck. Added to an absence of lifejackets, the lack of both a functioning GPS system and competency regarding the Italian language meant that a May Day call seeking immediate assistance was also placed in vain; the fact that the ringleaders of an illegal operation resorted to relying on state authority perhaps highlighting the grave nature of the circumstances. Upon the arrival of the Maltese Navy, Tesfalem felt relief. However, stepping aboard the more resilient vessel signified the fact that his attempt at refuge in Europe had failed. Tesfalem explained his arrival in Malta:

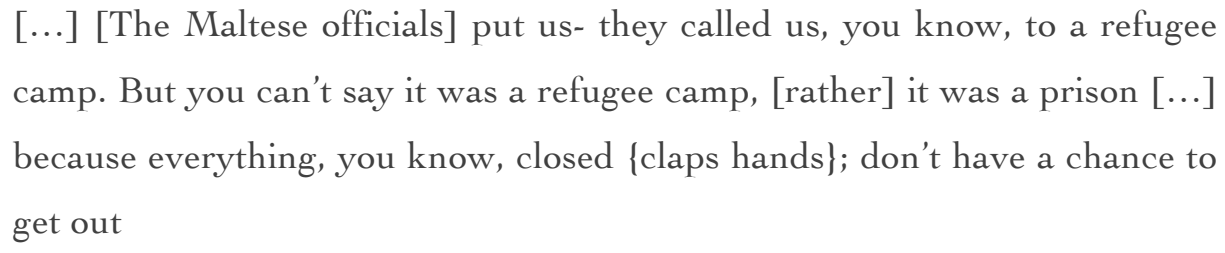

Indeed, the "friendly and human" way in which the Maltese authorities treated Tesfalem and his fellow asylum-seekers was juxtaposed by such management being carried out within the confines of a jail - essentially, the lack of movement meant the violence of enclosure descended on the group; it was hospitality that was inhospitable. At times, this paradox meant that, throughout the two months that Tesfalem was incarcerated, tensions flared between prison guards and the refugees-cum-prisoners. One incident saw the guards' anger come to the fore when Tesfalem and his Eritrean 
cohort started chanting "Italia uno! Malta zero!" in order to express their dissatisfaction with the ill-fated situation. Furthermore, Tesfalem experienced increasingly subtle forms of mistreatment in the jail; he was acutely aware of the negative stereotypes inherently tied to being asked "Do you know how to write your own name?" - in Feldman's terms, authoritative empowerment was being enacted via micropractices containing the subtle logic of the state (2004: 210). Following this, the bureaucratic processes encountered whilst imprisoned meant that completing a form incorrectly could result in the difference between being considered a 'refugee' or an 'illegal immigrant. ${ }^{63}$ In the end, neither term would be applied to Tesfalem: subsequent to talks behind closed doors between the Maltese and Eritrean governments, Tesfalem was ultimately rendered a 'national traitor.' Amidst ongoing speculation and failed protests by the international community, Tesfalem was left with the stark realisation that he would be forced to return to the country that he had absconded from almost three years prior. However, this realisation only came to light on the day that the freshly-dubbed 'traitors' would be forcefully removed from their dwellings and shipped to the nearest airport to await deportation, albeit under the guise of repatriation. ${ }^{64}$ As Tesfalem sat handcuffed between two soldiers, added irony and dismay found its way in to the Eritrea-bound flight - Tesfalem's first experience aboard a plane - as his efforts to overcome the adversity of shoot-to-kill policies, arid desert conditions, and the constant threat of being harmed were unravelled in a space of several hours. Tesfalem:

\section{$[\ldots]$ I felt as if I was dreaming [...]. I didn't believe it was true [...]. I couldn't believe it $[\ldots]$, even it was my first time to go in the plane as well $[\ldots]$, so I didn't feel, you know, this was the reality [...]. But, you know \{laughs\}, this was reality; the reality check was come to you - it was true ${ }^{65}$}

A momentary glimmer of hope accompanied Tesfalem's arrival at the Asmara airport: alongside the several dozen other repatriates, he was instructed to complete forms that required stipulating who is family were, and where he would be residing now that he was back on Eritrean soil. ${ }^{66}$ Tesfalem entertained the possibility that his period of truancy had indeed seen the regime morph from a brutal dictatorship in to a just system

\footnotetext{
${ }^{63}$ For this reason, Tesfalem and his compadres rejected the forms set-out in front of them on more than one occasion.

${ }^{64}$ See Human Rights Watch (2004: 30-31) for more on this particular incident.

${ }^{65}$ Emphasis added.

${ }^{66}$ Retrospectively, Tesfalem described these forms as being not unlike the standard Passenger Arrival Cards that any civilian traveller is required to complete upon reaching an international destination.
} 
with loosened nationalistic tendencies and punitive procedures. However, the submitting of his forms coincided with the inauspicious presence of military buses arriving outside the airport terminal. Within an hour, the group were commanded to board the buses and soon found themselves at another military compound. Tesfalem's two-month residency at the site involved being subjected to "serious interrogations" every fortnight - this was on top of the living conditions being "very bad"; at times, the detainees were forced to share a single loaf of bread per day. The sustained probing was carried out by members of the military whom Tesfalem considered to be "brainwashed," and to refrain from divulging information would be to risk enduring physical beatings - on this point, Elaine Scarry writes that "[a]lthough the information sought in an interrogation is almost never credited with being a just motive for torture, it is repeatedly credited with being the motive for torture" (1985: 28). In spite of this, Tesfalem refused to fully comply and, instead, ran the middle-ground strategy of supplying the inquisitors with half-truths. Thus, in the face of questions concerning how he managed to escape - who financed him? who smuggled him? when did he cross the border? who were his contacts abroad? - Tesfalem was steadfast in his capacity to rely on deceit as a means to avoid further ensnaring himself and others as 'national traitors' in the eyes of the state. Ultimately, however, the tactic would prove to be impotent, and Tesfalem soon found himself further isolated after being transported to the Dahlak Archipelago, a group of islands located in the Red Sea just off the coast from the port city of Massawa.

The desiccated conditions were compounded by the fact that the group of defectors were holed up in a hangar that once belonged to the Soviet Union. For Tesfalem, the intensified heat and lack of water was enough to cause considerable deterioration in physical welfare. Yet, in light of the seemingly un-erasable status of treasonous 'Other' that had been projected over the incarcerated group, exposure to the blistering elements was, in and of itself, not considered by the state as a sufficient measure of repentance. Accordingly, forced labour ensued and the prisoners were made to lift and carry stones from one arbitrary site to another. The unproductive nature of the punishment was not lost on Tesfalem, and he felt that the psychological agony would have been reduced had the task been, at least, geared toward an end-result that benefitted Dahlak's local residents.

The life of toil that constituted Tesfalem's existence at Dahlak prevailed for almost two years. The only reprieve granted to the dissenters during this time hinged on the mood of the soldiers that were in charge on any given day. Indeed, as Tesfalem revealed, 
it was "hard $[\ldots]$ to put all the soldiers in one basket," and there was a vast contrast in the degree of empathy that each of the soldiers exhibited in relation to the forced labourers. On one hand, the individuals in command would ply their lackeys with motivational remarks - even if they ultimately created false hope - such as "Oh, don't worry, be strong," “[...] tomorrow gonna be out of the prison, so don't worry," and "Don't lose your mind." On the other, however, some of the soldiers would respond to workers' requests for provisions by shouting insults - "You traitor!" - at them; in the mind of a "brainwashed" trooper, betrayers of Eritrea were not worthy of water. In addition to the contingent temperaments embodied by those controlling the labour camp, the two-year period that Tesfalem remained at Dahlak was by no means a pre-designated sentence. Occasionally, rumours would swirl among the forced inhabitants of the island surrounding the supposed release of prisoners, but, for Tesfalem, hope was maintained though prayer, and a degree of solace was found in the knowledge and skills he learnt from fellow inmates:

[...] even people gain a positive things from the prison: um, you get to know a lot of different people with knowledge [...]. I can say, because there- there are a lot of people who have knowledge of, um, for example, you know, the carpentry, you know, this woodworkers [...], um, metalworkers, and musicians $[\ldots]$. So, they begun to teach $u s$, you know [...]; that is the- another, you know, way of my own experience $[\ldots]$ - those talented people

Again, the fortunate intermingling of expertise among the prisoners was heavily negated by the pitiless orientation of many of the guards in charge. Tesfalem elaborated on the way in which he was belittled for requesting to access otherwise everyday facilities:

[...] the negative [experiences] was really, I can say, ah, you know, the old people, you know, the brainwashed, indoctrinated people who only knows what the government told them to do [...]. That is, you know, sometimes, you know, you feel, you know, very hard beating, you know [...]. If you get, for example- if you ask them, for example, sometimes at night, you have to wait to have a toilet, for example, and ask them so, yeah, their reaction was very serious, so- even they beat you [...] and then they don't allow you to go out to have a toilet, so, you know, this kind of stuff [...]. I can say, personally, um, they actually responded with us in a very cruel way $[\ldots]$ 
Eventually, the factor that disrupted Tesfalem's interminable existence living out of a former Soviet hangar was the demand for labour on the construction site of a hotel. The government persisted in its capacity to extract free labour from the 'traitors' in order to serve the country's tourism industry. Yet, there was an upshot for Tesfalem in that, by being relocated to the town of Gel'alo, he was now situated back on the mainland. The tasks that Tesfalem carried out on the hotel construction site mirrored the back-breaking routine at Dahlak. However, the new location also saw a fusing in the workforce of prisoners and soldiers; the only difference between the two was that, whereas the prisoners returned to a jail at the end of the day, the military personnel retired to their army barracks. This would continue for another eighteen months. In all, the length of time that had unfolded since Tesfalem's arrival at Asmara airport totalled almost five years, and, by this point, the inevitable tendency to simply adapt to the circumstances had increasingly superseded any remainder of hope that he held out pertaining to being discharged from his punitive obligations. However, upon completion of the hotel construction, the Eritrean state issued an amnesty for the - now former - traitors. Yet, what this meant for Tesfalem was not a long overdue return to his family, but, rather, deployment on an agricultural pastureland in the south of Eritrea as part of further military service. The location of the town of Mendefera proved to be a double-edged sword for Tesfalem: being situated close to the Sudanese border meant that there was both a greater possibility of finding himself in harm's way if a deterioration in internation relations were to occur, yet his opportunities to re-escape from Eritrea were enhanced.

Ultimately, Tesfalem would take advantage of the chance to abscond the bounds of Eritrea for a second time. However, this was not before serving for a month in Mendefera. Although Tesfalem had, technically-speaking, been reformed through years of forced labour at both Dahlak and Gel'alo, he was still earmarked with suspicion in the eyes of officials; this made the obtaining of a permit to visit his family - after the best part of a decade having not seen them - all the more difficult. Eventually, the travel permit was granted and he managed to spend three weeks in the company of his kin. The permit was afforded to Tesfalem on the strict conditions that he return to Mendefera in order to continue military duties in the agricultural fields. Tesfalem agreed to the conditions and, in fact, returned to Mendefera on his own accord. However, this act also signified an appropriation of deceit - again, a customary tactic of the Eritrean state - on Tesfalem's part. By returning to Mendefera, Tesfalem's supposed remorse for prior 
unpatriotic actions and newly-found nationalistic commitments were thereby concretised - at least, that was, in the minds of his commanders. The time spent with family had ruptured Tesfalem's adaption to military life and re-instilled the aspiration to live a life constituted by anything other than political oppression and forced labour. The decision had been made to cross the border to Sudan for a second time, albeit if Tesfalem's family were not privy to his choice for fear of being exposed, inadvertently or otherwise.

By applying for a permit that would allow him to seek medical advice in a nearby township, Tesfalem's second attempt at freedom was initiated. The permit was granted on the basis that he had willingly returned from visiting his family a few weeks prior. This time around, however, the permit meant he could leave the military quarters without suspicion. Instead of utilising the local medical facilities, Tesfalem, alongside a fellow serviceman, embarked on a six-day journey - on foot - to cross the border to Sudan. Reminiscent of his first escape, Kassala was the intended destination. A sense of relief befall the pair as they stepped-foot on Sudanese turf, and a degree of familiarity arose as they entered Kassala. The pre-existing acquaintance with the town lead the pair to a refugee camp whereupon they stayed three weeks, occasionally travelling to the capital city, Khartoum. Due to the international awareness surrounding the case of those Eritreans that were repatriated from Malta in 2002, Tesfalem was quickly guaranteed refugee status and provided with a small, temporary home by the UNHCR. Tesfalem spent a further two years in Sudan as an "urban refugee" teaching school children at elementary level; he was living a "normal Sudanese citizen's life." In spite of this, an opportunity to start a new life in New Zealand eventually materialised. As the final months of 2008 unfolded, Tesfalem would board a plane for a second time. The difference in circumstances when compared to his first flight were obvious, yet new contrasts - or, in Tesfalem's words, “culture shock” - presented themselves upon arrival

in New Zealand: although he had encountered "white people" in Malta, the people he faced in Auckland were strikingly different.

\section{§ 3 Chapter 3 summary}

This chapter has detailed the 'middle period' narratives of Iaokim and Tesfalem. Underlying the swirl of interpersonal interactions throughout their experiences - 
whether it was the physical violence levelled by trainers against the participants or the deceit co-opted by the participants and enacted toward friends, family, and military superiors as their only realisable form of agency if they were to flourish - violence was present in one form or another. Additionally, the interpersonal interactions at play throughout this chapter can be seen to be linked to the state-sponsored institutional violence outlined in Part I; thus, the relational structures therein can also be seen to be the mechanism through which such morphostatic violence is perpetuated.

Chapter 4 takes-up the 'middle period' narratives of Isaac, Haile, and Eyob, respectively. 


\section{CHAPTER 4}

\section{'Middle period' narratives II}

\section{$\S 1$ Animalistic anaesthesia}

"[...] you feel like such, you know- you know- when you left your country, yeah, your family, it's difficult [...]. Sometimes, when I was in jail, I- I wanted return back to my mum, my family" - Isaac

Ongoing political repression and dissatisfaction with life as a fugitive-cum-fisherman had compelled Isaac to seek asylum in Yemen alongside a small group of friends. A voyage of several hours across the Red Sea in a borrowed boat - the reality of the circumstances perhaps insinuating an arrangement more attune to a gift - saw the hopeful collective arrive successfully only to be herded in to a jail doubling as a refugee camp. Subsequent to a two-hour interview that confirmed his status as a refugee, Isaac entered a world that abruptly dissolved any significance pertaining to epithets, social repute, and UNHCR-administered monikers. Isaac elaborated on the way in which the everyday was suddenly rendered unfamiliar:

$[\ldots]$ the life was very tough $[\ldots]$, in jail is... even in Yemen is especially. Jail was very ... bad $[\ldots]$ : when you go to shower, when you go toilet, you know... you know, some of risk people [...], like, they rape you, like... they rape each other $[\ldots]$. And some of them, they kill each other [with shanks fashioned out of metal]

The notion that the triangular milieu of violence he encountered between refugees, prisoners, and soldiers within the jail would constitute his asylum for the next twentyseven months was so unimaginable that it never occurred to him whilst assessing the risk involved with absconding. Yet, he did disclose an awareness shared among his family concerning the potential repercussions that would befall them if the Eritrean government became privy to his fleeing. Ultimately, the risk did not outweigh the striving for a life 
beyond the military fate of his older brother. However, Isaac's actions did, in fact, trigger retribution for his family at the hands of the Eritrean judicial system: ${ }^{67}$

What happened is when I reached Yemen [...], the [Eritrean] government, when they hear about $[\ldots]$ the boys crossed to Yemen - escaped to Yemen $[\ldots]$, they came to every family's home and [...] they put our family - my mother $-[\ldots]$ in court $[\ldots]$. They talk about "Why you left to go - your child - to advise them to [...] cross to Yemen?" [...] My father, he been... they put my father for one month in jail [...], because in Eritrea if you left- if your child left to cross to other country... they catch your family

If Isaac's family were in no position to question authority - they were fined large sums of money -, Isaac himself was exposed to similar frustrations when up against violence directed at him and the other refugees from all angles within the compound. Additionally, whereas the unchecked corruption throughout the jail meant that the inhabitants could obtain desired items from the outside such as cigarettes and khat, ${ }^{68}$ Isaac and his friends found themselves with no money and endured slave-like treatment at the decree of those around them. In recalling the scene, Isaac spoke of the conditions and degree of contingency that underpinned the interpersonal relations he encountered; having no capacity to retaliate such untoward treatment transpired, for Isaac, as a particularly onerous circumstance:

ISAAC $[\ldots]$ [the prisoners and soldiers] are very bad $[\ldots]$. Oh, they treat you like... slave [...]. In Yemen, everything is money [...]. If you have even in jail, if you have money... everything you wanted from outside [ ] bring you $[\ldots]$. But that time we was, you know, we don't have anyone $[\ldots]$, we don't have money and $[\ldots]$ if $[\ldots]$ someone come and they say something... and even they insult you, you have to-... you have to say $[\ldots]$ nothing $[\ldots]$. You can't attempt, you know, "What did you say?" [...] And [...] even the $[\ldots]$ soldiers, they see and they are... nothing they can do and they will insult you $[\ldots]$ as well $[\ldots]$. Yeah, they treat you like slave

JC So, even though you were a refugee-

ISAAC Yeah, even if you a refugee, they don't care

\footnotetext{
${ }^{67}$ It is unclear as to how information surrounding Isaac's escape was revealed to Eritrean officials.

${ }^{68}$ The practice of chewing khat "dates back thousands of year in the Horn of Africa and the Arabian Peninsula where the khat plant is widely cultivated [...]. The chewing of khat leaves releases chemicals structurally related to amphetamines, which give the chewer a mild high that some say is comparable to drinking strong coffee" (Al-Mugahed 2008: 1).
} 
JC So what types of things would they do?

ISAAC $[\ldots]$ one day, ah, between refugee and $[\ldots]$ between prisoners $[\ldots]$, we fight- they fight with us and the soldiers as well, they help them

JC Help the prisoners?

ISAAC Yeah $[\ldots]$, they hit us; some of our friends $[\ldots]$, they hit him a lot $[\ldots]$. The prison was very tough to us because... a lot of things happened like that $[\ldots]$ and, ah... some of them didn't kill you, but they trying to kill you, but $[\ldots]$ the $[$ soldiers] will save us...

JC The guard $[\ldots]$ will or won't [save you]?

ISAAC [...] I mean the guard will save us because they [the prisoner] trying to kill us $[\ldots]$

Thus, where the guards prevented violence to the degree that it would result in death, a modicum of "reasonable violence" was, in fact, permitted; a phenomenon that can be linked to the sensitised relationship to violence exhibited by the guards and the notion that the refugees harboured an "animalistic anaesthesia to pain" (Feldman 2004: 213). As Isaac went on to explain, the quotidian nature of the violence surrounding him was coupled with a perception of individuals being reduced to non-human entities: "[...] they shoot you, they don't care if someone dead. They don't care because nothing to them. [...] They kill each other, like nothing, like animals." Indeed, the execution of convicts took place in the central courtyard of the prison - Isaac witnessed three in total. In spite of this, Isaac perceived the streets of Yemen to be essentially just as dangerous: asylum seekers that were not granted refugee status found themselves released on to the streets of Sana'a - Yemen's capital - and were considered to be, as Isaac stated, "in a bad situation now." The volatile environment was also reflected in Isaac's endeavour to avoid the public arena when, after twenty-seven months in confinement, his name was called by visiting officials and he was bussed to Sana'a where he spent three weeks holed-up in a hotel awaiting the finalisation of his visa so that he could be transported to his adoptive home, New Zealand: “[...] I was in hotel, I didn't walk around 'cos I was... you don't feel safe in Yemen [...], especially in Sana'a [...]; that place was very dangerous [...] because they have guns- everyone have guns."

The eventual comfort that came with being saddled aboard an international flight from Sana'a to Auckland via Dubai and Hong Kong offered little reprieve as the threat of violence dissipated and the uncertainty of new territory accrued. In many ways, the finalisation of Isaac's visa also confirmed the reality that he would not return to Eritrea. 
Furthermore, as Chapter 5 will depict, being resettled in New Zealand ushered in an unforeseen set of challenges and constraints pertaining to limitations surrounding language and communication.

\section{$\S 2$ "If you wanna be successful in your life, you have to be corrupt like them"}

"It's all the same result: stay in Eritrea... you are already dead"- Haile

Haile's youth and schooling was disrupted by the Ethiopia-Eritrea war in 1998. At the time, his allegiance to the nationalist cause was cultivated through state indoctrination and the experiences of his older siblings. Throughout the years following, with the war relegated to the history books and his High School education resumed, further political crackdown transpired and changes to governmental policy in $2004^{69}$ meant that options were scarce: he could either leave school and join the military - a destiny that would likely constitute the rest of his working life -, or pursue further education through a scheme that, ironically, resembled militia-style training. For Haile, the urge to demonstrate his loyalist commitments would not wholly outweigh his pursuit of learning, and he joined the six-month national service programme with vigour. However, upon arriving at the national service barracks, his preconceived ideas were quickly shattered. As Haile explained, one's experience and treatment at the camp was intimately tied to the comportment of particular trainers:

\footnotetext{
[Upon arriving at national service] - being at that young age and so nationalist - all you want to be was a patriot making a name for yourself, for your country, and for your family [...]. The first feeling is... “Oh, I'm good; in the right place [...]. This is the place where... the greatest nationalist people will come out" [...]. Theoretically and practically, it's way different [though] [...]. Nothing was according to [my preconceptions]; that's the interesting thing: absolutely no way - it all goes according to who the trainer is [...]. They like you, you can have the most adventurous lifestyle [...]; they don't like you, that's it, end of story
}

\footnotetext{
${ }^{69}$ See Chapter 2, $§ 8$.
} 
Inevitably, to be despised by the personnel in charge lead to violent retribution. Haile expanded on the 'professional' nature of the severe procedures that were carried out:

[...] one thing I- I have figured out when I was there was... they are extremely... smart... in a bad way [...]. They never... give you any evidence that you've been tortured [...], unless they do it publicly [...]. If [one of the trainers] has personal hate, they never show to anybody that you had been tortured, you had been exploited [...]. A \{clears throat\} normal human being would never do that $[\ldots]$ kind of things. That's- that's the crazy thing: I have no idea how they become so smart $[\ldots]$ to do the evil thing

With regard to Haile's circumstances, to be on the receiving end of violence enacted 'publicly' was to be punished in a way that was directly visible to other national service conscripts. Such tactics were sagacious where the aim was to cause a breaking-down in social cohesion and confidence between the teenage boys. The result was a dissolution in trust among peers and the stark reality of having nowhere to turn in order to seek equity:

[The trainers] are geniuses [...], I can assure you. They are extremely perfect [...]. Nobody can track them down. If they was [to enact violence] in public, nobody's gonna ask them [...]. So, that's- that's the circumstance. Even if you wanna say you've been treated unfairly [...], you're not allowed [...]. [Also], your mate - the one who sleeps next to you - is going to witness against you [...]. That's how genius [the trainers] become [...]. Some of them, they [enact violence publicly] because... there is no questioning - who do you ask? [...] who do you seek justice? $\Delta$ So you will kind of curse your friend \{laughs\} and your trainer $\Delta$ [and] that's how they control the, um, whole- the whole team... But, yeah, the punishment is endless- there is no border for them

Accordingly, the disjunct between Haile's preconceived ideas and the corporeal existence he now faced caused a significant degree of psychological torment. ${ }^{70}$ As confusion and guilt set in, Haile quickly began to question his suitability for the nationalist endeavour; the disparity between himself and the trainers was incommensurable. If to be one of "the greatest nationalist people" involved manipulating others to the point that they have no option but to break a rule - thereby inciting violent

${ }^{70}$ See Chapter 5 , $§ 5$. 
punishment on themselves -, then the Eritrean state was not worthy of Haile's support. One such mechanism for legitimising violence involved imposing two contradictory dictums over the recruits:

HAILE [The first rule is that] they ask you to keep quiet [...]. And then [...] they personally come and ask your name. So, the first rule says "Keep quiet no matter what," and the second thing they come and ask your name $[\ldots]$ - what do you do? [...] [If] you tell your name... rule number one was broken, so you will get something; you don't reply ... you are going up against their will $[\ldots]$. So, at the end of the day, even though it's contradicting, you will get something. And that's how they behave when they want you to get something

JC What do you mean by "get something"?

HAILE [...] If they want you to be in a problem, or in a punishment [...]

- they can get you in any way they want $\Delta$

JC So what would they do?

HAILE ... A lot of things; a lot of things that you shouldn't do to a human being

Indeed, from the moment he entered national service, Haile's experiences lead him to one unavoidable conclusion: he would have to leave - not just national service - but the nation of Eritrea itself. However, for the time-being - and with nobody to turn to, nor any chance of fleeing national service - he would have to endure the six-month period of sustained torture manifesting as both mental and physical anguish. With this in mind, it is possible to see how - from the point-of-view of the state and its particular apparatus appearing here in the form of national service trainers - torture is particularly effective as a means for silencing and breaking down trust between individuals. As Scarry writes: "Torture inflicts bodily pain that is itself language-destroying, but torture also mimes (objectifies in the external environment) this language-destroying capacity in its interrogation, the purpose of which is not to elicit needed information but visibly to deconstruct the [conscript's] voice" (1985: 19-20). Hence, the 'professional' nature of the punishers is exemplified.

Subsequent to completing six months national service, Haile was permitted to return to his schooling in order to complete secondary education. The newly-implemented policy meant, however, that the next twelve-month period of schooling would be carried out in virtually the same location - and under similarly strict disciplinary measures - as 
his national service had been. In all, the curriculum was laughable. Haile found that his specific vocation for physics and chemistry was anything but fostered under a milieu that simulated disarray. Moreover, he was being directed by teachers that were bereft of any capacity to educate convincingly. Additionally, the detriment contained within eighteen months of manipulation-veiled-as-education was compounded due to the fact that Haile was refused visitation with his family. Eventually, national service and high school coalesced with a final exam. For Haile and the other students, the stakes were high: failure meant an inevitable fast-tracking to the military; success, on the other hand, would open doors to tertiary study. Fortunately, Haile gained the sufficient points to be placed in the latter category. However, he remained unaware of his result and a fourmonth period of government-instigated 'summer work' ensued. ${ }^{71}$

At the time, Haile was unenlightened as to the reasoning behind being assigned to pick cotton and carry out other laborious tasks - details were scarce and a wage remained to be evident. It was only in retrospect that the lengths the Eritrean state was willing to go in order to maintain control over its youth became clear. Under the jurisdiction of soldiers, two months of sustained slave-labour transpired. It was at this point that Haile felt the state of affairs to be unbearable, and, amid a high degree of risk, he began formulating plans to gain the trust of his overseer. In doing so, he was counting on the possibility that it would allow him the opportunity to venture to a nearby township from time-to-time for provisions. Haile elaborated on the situation and the way in which the evocation of deceit was legitimised:

[...] I had a relative, um, who was staying in that town... ah, where we were working. And I had to make a really good relationship with [the trainers and] with the boss of mine. I was like, "I'm going to town, what can I bring you?" [...] And, I used to cut his hair [...]. He never knew what I'm gonna do, but I had this good foundation so I can get permission anytime I want [...]. 'Cos [...], if you wanna be successful in your life, you have to be corrupt like them. So I had to give him a free haircut, so he'd give me permission to go to town [...]. By the time I was going to town... I had, yeah, this chance to \{rubs hands together\} search for The Network. You can't- you can't just go publicly cos, yeah, everyone is a spy

${ }^{71}$ See Chapter $2, \S 7$. 
Even Haile's family weren't privy to his plans to cross the border to Sudan: “The only people who I will trust were those of my relatives, [yet] I never told them [about my plans to flee]. I never told them because they can leak the information." In his endeavour to solicit the expertise of a smuggler, Haile framed - when necessary - the situation as if he was doing so on behalf of someone else. Similarly, the monetary resources required to hire a trafficker were sequestered from family members, but under a false pretence. Eventually, Haile's scheme materialised and he surreptitiously left the position of cotton-picker and occasional pseudo-barber for Sudan where other family members, including his sister, were already residing; a factor that undeniably shaped his desire to abscond in this particular direction. Again, the risk tied to such a voyage was compounded by the shoot-to-kill policy that was warranted by the Eritrean state. As Haile stated, the one-way trek was:

\section{$[\ldots]$ the most intense eight hours of [my] life [...], in terms of not making any mistake [...]. I was extremely curious, careful... ready to take any order from the guy who- who was taking me. [I was also] extremely sensitive to the whole environment I was in [...]. Even I didn't trust bim [...]. There is no place to trust... How- why would I trust a random, strange person, when I don't trust my own family?}

The friction inherent in taking orders from someone he didn't trust gave way to feelings of anger and sadness at the moment Haile crossed the border to Sudan. Stereotypes lingered in Haile's psyche surrounding the nature of the Sudanese people; the fact that he had taken it upon himself to leave Eritrea - the nation for which tens of thousands of people had fought and died during the struggle for independence - only to arrive in a "useless" country, meant that his "only option" was also the "lowest point in [his] life." However, Haile made his way to the home of his former neighbours who had also escaped the Eritrean regime at a previous point in time. He was accommodated by the Muslim family for two weeks before they chaperoned him to a UNHCR-run refugee camp where he was interviewed, accepted, and processed. The conditions of the camp were grim, but, as Haile remarked, when "coming from the worst level of life [...], you don't complain a lot." Following this, Haile was able to travel to Khartoum and reunite with his sister.

Haile would stay with his sister in Khartoum for a further two and a half years. At first, the pivotal factor was that the new environment simply allowed him the space to 
think. ${ }^{72}$ Before long, however, Haile managed to obtain employment - wages not excluded - as a barber. Additionally, contact had been maintained with family members that remained in Eritrea. Life was good, and his first pay instalment was used to purchase a kilo of oranges, thereby constituting, at the time, "the proudest moment in [his] life." Ongoing employment opportunities saw Haile eventually obtain work as a cashier in a British-owned restaurant. It was the experience of developing friendships in Khartoum, and subsequently seeing those same friends orient themselves toward resettling in other parts of the world, that sparked consideration as to what Haile's own future would hold. Ultimately, the possibility of discreetly being deported back to Eritrea persisted, and it was this factor - combined with the ambition to create a new life, as opposed to simply obtain citizenship rights - that compelled Haile to seek refuge abroad. Indeed, as tensions arose between the Sudanese and Eritrean governments, the staff members working for a local radio station - including Haile's sister - were seen to be unruly and were subsequently threatened with deportation. The unpredictability inherent to Sudanese society inevitably funnelled Haile and his sister in to accepting an offer for resettlement in New Zealand. Within five weeks they would be transported halfway around the world to begin a new life. However, in perhaps what can be seen as a final testimony to the uncertainty that Haile had experienced throughout his life in the Horn of Africa, a coup erupted just days before his flight was scheduled to depart. ${ }^{73}$ Haile's first experience onboard an aeroplane lasted in excess of two days. From Khartoum, the flight path touched down in Kuala Lumpur before landing in Auckland where both happiness and nervous strain descended on the newly-arrived - would the locals do things the same way? would they eat the same? would they think the same?

\section{$\S 3$ Fractured families and the "useless" by-products of war}

“Cos, like I said [...], if you not allowed to ask for your right, what kind of life is that?" Eyob

Disruption and hardship constituted the early years of Eyob's life in Ethiopia. The absence of his father at the mandate of military authorities meant that Eyob's early

\footnotetext{
${ }^{72}$ See Chapter 5 , $§ 5$.

${ }^{73}$ Iaokim and Haile were schedule to take the same flight.
} 
education was thrown in to disarray. Moreover, exacerbating circumstances had lead to a further fracturing of his family across the Eritrean-Ethiopian divide: two of his siblings - one brother and one sister - were now embroiled in the verity of the Eritrean army and national service, respectively. ${ }^{74}$

As options waned and his family continued to be teased apart during his teenage years, Eyob remained unshakable in his adversity to joining the Ethiopian army during this period; a stance that was undoubtedly a response to being exposed to the experiences of his older siblings. At perhaps the pinnacle of incongruity and misfortune, two of Eyob's brothers came to be simultaneously serving either the Ethiopian or Eritrean armies. Eyob described the contingency and danger that his brother in the Ethiopian army faced:

JC Did you ever consider going in to the Ethiopian army?

EYOB [...] No, because I have seen my brother... struggling, so [...] I never like the army [...]. He was [in] the Special Forces [...]; in Ethiopia is called 'The First.' If anything happens, The First will [respond]. Once he went to Somalia, there was Al-Shabaab [...] - the terrorists [...]. There was a big fight in the capital city- like, my brother was... fighting and shooting, like, do a lot of things $[\ldots]$

Whereas the precariousness of active military service across the Horn of Africa clinched Eyob's aversion to following in his sibling's footsteps, the death of his brother whilst serving in the Eritrean army solidified his ultimate concern surrounding the importance and reunification of his kindred. Adding to the trauma of losing a loved one, the family were not provided with any information concerning the death, nor did they encounter any efforts on the part of authorities to return the body of the deceased. Eyob elaborated on the way in which this predicament was emblematic of an intrinsic absence of rights in Eritrea:

EYOB $[\ldots]$ we don't have much information [about the death $[\ldots]$

JC [The authorities] didn't say how it happened?

EYOB Nab \{disapprovingly\}, nah, there's no way. They don't care [...]. You can't even ask; you're not allowed to [...]. They only told you he died or $\{$ hushed tone\} he is dead $[\ldots]$ - have to accept it

\footnotetext{
${ }^{74}$ It was unclear as to what the precise circumstances were that lead to these particular members of Eyob's family being situated in Eritrea.
} 
JC $[\ldots]$ you don't get the body [returned] or anything like that?

EYOB No, not at all. In Eritrea it's very... you bave no rights in Eritrea [...]; it's very hard to ask for your rights $[\ldots]$ because they will put you in jail. They will come at night, knock your door \{clicks fingers\}. So, many people [...], they don't know where [their loved ones] are

Here it is possible to intuit the Eritrean state's perception of death as a "by-product" of war and, following this, the "uselessness" of a cadaver (see Scarry 1985: 73).$^{75}$

As Eyob continued, it became clear that the splintering of his family had continued to filter down generationally, subsequently infiltrating the lives of his sister's children - Eyob's niece and nephew -, both of whom he is yet to meet:

Like $[\ldots]$, my nephew $[\ldots]$, he was in jail; they caught him once when he tried to escape to Sudan [from Eritrea] [...]. They put him in jail, like, five months. His mum, she didn't know where he is [...] because she's not allowed to ask "Where is he?" Five months they put him, like, very bad-we didn't even know where he- or $[i f]$ they killed him $[\text { or if] he is alive [...]. [His parents }]^{76}$ tried to find him, but they not allowed to, like, ask the government officially, like, "We wanna see our son" [...]; they might put her in jail [...]. You can't ask for your rights...

More recently, Eyob and his family managed to facilitate his nephew's escape from Eritrea to Ethiopia by financing smugglers to transport him across the border. Even in spite of the risk involved in such an expedition - “it's, like, 50-50 you will die or you will survive," stated Eyob -, the only alternative was akin to being rendered lifeless: "the option [of] staying in [Eritrea is] like dying." Whereas the successful inter-border peddling was an ostensible triumph in the scheme to liberate and reunite Eyob's family, any potential freedoms surrounding his niece's circumstances were - and continue to be - nullified:

EYOB [My niece], she's 13, she's in the Academy now [...]. They took her from her $[\ldots]$ mum JC What's the Academy?

\footnotetext{
${ }^{75}$ Scarry elaborates: “The language of "by-product" denotes "accidental," "unwanted," "unsought," "unanticipated," and "useless." The last meaning is the most crushing, for while the others are only an abdication of responsibility, the last asserts that [death was not] centrally useful to whatever it was that was being sought through the [activity of war]" (1985: 73).

${ }^{76}$ For reasons that were unclear, the whereabouts of the father of Eyob's nephew is also unknown.
} 
EYOB Well, they say it's a school [...]. The government's insecure 'cos so many young people's leaving [...], so he's [Afwerki] keeping everyone there $[\ldots]$. He just $[\ldots]$ keep them brainwashed [...]. Thirteen, it's very young; they will believe whatever they told them [...]. She doesn't live with her mum now $[\ldots]$, she lives with $\{$ disapprovingly\} the government $[\ldots]$ in government school, which is in the army camp... So they're gonna see there everything about the army, about the government $[\ldots]$. So, they will be brainwashed $[\ldots]$ when they grow up $[\ldots]$

By age 19, the instability of life in Ethiopia compelled Eyob to seek asylum. Although the fact that his aunt had emigrated to New Zealand in 2001 may have made the decision somewhat unexacting, a new paradox arose: by pursuing a more secure - and, therefore, more desirable position relevant to the aim of reuniting his family - Eyob would have to, geographically-speaking, significantly distance himself. Additionally, in spite of Eyob's mother accompanying him and his sister on the flight to New Zealand, the dichotomous nature of this transitional point in Eyob's life sparked internal conflict with regard to leaving loved ones behind; the longing for home that he felt at the time would not dissolve during the years following resettlement in New Zealand:

Oh, it was very hard to leave your [...] home country, family, friends you grow up with. Yeah, I was crying, but I have to [...] say [to myself]... "I know that it's for good [...], for better thing [...]." Yeah, it was very hard to leave for me. I wish I can't; I wish I could of stayed in my... homeland, but I know something is pushing me behind my back

However, the many emancipatory expectations that Eyob held about life in New Zealand, and, significantly, what his new life would entail with respect to providing for his family, remain unmet.

\section{$\S 4$ Chapter 4 summary}

This chapter has expounded the 'middle period' narratives of Isaac, Haile, and Eyob. Again, by foregrounding the interpersonal relationships that were inherent to each of the participant's lives, it is possible to establish routinised fear and terror as a predominant structuring factor leading up to the point at which each individual took 
flight from the Horn of Africa. Following this, it is also possible to see how such relational structures of violence are morphostatic.

Part III - constituted by a single, two-part chapter - concludes each narrative by briefly describing, firstly, a vignette excerpted from each participant's story that relates to the subjective implications of violence, and, secondly, the events that constitute each interlocutor's period of resettlement. 


\section{PART III}

\section{The subjective reverberations of violence}

Following the institutional and relational elements of social structure that have respectively formed the foci of Part I and Part II, Part III turns to the third and final strand of Scott's conceptually interdependent scheme: embodied structure. Echoing Giddens and Bourdieu, Scott considers an embodied structure to be any given organised way of acting that is the result of the learned behaviours, skills, and actions bestowed upon an individual; albeit if these learned ways of acting are often performed unconsciously (2001: 84). Furthermore, Scott continues by stating that "[e]mbodied structures are found in the habits and skills inscribed in human bodies and minds. These embodied structures allow them to produce, reproduce and transform their institutional and relational structures" (2001: 84). The allusion to the human mind is significant in that it provides a central link between social structure, embodiment, and subjectivity. Hence, with regard to the way in which violence is inevitably embodied both physically and psychologically, as well as being tied to a context comprised of violent institutional and relational structures, this chapter foregrounds the subjective experience of violence. $^{77}$

Das and Kleinman understand subjectivity as "the lived and imaginary experience of the subject" (2000: 10). Thus, with regard to violence and subjectivity, the same authors continue by outlining several caveats that align with the notion that the institutional, relational, and embodied facets of violent structures are inherently interlaced:

\footnotetext{
One cannot draw a line between collective and individual experiences of social violence. These are so thoroughly interwoven that moral processes (i.e., social engagements centered on what is at stake in relationships) and emotional conditions are inseparable. Violence creates, sustains, and transforms their interaction, and thereby it actualises the inner worlds of lived values as well as the outer world of contested meanings. Neither are social violence and its consequences only of one kind. Multiple forms and dynamics of social violence animate local worlds and the individual lives in them. From
}

\footnotetext{
${ }^{77}$ Hence, it should be noted that - due to the content of the interview data - 'embodiment,' as it is evoked here, foregrounds perception over practice (see Csordas 1990).
} 
this perspective, the social violence of day-to-day living are central to the moral order: they orient norms and normality (2000: 5)

Following this, the current chapter includes two primary sub-sections. The first includes a brief vignette from each participant's narrative that relates to the theme of violence and subjectivity; drawing on the work of Arendt, Strathern and Stewart, Das and Kleinman, and Robben and Nordstrom this sub-section demonstrates the notion that violence can, among other things, affect one's memory, evoke critical reflection, result in dehumanisation, and, significantly, permit a sense of certainty amidst an otherwise uncertain world. Finally, the second sub-section acts as a coda to the overall trajectories of the life accounts by briefly outlining the 'resettlement periods' of each interlocutor. Taken together, these central points again illustrate the underlying argument that, where morphostatic structures of violence shape - yet do not wholly determine - lives, the violence inherent to Eritrea's socio-political context demands the harnessing of one's agentic crawl-space if they are to flourish. 
CHAPTER 5

\section{Violence, subjectivity, and resettlement}

\section{Sub-section I: Violence and subjectivity}

\section{§ 1 Forgiving The Devil}

During his time working as a translator for the UNHCR in Sudan, Iaokim had a chance meeting with an adversary he had originally encountered whilst completing his national service duties. The anecdote that Iaokim enumerated in relation to this particular person - dubbed 'The Devil' by Iaokim and the other recruits - illustrates the way in which one's subjective experience of violence can both change over time and, in this case, give rise to forgiveness as a means for coping with such merciless past experiences. Subsequent to describing the way in which trainers are typically people drained of their humanity - "if they [are] asked to kill they would kill" - Iaokim went on to justify the nickname projected over this particularly cruel trainer by elaborating on the types of characteristics that The Devil exhibited:

\footnotetext{
I will tell you one story [...]. This guy, he was mistreating us [during national service] - everyone -, we used to call him 'Devil' [...]; he is $[\ldots]$ just... the worst guy ever you could $[\ldots]$ see on $[\ldots]$ this earth $[\ldots]$. I remember $[\ldots]$ his dirty shoes \{stomps foot\} on my neck [...] while I was being punished [...]. Sometimes [he was] just going, ah, you know, out of the rules
}

As it turned out, The Devil would later abscond from the Eritrean military and cross the border to Sudan. Before long, however, he was to find himself in the company of Iaokim once again. Yet, this time the power imbalance that formerly constituted the relationship between the two had been overturned; The Devil was now relying on Iaokim for translation assistance as he was being processed at the UNHCR-led camp for refugees. Although The Devil did not recognise the conscript-cum-translator, The Devil understandably remained etched in the mind of Iaokim. However, in spite of their turbulent past, Iaokim invited The Devil and a few others to lunch, where he set about 
verbalising his perspectives concerning the situation - Iaokim turned to his former trainer and said: ${ }^{78}$

IAOKIM [...] they used to call you 'Devil,' right?

THE DEVIL $[\ldots]$ Yeah $[\ldots]$

IAOKIM So, remember, like... maybe you don't remember because you trained thousands of people [...], but you actually [...] treated me [unfairly] and then you went further, like, stepping \{stomps foot $\}$ on my neck...

THE DEVIL [...] Just orders, you know [...]

IAOKIM One day, ah... when you were training me, I was nobody [...]; to you, I was no one. But, today, look, I am- I am your interpreter [...] and I could help you with a lot of things. I could also, you know, mistreat you [...] if I was a bad person

As Iaokim continued, it became clear that to cultivate Eritrean solidarity was, for him, more desirable than upholding a revengeful, eye-for-an-eye type mentality against The Devil:

[...] Today you are no one, in front of me, and in front [of] everyone. You can be someone tomorrow \{claps hands\} [...]. So [...], at the end of the day... Eritreans, we all victims of this- this regime $[\ldots]$. I bope $[\ldots]$ that, one day, you can go and help your people [...] actually to bring the change that we need in our country [...]. Whatever you did, I forgive you

Hannah Arendt writes that the act of forgiving "is the only reaction which does not merely re-act but acts anew and unexpectedly, unconditioned by the act which provoked it and therefore freeing from its consequences both the one who forgives and the one who is forgiven" (1998: 241). Thus, Iaokim's brief anecdote illustrates the way in which, in spite of past brutality, one's change of mind can evoke the unexpected and therefore potentially contribute to the realisation of one's own ultimate concern - in this case the change required to overcome the oppression of the Eritrean state ${ }^{79}-$ by forgiving, and therefore liberating, both himself and his former oppressor.

\section{$\S 2$ Repeated ruptures and the subjective residue of imprisonment}

\footnotetext{
${ }^{78}$ Iaokim recounted this portion of the anecdote as if he was speaking to The Devil.

${ }^{79} \mathrm{It}$ is worth noting that Iaokim does not forgive Afwerki or the Eritrean state for past grievances.
} 
As Isaac spoke of his time in a Yemeni jail, the experiences he outlined were predominantly constituted by either violence or a yearning to return to his family. However, amidst these fragments of ferocity and hardship, he made the following remark: "If you get in jail, you can't get out." Of course, being seated in the relative comfort of a university office in Wellington, New Zealand as he verbalised his recollection of past events contradicted the very statement. Yet, with regard to the impacts violence can have on one's subjectivity, the utterance encases - when contextualised - more than an unintended contradiction. For Strathern and Stewart, 'the imaginary' and memory are intimately linked, particularly within the context of violent or emotional experiences:

\footnotetext{
'The imaginary' $[\ldots]$ does not signal that the thoughts involved are either factually 'true' or 'untrue' with respect to the world. It simply indicates that people's thoughts about the world often run far beyond its obvious empirical manifestations, and that the frameworks that are built out of people's thoughts become as important as, or even more important than, their everyday empirical observations, especially when their emotions $[\ldots]$ are strongly present (2006: 6-7)
}

Thus, it is possible to see how, upon recollecting his past experiences of incarceration, Isaac's empirical surroundings were outstripped by his own imaginative capacity. In other words, where the violent experiences that constitute Isaac's past can be considered as "repeated ruptures," his perception was altered; a phenomenon that can "render [one] progressively more anxious and vulnerable [...]" (Strathern and Stewart 2006: 7). Following this, the contradiction contained in Isaac's remark provides insight in to the extent with which violent experiences can become embedded in one's memory. Accordingly, it can be seen that an altered subjectivity can even override "the mundane processes on which [one's] social life otherwise depends" (Strathern and Stewart 2006: 7); or, in Isaac's case, the interpersonal interactions contained within the activity of being interviewed were arguably eclipsed by the remnants of a perceived non-freedom and the subjectively deterministic notion that 'once you're in, you can't get out.'

\section{§ 3 Reflection, bare-life, and 'the secret life of the state'}


As has been revealed in earlier chapters, Tesfalem exhibited an initial willing servitude when it came to fighting Eritrea's nationalist cause. However, subsequent to being situated on the front line during the Ethiopia-Eritrea war, a shift in his understanding and perspective was catalysed. As Tesfalem explained, the lack of military training that preceded his experiences amidst such conflict was insufficient relative to the reality of the consequences of war; and it was this direct exposure that initiated a stream of reflexive thought involving, firstly, his own position in the war, and, secondly, what the potential repercussions for his family may have entailed:

I can't say myself I [was an] experienced soldier, or I have experience in the military because [the six months training I had] was really just spent, you know, just going somewhere without knowing in detail the military, um, knowledge. But, after that, ah, my mind [and] my heart was in the war because you think about yourself, you think about your family $[\ldots]$ - because you [now] know all the consequences of the war

Additionally, it was by way of conversations with a fellow fighter that Tesfalem's own critical reflections continued to develop. Tesfalem revealed how his friend inevitably exposed a perspective on the Eritrean government's underlying motivations for engaging in war that, at the time, had not occurred to him:

You know, the war claims a lot of lives. So, what you think is: [Am I] going to live or to die? [...] This - between being alive and die - that's [...], you know, the problem. But [...], for me it is quite different ah... [...] there's one guy - a friend of mine -, he told me "Look, imagine" - he was very smart, the guy -, he told me "[...] Imagine those $[\ldots]$ politicians, those leaders, they are gambling because they are [risking having us killed]. What they are doing is really, ah, unacceptable." [My friend continued by saying] "Imagine, look, a soldier, you know $[\ldots]$, gain a victory by shooting - by killing $[\ldots]-$ the soldiers of enemy $[\ldots]$, and then $[\ldots]$ who receives the victory? [...] It's not you, the ordinary soldier, but the Generals [that receive the victory]"

Tesfalem's allusion to his reality having devolved to a matter of life or death highlights what Das, following Agamben, asserts with reference to the way in which a "biopolitical state can strip someone to what is bare or naked life [thereby producing] bodies that are killable with impunity"; she continues by stating that the "blurring between what is 
human and what is not human shades into the blurring over what is life and what is not life" (2007: 16).

Thus, it is possible to see the way in which direct exposure to the realities of war, alongside interpersonal relations that added a critical perspective to Tesfalem's own thinking, indeed illuminated the contested meaning inherently tied to violence whilst also shaping the decision-making processes that eventually lead to his fleeing Eritrea altogether:

I didn't know at that time [...] what [my friend] was talking about $[\ldots]$ and why he was complaining [...]. But, after that, I began to realise the war [was] what he told me $[\ldots]$. Yeah, [there was] a shift [in my thinking] [...]; I talked with my family and we decided [I would] go to Sudan

Das and Kleinman state that "[b]ehind, or rather in the neighbourhood of, the official rationality and the rule of law to which the modern state is officially committed, lies the secret life of the state" (2000: 6). Following this, the currents of thought contained in Tesfalem's narrative are significant in that they also demonstrate the way in which the institutional, relational, and embodied structures of his life converged to ultimately reveal both the 'secret life of the state' and the notion that the preferable - perhaps only, if he were to avoid death - course of action would involve removing himself from the military altogether by absconding from his country of origin.

\section{$\S 4$ Uncertainty and certain death}

Ensconced in Eyob's ongoing endeavour to reunite his family is an acute degree of uncertainty. Whether it has been the unknown whereabouts of his father from a young age at the hands of the Eritrean state, the constant need to shift residencies due to being unable to make rent payments, or the lack of information provided by Eritrean officials surrounding the death of his brother during military service, Eyob's life has been shaped - perhaps even permeated - by not-knowing. Robben and Nordstrom write that, in contrast to "punishment, coercion, and even power, which may become predictable when embedded in structures of domination, violence adds to these an inordinate degree of uncertainty because it is played out at the experiential level. The uncertainty of violence is invariably related to a summoning of fear, terror, and confusion [...]" (1995:10). Thus, it is possible to see how the various events and forms of violence that have demarcated 
Eyob's life contribute to the unstable ground upon which his ultimate concern persistently resides. However, Eyob outlined his desire for family reunification in the following way:

\section{I really wanna see my family [...]; my dad and my sister. I didn't get a chance [to see] my brother - he's died already - but, yeah, it will be good if I meet them before [...] it [i.e. unnatural or violent death] happened [to them too]}

This remark allows for the recognition that, amidst the uncertainty, Eyob is certain that death at the hands of the state remains as a real threat to his kindred whom continue to endure within the confines of Eritrean borders. Hence, experiencing the violent death of a sibling caused Eyob to internalise the incident to the point that the events ushered forth a particular sense of certainty which, in turn, gave rise to a degree of urgency relevant to his aim of familial reunification. In other words, although Eyob's world was - and continues to be - underpinned by uncertainty, death has become the certainty through which his world and decisions are reshaped and remade. Of course, this form of internalised certainty pertaining to death by violent or unnatural means gives rise to further friction when considered in the context of resettlement in a social milieu that contains its own set of constraints and obstacles. For Eyob, the urgency tied to realising his ultimate concern persists in being a matter of life or death.

\section{$\S 5$ Forgetting the past}

Haile's recollection of his experiences during national service provide striking insight in to both his inner world at the time, as well as the extent to which violence, more broadly, can severely impact upon one's subjectivity. In Haile's case, it is even possible to say that he was on the verge of developing a preference for physical suffering; this was due to the psychological effects that were a result of the treatment he endured during national service being too much to cope with - the threat of violence, the direct violence, the constant questioning of oneself, the feelings of worthlessness, and, inevitably, the inability to think - nor discern right from wrong - converged on him so heavily that he feared for his own sanity.

As we have seen, Haile was indeed caught up in the nationalist cause before arriving as a conscript at the national service camp. However, it wasn't long before confusion set 
in; in retrospect, this disconcerted state was merely the beginning of an ongoing internal 'war' with himself. Haile described the initial fissure that catalysed his emotional strife:

I went [to the national service, and] I thought I would be... a nationalist, 'cos
that's what I was thinking of $[\ldots]$. I thought they were a bigger picture of
who I want to be $[\ldots] \ldots$ it $\{$ taps knee\} didn't- it didn't happen. The first thing
they made you to think is you are absolutely worthless - nothing [...]; the most
useless person you could ever- and they stop you to think at all

The immediacy of being treated as worthless can be seen in the trainer's brandishing of the term abruk. Haile's brothers had forewarned him of this term and the insinuations contained therein; they had asserted the fact that it would be the first thing he would hear upon disembarking from the bus at the national service camp. However, Haile's staunch nationalistic stance meant that he failed to take heed of their advance notice. Haile explained his arrival at the camp and the implications of abruk:

[...] in Tigrinya abruk [...] is, kind of, 'sit down,' but not with your bottom; it's kind of- it's- it's just strange feeling [...] $\Delta$ Because once you get off from the bus, you're gonna stand, of course [...]. [But], they want you to be like this \{demonstrates abruk position\} [...]. So you don't sit comfortably, you don't stand, it's just... [kind of like a squat] [...]. Then, yeah [...], they will control you $[\ldots]$ - as simple as that. Easy for them to count you $[\ldots]$; even if you are a tall or short person, easy- easy to access

By forcing conscripts to assume the position of abruk, a degree of deindividualisation, reification, and control had occurred. Thus, the recruits were also more vulnerable to being, in Haile's words, “accessed." Haile continued by outlining the ramifications he experienced as his inner world began to be perforated:

\footnotetext{
Ah... they just made me a dormant person [...]. You cannot think of anything even for yourself... I have never experienced in my life... feeling myself so lazy to go and drink water; they just made you to that degree [...]. You just think you are $[\ldots]$ not capable of doing [anything for yourself] $[\ldots]$. Psychologically, the first thing they do is they isolate you from everything and just make you to believe you are worth nothing [...]. And, yeah, from there, being punished is nothing - being tortured is nothing - because you have already convinced yourself that you have got no body of life
} 
Being exposed to such extreme forms of maltreatment at the hands of his trainers - the same trainers that Haile had considered as brothers-in-arms prior to his arrival at the camp - sparked an unyielding cognitive dissonance relative to his own patriotic beliefs at the time. In Haile's words, it caused a

$$
\begin{aligned}
& {[\ldots] \text { big misunderstanding between }[\mathrm{me}] \text { and }[\mathrm{my}] \text { mind }[\ldots] \text {. And that's }[\ldots]} \\
& \text { the worst thing. For me, the physical inconvenience or torture was not the } \\
& \text { problem }[\ldots] ; \text {;instead], the psychological war against... [myself] was the } \\
& \text { biggest problem }
\end{aligned}
$$

In other words, Haile was forced to confront the beliefs that he had developed over the course of his youth; suddenly, his confusion was compounded by feelings of guilt - a combination that caused Haile to unrelentingly question himself:

$$
\begin{aligned}
& \text { Am I, kind of, going to betray my country }[\ldots] \text { for thinking that [the actions } \\
& \text { of the trainers is wrong]? [...] Am I trying to become less nationalist? That } \\
& \text { was the stage I didn't know whether it was me or not } \Delta \text { Yeah, [I questioned] } \\
& \text { my own belief and my own nationalism and my own thoughts at the same } \\
& \text { time }
\end{aligned}
$$

As was outlined in Chapter 4, Haile's experiences during national service inevitably lead to the decision that fleeing Eritrea was the only way to both maintain his mental stability and avoid being forced to duplicate the actions of the very trainers that had perpetrated violence against him. In many ways, however, the psychological damage had already been done. The military training that Haile had endured - training whereby, in Haile's words, "they make you... from human to animal kingdom" - meant that he had become emotionally barren:

$$
\begin{aligned}
& \text { You never }[\ldots] \text {, um... feel anything, even when you see the worst thing [...]. } \\
& \text { I had- I had a lot of problems even when I- when I came [to New Zealand], } \\
& \text { to get rid of that feeling [...]. [For example], I see someone crying, I don't } \\
& \text { feel anything at all; [I get told] someone is dead: nothing [...]. [The trainers] } \\
& \text { just wash [away] your bumanity }
\end{aligned}
$$

In considering Haile's experiences, it is possible to see that national service training involved a process of dehumanisation. This is so in relation to Arendt's notion that the "manifestation of the wind of thought is not knowledge; it is the ability to tell right from wrong, beautiful from ugly. And this, at the rare moments when the stakes are on the 
table, may indeed prevent catastrophes, at least for the self" (2003: 414). In other words, Haile's account of the internal war against himself that arose due to the treatment he suffered at the hands of his trainers illustrates the notion that to be rendered incapable of thinking and judging is, indeed, as far as Arendt sees it, catastrophic for the self. Furthermore, Haile went on to portray the way in which he attempted to come to terms with these untoward experiences by essentially erasing them from his mind at the point of stepping foot on Sudanese soil:

Coming from that background with brainwashing mentality - very young - it was not easy... But, once I decided, I was like... completely erased everything about Eritrea [...]. I remember, I told [the smuggler]: "You know, ah, the first step I will take - this one - I will completely erase anything about what I had in my life" $\Delta$ The reason why I left Eritrea, I couldn't survive... physically, never mind... mentally, I couldn't survive $[\ldots]$

Ultimately, as Haile concluded, "[he] was just looking for any kind of place... to think."

\section{Sub-section II: Resettlement narratives}

The remainder of this chapter briefly outlines the resettlement period of each of the participant's lives, thereby acting as a coda to the overall trajectory of their respective narratives. Whereas Chapters 3 and 4 concluded each of the chronicles at the point of taking flight from Africa, the current sub-section resumes with their touchdown in Auckland, New Zealand. With the exception of Eyob, all of the participants underwent a six-week orientation period at The Mangere Refugee Resettlement Centre (MRRC). From there, varying circumstances saw the newly-arrived citizens converge on Wellington as their long-term locality.

\section{$\S 1$ ' Violence of the past reflected in new beginnings}

For Iaokim, entering New Zealand in May 2008 was akin to "opening a new chapter" in his life; or, alternatively stated, a means for marking time in a reflexive way in order to create a "pause" between his violent past and ostensibly - perhaps ideally - nonviolent future (see Rabinow 2008: vii). Although fraught with contrasting emotions, the 
opportunity to run aground on the shores of this somewhat isolated Pacific nation was ultimately embraced. However, as the script of this new chapter was essentially yet to be written, the years since Iaokim's arrival have presented more than a few unforeseen 'twists' in the plot that is his life.

Initially, Iaokim's robust comprehension of English meant that he was often called upon to volunteer his skills as a mediator between those working at the MRRC and his fellow asylum seekers. The capacity to translate also lead to further training and work once Iaokim arrived in Wellington. Of course, amidst opportunities to work and volunteer as a translator, it was indeed the possibility of further pursuing his education that remained as the motivating factor in Iaokim's decision-making processes. Furthermore, it was information he had received from both the staff members at the MRRC and other Eritreans that had been resettled in the capital city for some time that compelled Iaokim to do his own research on the quality of the universities in Wellington and, in the end, to follow the impulse to situate himself in the educationally-savvy city long-term. However, subsequent to stepping off the plane in Wellington, the living arrangements that Iaokim was initially afforded quickly came to resemble past environments; ones that he had been so determined to escape.

Whereas the flat itself was "flash," Iaokim swiftly realised that the area he found himself residing in was by no means exempt from violent activity. Indeed, within an hour of arriving at his new home in Pomare - and once the refugee service staff had dissipated - Iaokim was interrupted by police officers knocking on his door asking whether or not he could supply any information pertaining to the "big guy" pictured in the photograph they presented. Iaokim continued to absorb the surrounding milieu of strange looks directed his way and violent vibrations transmitted through the walls of adjacent flats that entertained consistent rounds of fighting - Iaokim was unable to discern whether or not the struggles were real or, instead, were a case of people simply "joking around." Anyhow, Iaokim had only spent a mere three weeks in his new residence when an incident that constituted 'the straw that broke the camel's back' occurred: once again, police were knocking on his door, and, once again, they presented him with a photo; however, this time the photo pictured a woman who, as the officers revealed, had been recently murdered somewhere in the immediate vicinity of Iaokim's home. Even though Iaokim alerted his case workers to the situation, an inevitable delay ensued as processes were initiated to help find an alternate address to accommodate him as he continued to find his feet in Wellington. 
A series of jobs followed, including pruning - an occupation that saw Iaokim exploited through lack of pay after one week - and apple picking in Hawkes Bay - a "very hard job," albeit carried-out in the company of other Eritreans. Eventually, Iaokim found work as a security guard in Upper Hutt. However, as Iaokim explained, the presence of his work uniform caused a noticeable switch in the attitude of his neighbours, and any perceived ascendency tied to the authoritative-style attire was not enough to ward off direct violence committed against him:

[...] These people [neighbours and gang members], like, as soon as they saw, you know, the security uniform they change, man $[\ldots]$. Some of them were [previously] saying "Hi" [and] smile at me, and now they don't say "Hi" anymore $[\ldots]$. They just snobbed me; you can see it in their face, they hate [the uniform]... One day, one of them, like, get in to the train with me [as I was heading to work] and, um, he was drinking [...]. When I hopped out of the train in Trentham, he followed me and he throwed a bottle in front of- in my way [...]. I just changed my [direction] and kept walking \{claps hands\}

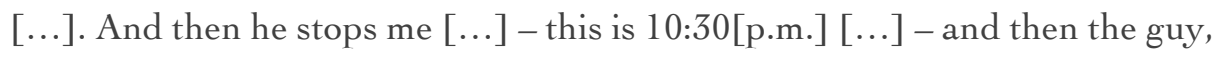
like, he pushed me and then I just pushed him around and made my way $[\ldots]$

At this point, a car load of people pulled up alongside the incident and acted as if they were going to help Iaokim. However, as became clear, the new arrivals to the scene were, in fact, assailants of the person who had initially accosted Iaokim:

So, when he was in train he was on the phone, and I am guessing that he was talking to his friends and stuff [...]. After that, ah [...], one of them, like punched me \{punches own hand\} on the... right here \{points to face\} [...]. I was bleeding and $[\ldots]$ it was, like, swelled $[\ldots]$

Once again, Iaokim found himself fleeing violent repercussions. Left with a swollen and bleeding face - and stripped of the contents of his bag - Iaokim headed for his place of employment whereupon he contacted police about the incident. If it was possible to cypher an upshot from the episode, it was that Iaokim's preference for being relocated to Wellington's central district now became a priority for the refugee service providers that he was associated with.

Since being permitted to live among Wellington's inner hub, Iaokim has moved through the ranks of various cleaning jobs, and, as of 2014, finally made in-roads relevant to his life-long ambition to study at university. However, this was not before working as 
a cleaner at the same university at which he was endeavouring to enrol. Iaokim would talk to the students who were studying late at night as he worked as a cleaner; interactions that he went on to describe as making him feel “jealous, but jealous in a good way." By extension, Iaokim's studies and ongoing dedication to political issues have lead to involvement with various campaigns surrounding, among other things, fair pay and increases to New Zealand's refugee intake quota. Iaokim's future ambitions include further study - "I could be studying for life almost" - in the realms of political science, development studies, and international relations, as well as entering in to politics in a capacity beyond the sphere of academia. Ultimately, as Iaokim's "new chapter" continues to be penned, he is currently in a position to reflexively and confidently say "I'm always, like, I'm a very, ah, open-minded person [...]; I am proud of who I am.”

\section{$\S 2$ ' Communicative constraints}

Arriving on New Zealand shores in 2014, the initial barriers faced by Isaac were those tied to difficulties surrounding language and communication. It was several months before he developed the confidence to speak freely; up until that point, "most of the time [he] was listening." Isaac's capacity to maintain communication with his family in Eritrea has been constrained by the fact that access to the internet in his country of origin is scarce. The ongoing restrictive ethos of the Eritrean government means that phone calls via landline make for the primary channel through which familial contact is maintained. Furthermore, any possibility of returning to Eritrea under the current conditions would involve a high degree of risk, and is therefore an unrealistic prospect. As Isaac mentioned, he was unsure as to precisely what would happen upon his return, and he went on to elaborate - based on past experiences - what he considered the likely repercussions to be:

\footnotetext{
[If I were to return to Eritrea], it's very bad [for] me. [The authorities] would kill me or they will $[\ldots]$ - if you are soldier - [...] they will kill you [...]; if you are a student, they will put you in jail. Yeah, you don't know. Maybe they will kill me $[\ldots]$
}

At this point in time, life in New Zealand has, at least, allowed Isaac to realise his initial ultimate concern by avoiding the military-bound fate of his older brother. 
Although Isaac demonstrated a degree of contentment with his new life, there were no explicit plans revealed concerning what he foresaw as his future aims and ambitions.

\section{$\S 3$ ' Disruption and relative freedom}

The contrasts embedded in the difference between Tesfalem's first and second midair experiences were plainly evident. Whereas his first flight signified a return to captivity as he was repatriated from Malta to Eritrea, his second was bound for the shores of New Zealand, and was thereby cause for permitting hope to permeate his outlook upon arrival in 2008. Subsequent to spending six weeks at the MRRC, Tesfalem and his partner ${ }^{80}$ were relocated to Wellington. Although there was a degree of choice granted to Tesfalem relevant to where he would potentially come to reside, himself and the other refugees in his cohort were required to make a case for the reasoning behind their decisions. The consensus put forward by members of the Eritrean diaspora already living in New Zealand's capital city was that Wellington was an attractive and welcoming place to call 'home'; this was enough to convince Tesfalem of Wellington's suitability. However, the otherwise cosmopolitan city was also known to be notoriously windy. Indeed, Tesfalem's third flight experience also harboured its own unique hallmark in that the intended destination was never reached; instead, Wellington's atrocious weather meant that the flight was forced to return to Auckland. Eventually, Tesfalem and his partner made it to their point of terminus where staff members of an organisation that provides assistance to refugees transported the newly-arrived to a flat in one of Wellington's suburbs not far from the airport itself.

The amenities contained in the flat - a new fridge, sufficient bedding, and a washing machine - initially held a certain novelty. Additionally, being privy to a guaranteed weekly income - although not much - also provided some relief as Tesfalem and his partner endeavoured to adapt to their new environment. Occasionally, difficulties arose pertaining to language and communication; an aspect that only compounded the often arduous task of dealing with governmental agencies. Ultimately, however, Tesfalem

\footnotetext{
${ }^{80}$ It was revealed that Tesfalem met his partner in Sudan and the pair were aboard the same flight to New Zealand. However, further details surrounding their pre-resettlement time together was not discernible from the interview data.
} 
experienced a degree of increased freedom relative to what his past experiences had bestowed upon him:

[Life in Wellington not long after arriving] was really good because um... yeah, I think, I feel happy [...], you know what I mean, because, ah... I wasI was different person [...] because I got my, ah, my own house over here [...]. I do whatever I want [...] because no longer, you know, fear from any, um, any policeman, for example [...], that can ask you- frequently ask you for money and just retain you [...]. Now I'm a free person, you know, ah, I do what I want to do

For Tesfalem, doing what he wants to do means raising a family with his partner whilst also pursuing further education in development studies. Although reconciling the two endeavours isn't always easy due to, among other things, the material constraints that he continues to face in New Zealand, Tesfalem's Christian faith and convivial relations with other Eritreans who are perhaps more politically outspoken allow him to maintain a life of contentment - even in spite of there being no chance of returning to the 'home' from which he was forced to flee multiple times.

\section{$\S 4$ ' Fractured families and the irony of contingent freedom}

Eyob's mother accompanied her teenage son and one of his sisters on their trip to New Zealand. However, whereas for Eyob and his sibling the journey would mark the beginning of a long-term - if not permanent - stay in the South Pacific, traversing the globe en route to Wellington would be no more than a sojourn for Eyob's only unencumbered parent. As it stands, the relative freedoms permitted to Eyob's mother hardly act as a sufficient counter-weight to the ongoing maltreatment and restrictions that befall the kindred - Eyob's father, in particular - who remain in the Horn of Africa. Added to the plight of Eyob's family's situation is that the government of Ethiopia - Ethiopia being the country from which Eyob's father was abruptly annexed a decade and a half prior - has since reformed its policies, thus allowing for the return of those who were once unwelcome. As such, the primary hindrance that prevents the realisation of Eyob's ultimate concern to reunite his family resides in the sustained oppressive principles of the Eritrean state. In other words, Eyob's father is so stringently tied to this oppressive nation by way of his nationality, that he is unable to get out. 
As far as Eyob's current set of conditions have allowed him to flourish, however, the upshot of life in Wellington is that the formerly unstable life of transience him and his family were confronted with due to being unable to afford rent payments has been consigned, for the most part, to memory. Additionally, Eyob's ambition to study has been fulfilled, even if it meant having to adapt from time-to-time in light of being faced with several unavoidable and limiting caveats: firstly, instead of engaging in the study of law, Eyob has ambitions to study biology as the former discipline, in Eyob's mind, involves a "deeper language" - the required comprehension of which would circumvent his ability to excel; and, secondly, ongoing commitments to the well-being of his family have meant that Eyob's educational pursuits have been occasionally overridden by the need to work full-time - predominantly as a cleaner, at times working up to 18 hours per day - in order to ensure he is in a position to provide financial support by way of sending monetary savings homeward via the route that brought him to New Zealand. Indeed, for Eyob, Ethiopia is still intimately tied to his sense of 'home.'

All things considered - both the fortunate and undesirable - the certainty that Eyob has derived from his life experiences thus far illustrate the notion that life in its corporeal lived-ness rarely unfolds in a way that aligns with one's preconceived expectations. As Eyob implied, this realisation is one that has imposed upon him the necessity of remaining open to change:

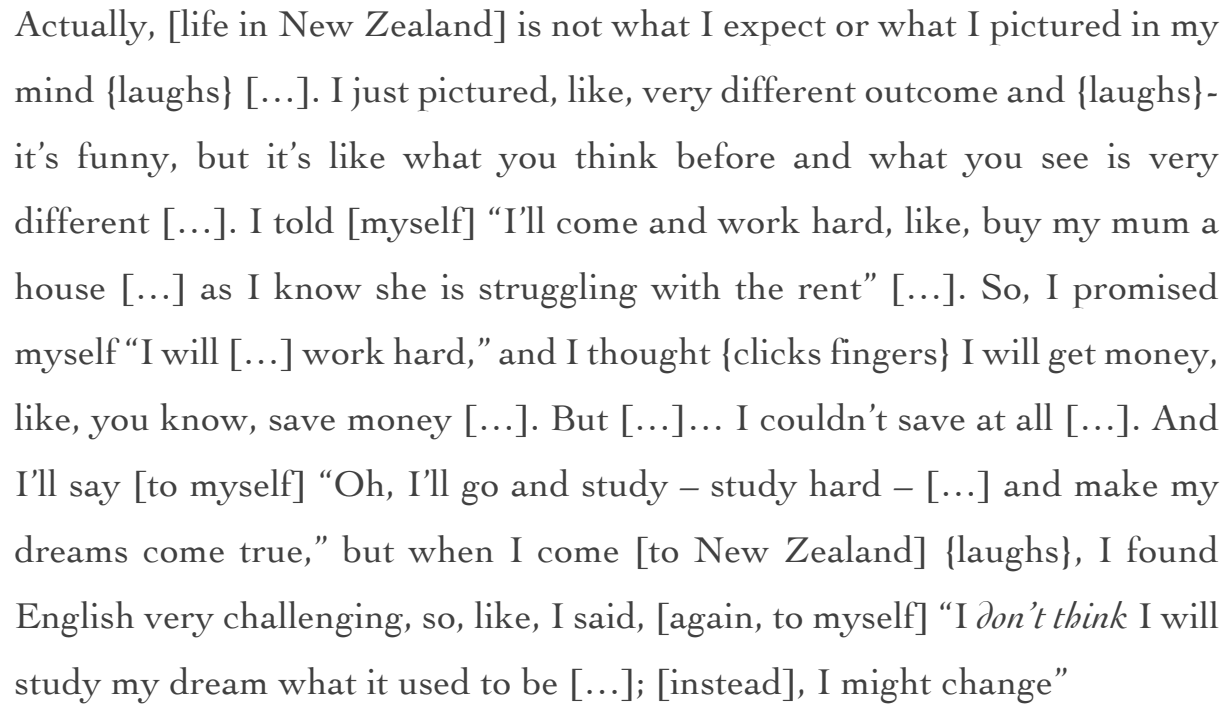

With recourse to family reunification as a striven-for corporeal reality, Eyob recognised that significant change - this time in reference to the state of Eritrea - is one of, if not the, primary gateway to his ultimate concern being realised. Eyob remains sanguine: "I hope one day [I] will be allowed to see [my] family face-to-face." 


\section{§ 5' Familial friction and regaining ownership of one's life}

A degree of eagerness beset Haile as he endeavoured to embrace life in New Zealand. However, the first six months would involve various unintended occurrences including an unscheduled bus tour of Wellington's outer suburbs - an excursion that was the result of being unable to decipher the enigmatic public transport timetables upon which the city operates. The language barrier proved to be less problematic, even if it required Haile to adapt to the 'Kiwi' accent - being asked to "Wash your name" ${ }^{81}$ gave rise to only a slight confusion for the first few times. However, the ease with which Haile adapted to the new, much cooler - and therefore, in Haile's mind, preferable - climate offered little reprieve from the initial stages of feeling isolated amidst his new community. The birth pangs of Haile's new life were amplified by the unavoidable separation from family who remain in Eritrea. In saying this, over time, the aforementioned friction would partly dissolve. In its place, however, a new point of contention arose between the relatively progressive views Haile began to embody subsequent to living in New Zealand for an extended period of time and the more traditional outlook that his parents still harboured:

[...] I start to think differently, I start to change my way of belief, I start to change my way of thinking. And [...], now, I don't even sometimes agree with [my parents] when we talk on the phone [...]; we cannot even come to an agreement $[\ldots]$ because how they think and how I think is like hell and heaven \{claps hands\} [...] - way different. [We] cannot even agree on the basic terms of life $\Delta$ I don't talk any politics or social life with my parents anymore 'cos we cannot agree

Haile went on to describe how his parents had persisted in endeavouring to organise an arranged marriage for his sister, whom also now resides in Wellington. Furthermore, he alluded to various points of contention with the elder members of the Eritrean community within Wellington that - even though they had been forced to flee Eritrea - maintained support for the Afwerki administration. ${ }^{82}$

In all, Haile's post-resettlement life has been "calm”; a term which perhaps indicates a stark contrast in relation to the uncertainty and anxiety-inducing circumstances that

${ }^{81}$ i.e. "What's your name?"

${ }^{82}$ See Conclusion. 
constituted his former life. Haile has been able to pursue both work and study, even if due to family commitments - his capacity to do so has fluctuated. Ultimately, and in spite of his unstable past, Haile is now at a point where he is able to say "it's a great feeling to own... who you are."

\section{$\S 6$ Chapter 5 summary}

Divided into two primary sub-sections, this chapter has, firstly, foregrounded the ways in which violence comes to be embodied subjectively, and, secondly, provided a coda to the overall trajectories of each participant's narrative by detailing their respective lives since resettlement. The brief vignettes that comprise the first half of this chapter revealed varying violent reverberations pertaining to memory, critical reflection, dehumanisation, and uncertainty; thereby supporting the premise that violent structures inform - yet do not wholly determine - lives. However, the resettlement narratives outlined in the second half of this chapter, by default, elucidate the fact that - due to the morphostatic nature of the violent embodied structures inherent to the Eritrean situation

- one must harness what little agency they have in order to absent themselves from such oppressive structures.

The next section includes a summary of the research findings alongside several concluding remarks. 


\section{CONCLUSION}

\section{$\S 1$ Summary}

This thesis has detailed the life narratives of five refugees hailing from the Horn of Africa. In doing so, myriad forms of violence have been revealed as inherent to the larger Eritrean socio-political context and thus also in the lives of each participant. Whereas Part I launched the overall narrative at Eritrea's historical inception and proceeded to identify extreme nationaliom as a generative, institutional form of violence, Part II revealed the relational structuring form of routinised fear as underpinning the interpersonal dimensions of the participants' lives - a factor that can be seen to foster the perpetuation of violence. In the final section - Part III - a series of brief vignettes illustrate how violence transpires in varying forms at the point that it inevitably comes to be embodied subjectively. The thesis argument also aligned with this tripartite scheme in a chronological sense: each section respectively detailed the participants' formative, 'middle,' and resettlement narratives.

Underlying the central findings there was a particular conceptualisation pertaining to the relationship between structure and agency; that is, social structures shape - yet do not determine - the agentic capacities of individuals. Following this, the actions of agents are also seen to either reproduce or transform structures. Significantly, with regard to the specifically Eritrean context from which each of the participant's narratives have emerged, it was maintained that the institutional, relational, and embodied structures identified above can be considered as morphostatic due to the way in which they severely constrained each participant's capacity to develop, pursue, and achieve their ultimate concerns. Furthermore, by drawing on a range of anthropological work, violence has been shown to operate on a continuum as a physical, symbolic, structural, and normalised phenomenon.

Thus, throughout the course of this thesis, I have argued that, by examining the lifenarratives of Eritrean refugees, violence can be understood as transpiring at the interstices of an ongoing - albeit skewed - dialectic between, on one hand, morphostatic structures of violence appearing in institutional, relational, and embodied forms, and, on the other, a degree of mimetic agency that, when harnessed, acts as a crawl-space 
through which individuals must absent themselves relative to such structures of violence if they are to realise their ultimate concerns.

\section{$\S 2$ Limitations and future directions}

There are a number of limiting factors inherent to this thesis: the low number of participants means that only tentative generalisations are possible. Also, if participant observation is considered to be the hallmark of ethnographic research, then the limited degree of depth that an interview-based project can provide is also an inherent shortcoming. However, the extended nature of these interviews and the level of detail extracted from them goes some way to rectifying this methodological limitation. ${ }^{83}$

When introducing Part II, it was noted that the concept of 'mimetic logic' was being utilised in a somewhat general way to denote an instance where a participant proceeded to imitate any given form of violence in order to potentially ensure their own flourishing. A more direct usage of this concept - otherwise understood as the colonial mirror (Feldman 2004: 213-214; Taussig 1984) - may prove constructive in future research. In others words, it can be seen that colonial violence and the chronicity of crises that constituted Eritrea's past came to be mimicked by the Afwerki administration throughout Eritrea's post-independence era. From there, the citizens embroiled in extreme nationalist tendencies could be seen to be mimicking the Eritrean state - particularly, of course, the soldiers trained to do so. Subsequently, and somewhat ironically, the participants' only means of engaging their agentic crawl-space often involved a mimicking of the more symbolic forms of violence - deceit, coercion, seduction - that had once been directed toward them.

Several of the participants alluded to the fact that many members of the Eritrean diaspora forced to flee their country of origin due the ongoing political crackdown have subsequently turned around to support the Eritrean regime, albeit from a distance. This in itself is a compelling phenomenon that may be worthy of future inquiry, particularly in relation to how it creates an obstacle for international solidarity among anti-regime Eritreans.

\footnotetext{
${ }^{83}$ On this point: any omissions with regard to the full extent of what was divulged by the participants have been done so on the proviso of limitations of scope. I hope that it is understood - particularly by the participants themselves - that any such omissions were made in order to maintain a coherent focus on the underlying theme of violence.
} 
Lastly, many of the participants solicited the services of human traffickers in order to liberate themselves from the clutches of the Eritrean government; Tesfalem even referred to trafficking as "Big Business." Thus, it is possible to see how this "shadow economy" (Warren 2002: 387) may also be an important area for ongoing research.

\section{§ 3 Final remarks}

At the outset of this thesis, I alluded to the notion of violence as being capable of crippling the will of a people. Furthermore, it was Nordstrom who posited violence as that which severs people from their traditions, futures, and - undeniably - their lives. Echoing this sentiment, Daniel states that " $[\mathrm{w}]$ here the present dominates, the future and the past, because they have to pass through the present, are shaken even as they partake of the present's impermanence" (1996: 107). Thus, in considering all that has transpired throughout the course of this thesis - the violence, absence, and pain of uncertainty - Haile's testimony perhaps captures it best:

"That's the thing in Eritrea [...] the worst thing in life is... you never know" 


\section{BIBLIOGRAPHY}

Accomazzo, Sarah

2012 Anthropology of Violence: Historical and Current Theories, Concepts, and Debates in Physical and Socio-Cultural Anthropology. Journal of Human

Behaviour in the Social Environment 22(5):535-552.

ActionStation

2015 Doing Our Bit: Welcome More Refugees to NZ.

http://www.actionstation.org.nz/refugees, accessed April 8, 2015.

Al-Migahed, Leen

2008 Khat Chewing in Yemen: Turning Over a New Leaf. Bulletin of the World Health Organisation 86(10):741-742.

Anderson, Benedict

2006 [1983] Imagined Communities: Reflections on the Origin and Spread of

Nationalism. London: Verso.

Archer, Margaret

1998 Introduction: Realism in the Social Sciences. In Critical Realism: Essential

Readings. Margaret Archer, Roy Bhaskar, Andrew Collier, Tony Lawson, and

Alan Norrie, eds. Pp.189-205. London and New York: Routledge.

Archer, Margaret

2000 Being Human: The Problem of Agency. Cambridge: Cambridge University Press.

Archer, Margaret

2003 Structure, Agency and the Internal Conversation. Cambridge: Cambridge

University Press.

Archer, Margaret

2007 Making Our Way through the World: Human Reflexivity and Social

Mobility. Cambridge: Cambridge University Press.

Archer, Margaret, Roy Bhaskar, Andrew Collier, Tony Lawson, and Alan Norrie, eds. 1998 Critical Realism: Essential Readings. London and New York: Routledge.

Arendt, Hannah

1970 On Violence. New York: Houghton Mifflin Harcourt Publishing Company.

Arendt, Hannah

1998 [1958] The Human Condition. Chicago and London: The University of

Chicago Press.

Arendt, Hannah

2003 The Portable Hannah Arendt. Peter Baehr, ed. New York: Penguin Books. Aretxaga, Begoña

2000 A Fictional Reality: Paramilitary Death Squads and the Construction of

State Terror in Spain. In Death Squad: The Anthropology of State Terror. Jeffrey

Sluka, ed. Pp.46-69. 
Baud, Michiel

1997 Imagining the Other: Michael Taussig on Mimesis, Colonialism and Identity. Critique of Anthropology 17(1):103-112.

Bhaskar, Roy

1998 General Introduction. In Critical Realism: Essential Readings. Margaret Archer, Roy Bhaskar, Andrew Collier, Tony Lawson, and Alan Norrie, eds. Pp.ixxxiv. London and New York: Routledge.

Bhaskar, Roy

2012 From Science to Emancipation: Alienation and the Actuality of

Enlightenment. London and New York: Routledge.

Bourdieu, Pierre

1977 Outline of a Theory of Practice. Cambridge: Cambridge University Press.

Bourdieu, Pierre, and Loïc Wacquant

2004 Symbolic Violence. In Violence in War and Peace: An Anthology. Nancy

Scheper-Hughes and Philippe Bourgois, eds. Pp.272-274. Malden: Blackwell

Publishing.

Bourgois, Philippe

2004 US Inner-city Apartheid: The Contours of Structural Violence and Interpersonal Violence. In Violence in War and Peace: An Anthology. Nancy

Scheper-Hughes and Philippe Bourgois, eds. Pp.301-307. Malden: Blackwell

Publishing.

Bourgois, Philippe

2009 Recognizing Invisible Violence: A Thirty-Year Ethnographic Retrospective.

In Global Health in Times of Violence. Barbara Rylko, Linda Whiteford, and Paul Farmer, eds. Pp.18-40. Santa Fe: School of Advanced Research Press.

Bourgois, Philippe

2015 Postface: Insecurity, the War on Drugs, and Crimes of the State: Symbolic

Violence in the Americas. In Violence at the Margins Urban Margins. Javier

Auyero, Philippe Bourgois, and Nancy Scheper-Hughes, eds. Pp.305-321. Oxford:

Oxford University Press.

Christian Solidarity Worldwide

2008 Eritrea: Sexual Violence Against Female Army Conscripts.

Collier, Andrew

1994 Critical Realism: An Introduction to Roy Bhaskar's Philosophy. London:

Verso.

Csordas, Thomas J.

1990 Embodiment as a Paradigm for Anthropology. Ethos 18(1):5-47.

Danermark, Berth, Mats Ekström, Liselotte Jakobsen, and Jan Ch. Karlsson.

2002 Explaining Society: Critical Realism in the Social Sciences. London and New York: Routledge. 
Daniel, E. Valentine

1996 Charred Lullabies: Chapters in an Anthropography of Violence. Princeton: Princeton University Press.

Das, Veena

2007 Life and Words: Violence and the Descent into the Ordinary. Berkley: University of California Press.

Das, Veena, and Arthur Kleinman

2000 Introduction. In Violence and Subjectivity. Veena Das, Arthur Kleinman, Mamphela Ramphele, and Pamela Reynolds, eds. Pp.1-18. Berkley: University of California Press.

Das, Veena, and Arthur Kleinman

2001 Introduction. In Remaking a World: Violence, Social Suffering, and

Recovery. Veena Das, Arthur Kleinman, Margaret Lock, Mamphela Ramphele, and Pamela Reynolds, eds. Pp.1-30. Berkley: University of California Press.

Davies, Charlotte Aull

2008 [1998] Reflexive Ethnography: A Guide to Researching Selves and Others. London and New York: Routledge.

Davison, Isaac

$2014 \mathrm{NZ}$ to take 100 Syrian Refugees. The New Zealand Herald.

http://www.nzherald.co.nz/world/news/article.cfm?c_id=2\&objectid=11197112, accessed April 8, 2015.

Engholm, Pär

2007 TMSA (transformational model of social activity). In Dictionary of Critical

Realism. Mervyn Hartwig, ed. New York: Routledge.

Farmer, Paul

2004 On Suffering and Structural Violence: A View From Below. In Violence in War and Peace: An Anthology. Nancy Scheper-Hughes and Philippe Bourgois, eds. Pp.281-289. Malden: Blackwell Publishing.

Feldman, Alan

1991 Formations of Violence: The Narrative of the Body and Political Terror in Northern Ireland. Chicago: Chicago Press.

Feldman, Alan

2004 On Cultural Anaesthesia: From Desert Storm to Rodney King. In Violence in War and Peace: An Anthology. Nancy Scheper-Hughes and Philippe Bourgois, eds. Pp.207-216. Malden: Blackwell Publishing.

Ghassem-Fachandi, Parvis, ed.

2009 Introduction. In Violence: Ethnographic Encounters. Pp.1-13. Oxford: Berg Publishers.

Graeber, David

2015 Radical Alterity is Just Another Way of Saying "Reality": A Reply to

Eduardo Viveiros de Castro. HAU: Journal of Ethnographic Theory 5(2):1-41. 


\section{Green, Linda}

1995 Living in a State of Fear. In Fieldwork Under Fire: Contemporary Studies of Violence and Survival. Carolyn Nordstrom and Antonius C. G. M. Robben, eds. Pp.105-128. Berkley: University of California Press.

Hage, Ghassan

2000 White Nation: Fantasies of White Supremacy in a Multicultural Society.

New York: Routledge.

Hedru, Debessay

2003 Eritrea: Transition to Dictatorship, 1991-2003. Review of African Political Economy 30(97):435-444.

Herman, Edward S.

1982 The Real Terror Network: Terrorism in Fact and Propaganda. Boston: South End Press.

Hilton, Steven M.

2015 Syrian Refugee Crisis Outstrips International Aid.

http://www.seattletimes.com/opinion/syrian-refugee-crisis-outstrips-internationalaid/, accessed April 8, 2015.

Human Rights Watch

2004 Eritrea: 'You Have No Right to Ask'-Government Resists Scrutiny on Human Rights. AFR 64/003/2004.

Human Rights Watch

2008 https://www.hrw.org/reports/2008/darfur0608/4.htm, accessed June 7, 2016.

Human Rights Watch

2015 Mass Rape in North Durfar: Sudanese Army Attacks Against Civilians in Tabit. https:/www.hrw.org/report/2015/02/11/mass-rape-north-darfur/sudanesearmy-attacks-against-civilians-tabit, accessed June 7, 2016.

Ingold, Tim

2005 Brereton's Blandishments. Journal of Critical Realism 4(1):112-127.

Jackson, Michael

2009 The Palm at the End of the Mind: Relatedness, Religiosity, and the Real.

Durham and London: Duke University Press.

Jackson, Michael

2013 [2002] The Politics of Storytelling: Variations on a Theme by Hannah

Arendt. Copenhagen: Museum Tusculanum Press

Kuhn, T.S.

1970 The Structure of Scientific Revolutions. Chicago: University of Chicago Press.

López, José, and Garry Potter, eds.

2001 After Postmodernism: The Millennium. In After Postmodernism: An Introduction to Critical Realism. Pp.1-18. London and New York: The Althone Press. 
Newlands, Emma

2013 Preparing and Resisting the War Body: Training in the British Army. In War and the Body: Militarisation, Practice and Experience. Kevin McSorley, ed. Pp.3549.

Nordstrom, Carolyn

1995 War on the Front Lines. In Fieldwork Under Fire: Contemporary Studies of Violence and Survival. Carolyn Nordstrom and Antonius C. G. M. Robben, eds. Pp.129-154. Berkley: University of California Press.

Nordstrom, Carolyn, and Antonius C.G.M. Robben, eds. 1995 Fieldwork Under Fire: Contemporary Studies of Violence and Survival. Berkley: University of California Press.

O'Kane, David 2012 Limits to State-Led Nation-Building? An Eritrean Village Responds Selectively to the Plans of the Eritrean Government. Studies in Ethnicity and Nationalism 12(2):309-325.

O’Kane, David, and Tricia Redeker Hepner, eds.

Biopolitics, Militarism and Development: Eritrea in the Twenty-First Century. New York: Berghahn Books.

Otterbein, Keith F. 1999 A History of Research on Warfare in Anthropology. American Anthropologist 101(4):794-805.

Rabinow, Paul 2008 Marking Time: On the Anthropology of the Contemporary. Princeton and Oxford: Princeton University Press.

Radio New Zealand 2015 Syrian Refugees Settle into New Zealand. http://www.radionz.co.nz/news/national/262966/syrian-refugees-settle-into-newzealand, accessed April 8, 2015.

Redeker Hepner, Tricia 2009 Soldiers, Martyrs, Traitors, and Exiles: Political Conflict in Eritrea and the Diaspora. Philadelphia: University of Pennsylvania Press.

Reid, Richard 2009 The Politics of Silence: Interpreting Stasis in Contemporary Eritrea. Review of African Political Economy 36(120):209-221.

Reid, Richard

2014 Writing Eritrea: History and Representation in a Bad Neighbourhood.

History in Africa 41:88-115.

Riggan, Jennifer

2011 In Between Nations: Ethiopian-Born Eritreans, Liminality, and War.

PoLAR: Political and Legal Anthropology Review 34(1):131-154.

Robben, Antonius C.G.M.

1995 The Politics of Truth and Emotion Among Victims and Perpetrators of 
Violence. In Fieldwork Under Fire: Contemporary Studies of Violence and

Survival. Carolyn Nordstrom and Antonius C. G. M. Robben, eds. Pp.81-104.

Berkley: University of California Press.

Sayer, Andrew

2000 Realism and Social Science. London: Sage.

Sayer, Andrew

2010 [1984] Method in Social Science: A Realist Approach. London and New

York: Routledge.

Saldaña, Johnny

2009 The Coding Manual for Qualitative Researchers. Los Angeles: Sage

Scarry, Elaine

1985 The Body in Pain: The Making and Unmaking of the World. Oxford: Oxford University Press.

Scheper Hughes, Nancy

2004 Two Feet Under and a Cardboard Coffin: The Social Production of

Indifference to Child Death. In Violence in War and Peace: An Anthology. Nancy

Scheper-Hughes and Philippe Bourgois, eds. Pp.275-280. Malden: Blackwell

Publishing.

Scheper-Hughes, Nancy, and Philippe Bourgois, eds.

2004 Introduction: Making Sense of Violence. In Violence in War and Peace: An Anthology. Pp.1-32. Malden: Blackwell Publishing.

Schröder, Ingo W., and Bettina E. Schmidt, eds.

2001 Introduction: Violent Imaginaries and Violent Practices. In Anthropology of

Violence and Conflict. Pp.1-24. London: Routledge.

Scott, John

2001 Where is Social Structure? In After Postmodernism: An Introduction to

Critical Realism. José López and Garry Potter, eds. Pp.77-85. London \& New

York: The Athlone Press.

Sluka, Jeffrey A., ed.

2000 Introduction: State Terror and Anthropology. In Death Squad: The

Anthropology of State Terror. Pp.1-45. Philadelphia: University of Pennsylvania Press.

Stewart, Pamela J., and Andrew Strathern

2002 Violence: Theory and Ethnography. London and New York: Continuum.

Strathern, Andrew, and Pamela J. Stewart

2006 Introduction: Terror, the Imagination, and Cosmology. In Terror and

Violence: Imagination and the Unimaginable. Andrew Strathern, Pamela J.

Stewart, and Neil L. Whitehead, eds. Pp.1-39. London: Pluto Press.

Taussig, Michael

1984 Culture of Terror - Space of Death: Roger Casement's Putumayo Report and the Explanation of Torture. Society for Comparative Studies in Society and History 26(3):467-497. 
Taussig, Michael

1989 Terror as Usual: Walter Benjamin's Theory of History as a State of Siege.

Social Text 23:3-20.

Taussig, Michael

1992 The Nervous System. New York: Routledge.

Taussig, Michael

1997 Mimesis and Alterity: A Particular History of the Senses. New York:

Routledge.

Tronvoll, Kjetil, and Daniel R. Mekonnen

2014 The African Garrison State: Human Rights and Political Development in

Eritrea. Woodbridge: Boydell \& Brewer Ltd

United Nations Human Rights Council (UNHRC)

2015 Report of the Detailed Findings of the Commission of Inquiry on Human

Rights in Eritrea A/HRC/29/CRP.1 (full report).

http://www.ohchr.org/Documents/HRBodies/HRCouncil/CoIEritrea/A_HRC_29_

CRP-1.pdf, accessed November 10, 2015.

Vigh, Henrik

2008 Crisis and Chronicity: Anthropological Perspectives on Continuous Conflict and Decline. Ethos 73(1):5-24.

Walter, E.V.

1969 Terror and Resistance: A Study of Political Violence with Case Studies of

Some Primitive African Communities. New York: Oxford University Press.

Warren, Kay B.

2002 Toward an Anthropology of Fragments, Instabilities, and Incomplete Transitions. In Ethnography in Unstable Places: Everyday Lives in Contexts of Dramatic Political Change. Carol J. Greenhouse, Elizabeth Mertz, and Kay B. Warren, eds. Pp.379-392. Durham and London: Duke University Press.

Woldemikael, Tekle M.

2009 Pitfalls of Nationalism in Eritrea. In Biopolitics, Militarism and

Development: Eritrea in the Twenty-First Century. David O'Kane and Tricia

Redeker Hepner, eds. Pp.1-16. New York: Berghahn Books.

Woldemikael, Tekle M.

2013 Introduction: Postliberation Eritrea. Africa Today 60(2):v-xix.

Žižek, Slajov

2009 Violence. London: Profile Books. 